\title{
Canadian Thoracic Society 2012 guideline update: Diagnosis and management of asthma in preschoolers, children and adults
}

\author{
M Diane Lougheed MD MSc${ }^{1}$, Catherine Lemiere MD², Francine M Ducharme MD MSc ${ }^{2}$, Chris Licskai MD³, \\ Sharon D Dell MD ${ }^{4}$, Brian H Rowe MD MSc${ }^{5}$, Mark FitzGerald MD ${ }^{6}$, Richard Leigh MD PhD ${ }^{7}$, Wade Watson MD ${ }^{8}$, \\ Louis-Philippe Boulet $\mathrm{MD}^{9}$; Canadian Thoracic Society Asthma Clinical Assembly
}

\begin{abstract}
MD Lougheed, C Lemiere, FM Ducharme, et al; Canadian Thoracic Society Asthma Clinical Assembly. Canadian Thoracic Society 2012 guideline update: Diagnosis and management of asthma in preschoolers, children and adults. Can Respir J 2012;19(2):127-164.
\end{abstract}

BACKGROUND: In 2010, the Canadian Thoracic Society (CTS) published a Consensus Summary for the diagnosis and management of asthma in children six years of age and older, and adults, including an updated Asthma Management Continuum. The CTS Asthma Clinical Assembly subsequently began a formal clinical practice guideline update process, focusing, in this first iteration, on topics of controversy and/or gaps in the previous guidelines.

METHODS: Four clinical questions were identified as a focus for the updated guideline: the role of noninvasive measurements of airway inflammation for the adjustment of anti-inflammatory therapy; the initiation of adjunct therapy to inhaled corticosteroids (ICS) for uncontrolled asthma; the role of a single inhaler of an ICS/long-acting beta 2 -agonist combination as a reliever, and as a reliever and a controller; and the escalation of controller medication for acute loss of asthma control as part of a self-management action plan. The expert panel followed an adaptation process to identify and appraise existing guidelines on the specified topics. In addition, literature searches were performed to identify relevant systematic reviews and randomized controlled trials. The panel formally assessed and graded the evidence, and made 34 recommendations.

RESULTS: The updated guideline recommendations outline a role for inclusion of assessment of sputum eosinophils, in addition to standard measures of asthma control, to guide adjustment of controller therapy in adults with moderate to severe asthma. Appraisal of the evidence regarding which adjunct controller therapy to add to ICS and at what ICS dose to begin adjunct therapy in children and adults with poor asthma control supported the 2010 CTS Consensus Summary recommendations. New recommendations for the adjustment of controller medication within written action plans are provided. Finally, priority areas for future research were identified.

CONCLUSIONS: The present clinical practice guideline is the first update of the CTS Asthma Guidelines following the Canadian Respiratory Guidelines Committee's new guideline development process. Tools and strategies to support guideline implementation will be developed and the CTS will continue to regularly provide updates reflecting new evidence.

Key Words: Asthma; Clinical practice guideline; Management

\begin{abstract}
Mise à jour des lignes directrices 2012 de la Société canadienne de thoracologie : le diagnostic et la prise en charge de l'asthme chez les enfants d'âge préscolaire, les enfants et les adultes
\end{abstract}

\begin{abstract}
HISTORIQUE : En 2010, la Société canadienne de thoracologie (SCT) a publié un sommaire consensuel sur le diagnostic et la prise en charge de l'asthme chez les enfants de six ans et plus et chez les adultes, y compris une mise à jour du continuum de prise en charge de l'asthme. L'assemblée clinique sur l'asthme de la SCT a entrepris un processus officiel de mise à jour des lignes directrices de pratique clinique qui portait, dans sa première mouture, sur des sujets controversés ou des lacunes contenus dans les lignes directrices précédentes.
\end{abstract}

MÉTHODOLOGIE : Quatre questions cliniques ont été retenues comme éléments centraux de la mise à jour des lignes directrices : le rôle des mesures non effractives de l'inflammation des voies aériennes pour rajuster la thérapie anti-inflammatoire, l'amorce d'une thérapie d'appoint à la corticothérapie par aérosol (CTA) en cas d'asthme non contrôlé, le rôle d'un seul inhalateur associant un CTA et des bêta -agoniste de longue durée pour soulager ainsi que pour soulager et contrôler l'asthme et l'augmentation de la médication de contrôle en cas de perte aiguë du contrôle de l'asthme dans le cadre d'un plan de prise en charge autonome. Le groupe d'experts a respecté un processus d'adaptation pour déterminer et évaluer les lignes directrices en place sur les sujets précisés. En outre, il a procédé à des analyses bibliographiques pour trouver les analyses systématiques et les essais aléatoires et contrôlés pertinents sur le sujet. Le groupe a évalué et classé officiellement les données probantes, puis a fait 34 recommandations.

RÉSULTATS : La mise à jour des recommandations contenues dans les lignes directrices souligne qu'il y a un rôle pour l'évaluation des éosinophiles dans les expectorations, en plus des mesures standard du contrôle de l'asthme, afin d'orienter le rajustement de la thérapie de contrôle chez les adultes atteints d'asthme modéré à grave. L'évaluation des données probantes à l'égard de la thérapie de contrôle d'appoint à ajouter à la CTA et de la dose de CTA à laquelle amorcer la thérapie d'appoint chez les enfants et les adultes contrôlant mal leur asthme a étayé les recommandations du sommaire consensuel 2010 de la SCT. De nouvelles recommandations sont proposées pour rajuster la médication de contrôle dans les plans d'action écrits. Enfin, on a déterminé les domaines prioritaires des futures recherches.

CONCLUSIONS : Le présent guide de pratique clinique est la première mise à jour des lignes directrices sur l'asthme de la SCT depuis que le comité des lignes directrices canadiennes en santé respiratoire utilise le nouveau processus d'élaboration des lignes directrices. Des outils et des stratégies pour soutenir la mise en œuvre des lignes directrices seront élaborés, et la SCT continuera de produire régulièrement des mises à jour reflétant les nouvelles données probantes. over, and adults (1), and a position paper on the role of long-acting beta 2 -agonists (LABAs) in asthma (2). Thereafter, a process began to formally update parts of the previous consensus guidelines and summaries, and to identify gaps in the existing clinical practice guidelines (CPGs) in need of new, formal, evidence-based recommendations. \begin{abstract}
including an updated Asthma Management Continuum, which encom-
\end{abstract} passed the diagnosis and management of children six years of age and

${ }^{1}$ Queen's University, Kingston, Ontario; ${ }^{2}$ University of Montreal, Montreal, Quebec; ${ }^{3}$ University of Western Ontario, London; ${ }^{4}$ University of

Toronto, Toronto, Ontario; ${ }^{5}$ University of Alberta, Edmonton, Alberta; ${ }^{6}$ University of British Columbia, Vancouver, British Columbia;

${ }^{7}$ University of Calgary, Calgary, Alberta; ${ }^{8}$ Dalhousie University, Halifax, Nova Scotia; ${ }^{9}$ Laval University, Quebec City, Quebec

Sponsoring Organizations: Canadian Thoracic Society, and The Lung Association.

Correspondence and reprints: Canadian Thoracic Society, 300-1750 Courtwood Crescent, Ottawa, Ontario K2C 2B5. Telephone 613-569-6411,

fax 613-569-8860, e-mail ctsinfo@lung.ca 


\section{Objective/scope}

The overall objective of the present CPG is to inform and provide evidence-based recommendations for the management of preschoolers (under 6 years of age), children (six to 11 years of age) and adults (12 years of age and over) with asthma to physicians and other health care professionals. This document was specifically developed to update the 2010 CTS Asthma Management Continuum based on new evidence, to identify and address important care gaps, and to provide direction for future areas in need of primary research and evidence synthesis.

\section{Target population}

The current CPG applies to preschoolers, children and adults with asthma. Asthma is defined as an inflammatory disorder of the airways characterized by paroxysmal or persistent symptoms such as dyspnea, chest tightness, wheezing, sputum production and cough, associated with variable airflow limitation and a variable degree of hyper-responsiveness of the airways to endogenous or exogenous stimuli $(1,3)$. The preferred pulmonary function criterion supportive of an asthma diagnosis in individuals six years of age and over is spirometry showing reversible airway obstruction; alternatives include peak expiratory flow (PEF) variability or a positive challenge test (such as a methacholine or exercise challenge) (1). In preschoolers, for whom it is not possible to routinely assess lung function, the combination of a careful clinical history (including family history and risk factors for asthma development) and physical examination are used to differentiate asthma from other causes of episodic respiratory symptoms (4).

\section{Target users}

The present CPG is intended for use by all health care providers involved in the care of individuals with asthma, including family physicians, pediatricians, general internists, respirologists, nurse practitioners, nurses, respiratory therapists, certified asthma and respiratory educators, and pharmacists. It is also intended to guide health care administrators and institutions in the implementation of best practices in asthma care.

\section{CLINICAL QUESTIONS}

\section{Noninvasive measurements of airway inflammation}

1. Does the use of noninvasive measurements of airway inflammation (A: sputum cell counts, B: fractional exhaled nitric oxide [FeNO]), either in addition to, or instead of standard measures of asthma control for the adjustment of antiinflammatory therapy, improve asthma outcomes in preschoolers (under 6 years of age), children (6 to 11 years of age) and adults (12 years of age and over) with asthma?

\section{Adjunct therapy with LABAs and leukotriene receptor antagonists (LTRA)}

2. At which inhaled corticosteroid (ICS) dose should adjunct therapy (LABA or LTRA) be added in children (6 to 11 years of age) and adults (12 years of age and over) with uncontrolled asthma who are on ICS monotherapy?

3. Which adjunct therapy (LABA or LTRA) should be added to ICS in children ( 6 to 11 years of age) and adults ( 12 years of age and over) with uncontrolled asthma who are on ICS monotherapy?

III. Single inhaler of an ICS/LABA combination as a reliever, and single inhaler of an ICS/LABA combination as a reliever and controller

4. What is the efficacy of using a single inhaler ICS/LABA combination as a reliever compared with a fast-acting beta ${ }_{2}$ agonist (FABA) as a reliever as part of a self-management plan in children and adults experiencing an acute loss of asthma control?

5. What is the efficacy of using a single inhaler of budesonide (BUD)/formoterol (FORM) as a reliever and controller as part of a self-management plan for individuals 12 years of age and over, compared with the following: a. the usual dose of controller (either ICS monotherapy or fixeddose ICS/LABA combination) with a FABA as a reliever?

b. 'guideline best practice' (defined as a practitioner adjusting controller therapy based upon regular review) with a FABA as a reliever?

\section{Controller therapy for action plans}

6. In mild persistent asthma, is the strategy of taking no daily controller therapy but initiating ICS as part of a written action plan at the onset of acute loss of asthma control as effective as taking daily ICS for preschoolers (under 6 years of age), children (6 to 11 years of age) and adults ( 12 years of age and over)?

7. In individuals with asthma on ICS monotherapy, what is the efficacy of escalating the ICS dose as part of a written action plan for children (6 to 11 years of age) and adults ( 12 years of age and over) with acute loss of asthma control?

8. As part of a self-management plan in children (6 to 11 years of age) and adults (12 years of age and over) experiencing an acute loss of asthma control, what is the efficacy of using a FABA reliever and:

a. starting a fixed-dose ICS/LABA combination in individuals who are on no maintenance therapy or ICS monotherapy?

b. escalating to a higher predetermined fixed dose of ICS/LABA combination compared with usual ICS/LABA dose in individuals on ICS/LABA combination as controller therapy?

c. escalating to a higher predetermined fixed dose of ICS/LABA combination compared with escalating only the ICS dose (either by addition of supplemental ICS to a fixed-dose ICS/ LABA or escalating to a higher ICS dose of a fixed-dose ICS/ LABA) in individuals on ICS/LABA combination as controller therapy?

9. In individuals with asthma, what is the efficacy of adding oral corticosteroids as part of a written action plan for preschoolers (under 6 years of age), children (6 to 11 years of age) and adults (12 years of age and over) with acute loss of asthma control?

\section{METHODOLOGY}

\section{Guideline development process}

The present guideline was developed by the CTS Asthma Clinical Assembly Steering Committee, which is comprised of individuals with content expertise in pediatric and adult respirology, allergy, emergency medicine and critical appraisal. A CTS guideline coordinator and a research methodologist provided regular consultation. Meetings of the CTS Asthma Clinical Assembly were held in Halifax, Nova Scotia, on April 29, 2010; Vancouver, British Columbia, October 30 to 31, 2010; Niagara Falls, Ontario, on April 28, 2011; and Toronto, Ontario, on October 30, 2011, and January 15, 2012.

The present guideline was developed in accordance with the CTS guideline production process and the 23-item Appraisal of Guidelines, Research and Evaluation (AGREE) II instrument $(5,6)$, which is the current gold standard in appraising the reporting quality of CPGs. The clinical questions were developed to address perceived gaps identified by the committee members, and input solicited from attendees at the 2010 Canadian Respiratory Guidelines Update, in accordance with a 'PICO' process, which takes into consideration the Population(s) at risk, Intervention(s), Comparator(s) and Outcome(s). This process guided the search strategy, including main topics and terms, inclusion and exclusion criteria, types of studies and databases in which to conduct the search. The committee chose to follow an adaptation process based on ADAPTE (7). Evidence from existing guidelines and published systematic reviews were used to base recommendations for the identified topics; in the absence of such evidence, the literature was searched for evidence from randomized controlled clinical trials (RCTs). 
TABLE 1

Topics addressed in literature review

\begin{tabular}{|c|c|c|c|c|}
\hline \multirow[b]{2}{*}{ Section } & \multirow[b]{2}{*}{ Topic } & \multicolumn{3}{|c|}{ Evidence informing recommendations for practice, $\mathrm{n}$ (references) } \\
\hline & & Guidelines & Systematic reviews & RCTs \\
\hline \multirow[t]{2}{*}{1} & 1. Noninvasive measurements of airway inflammation & & & \\
\hline & a) FeNO & 3 & 1 & 0 \\
\hline \multirow[t]{2}{*}{ II } & 2. Adjunct therapy - ICS dosage & 6 & 4 & 6 \\
\hline & 3. Type of adjunct therapy (LABA or LTRA) & 4 & 1 & 0 \\
\hline III & 4. Single inhaler of ICS/LABA as a reliever (versus FABA) & 0 & 1 & 0 \\
\hline \multirow[t]{4}{*}{ IV } & 6. Intermittent ICS & 1 & 1 & 0 \\
\hline & 7. Escalating ICS & 3 & 1 & 0 \\
\hline & 8. Starting or escalating ICS/LABA controller with FABA as reliever & 0 & 1 & 3 \\
\hline & 9. Systemic corticosteroids & 3 & 2 & 1 \\
\hline
\end{tabular}

BUD Budesonide; FABA Fast-acting beta ${ }_{2}$ agonist; FeNO Fraction of exhaled nitric oxide; FORM Formoterol; ICS Inhaled corticosteroid; LABA Long-acting beta ${ }_{2}$ agonist; LTRA Leukotriene receptor antagonist; RCTs Randomized controlled trials

\section{Literature search}

The literature was searched using MEDLINE (OVID: 2005 through June 2010), and EMBASE (OVID: 2005 through June 2010) databases for relevant CPGs addressing the clinical questions. In addition, the National Guideline Clearinghouse, CMA Infobase and Guidelines International Network (G-I-N) database were also searched from 2005 to June 2010 using keywords for asthma. Guidelines that addressed one or more of the clinical questions, and were published in English or French were included. When no CPGs were found to answer a clinical question or when all guidelines addressing a question were more than one year old, a search for systematic reviews was also undertaken in MEDLINE, EMBASE and the Cochrane Database of Systematic Reviews to October 2010. If a systematic review of RCTs was identified and the end date of literature review was more than one year old, the search strategy was updated using the same search criteria and search terms as used in the original systematic review to identify new RCTs published since the last update. In the absence of an available systematic review, a search for RCTs was conducted using specific search strategies indicated below for each section. Supplemental searches of the Cochrane Airways Group Register of Trials (CAGR) were conducted to identify recent RCTs on oral corticosteroids, increased ICS dose and inhaled corticosteroid/LABA combination therapy. This strategy ensured that the recommendations were based on the best current available evidence.

It should be noted that there was no comprehensive search for evidence of harm or effectiveness. Data regarding harm were derived from RCTs and systematic reviews whenever available; data from other study designs were not reviewed. Therefore, we advise caution in the assessment of the safety profile and the real-life effectiveness of the recommended strategies.

\section{Search strategies}

See the online supplementary materials for full search strategies. The following search terms were used to identify practice guidelines in MEDLINE (OVID): (exp asthma/ OR asthma:.tw.) AND (practice guideline.pt. OR guideline:.tw. OR recommendation:.tw. OR exp consensus development conference.pt.). Results were limited to CPGs published in 2005 or later, and to English or French language. Modifications were made as necessary in EMBASE. CPG databases were searched using the keyword "asthma".

Literature search strategies used to identify systematic reviews and RCTs for each clinical question used a combination of the following asthma terms as Medical Subject Headings (MeSH) and text words in MEDLINE and EMBASE (OVID): "asthma", "bronchial spasm", "wheeze", "bronchoconstriction", "airway inflammation" and "bronchospasm".

A combination of the following terms, as $\mathrm{MeSH}$ or text words, were used to identify systematic reviews and RCTs specific to each clinical question: nitric oxide, nitric, eNO, feNO, sputum, mucus, phlegm, beta agonist, long acting, adrenergic, bronchodilator, salmeterol, formoterol, eformoterol, advair, symbicort, steroid, glucocorticoid, corticosteroid, budesonide, beclomethasone, fluticasone, triamcinolone, flunisolide, leucotriene, anti-leucotriene, exacerbation, acute, status, severe, worsen, attack, crisis, emergency, self-management, action plan, self care, self medicate, management plan, management program, double, increase, dose response, pulmicort, aerobid, beclovent, azmacort, vanceril, becotide, flixotide, aerobec, qvar, ciclesonide, alvesco, prednisone, medrone, methylprednisone, precortisyl forte, decadron, medrol tablets, hydrocortisone, or hydrocortone.

Search filters to specifically identify systematic reviews and RCTs were adapted from the Scottish Intercollegiate Guidelines Network (SIGN) (8).

\section{Evidence selection}

Working groups of three to four committee members were assigned to each question. An initial review of the identified guidelines, and titles and abstracts of systematic reviews and primary studies was completed for each question. Publications addressing the clinical questions were retrieved for a full-text review. Agreement on inclusion of practice guidelines, systematic reviews and RCTs addressing each clinical question was achieved by informal consensus. Abstracts from conference proceedings were excluded. The evidence informing the recommendations (type and number of references) for each clinical question is summarized in Table 1.

\section{Evidence synthesis}

Data extraction tables were used to extract and summarize relevant evidence from included full-text publications based on the predetermined inclusion and exclusion criteria supporting each clinical question. All data extraction was conducted by a minimum of two reviewers; the secondary reviewer verified the accuracy of the extraction performed by the primary reviewer. Complete data extraction tables are available as online supplemental material (www.respiratoryguidelines.ca). The following outcomes were considered: need for systemic corticosteroid for an exacerbation; emergency department (ED) visits; hospitalizations; time to exacerbation; duration and intensity of symptoms of an exacerbation; rescue beta ${ }_{2}$-agonist use; pulmonary function; airway inflammatory markers; quality of life; withdrawals; and adverse effects. These data formed the basis for the recommendations and narrative text.

\section{Critical appraisal of the evidence}

The quality of the source guidelines, systematic reviews and RCTs on which recommendations were made were appraised by the AGREE II, the Assessment of Multiple Systematic Reviews (AMSTAR) (9) and Cochrane Risk of Bias (10) instruments respectively. The overall 
TABLE 2

Grading the quality of evidence and strength of recommendations

\begin{tabular}{|c|c|c|c|}
\hline $\begin{array}{l}\text { Grade of recommendation/ } \\
\text { description }\end{array}$ & $\begin{array}{l}\text { Benefit versus risk } \\
\text { and burdens }\end{array}$ & $\begin{array}{l}\text { Methodological quality of } \\
\text { supporting evidence }\end{array}$ & Implications \\
\hline $\begin{array}{l}\text { 1A/strong recommendation, } \\
\text { high-quality evidence }\end{array}$ & $\begin{array}{l}\text { Benefits clearly outweigh risk } \\
\text { and burdens or vice versa }\end{array}$ & $\begin{array}{l}\text { RCTs without important limitations or } \\
\text { overwhelming evidence from observational } \\
\text { studies }\end{array}$ & $\begin{array}{l}\text { Strong recommendation, can apply to most } \\
\text { patients in most circumstances without } \\
\text { reservation }\end{array}$ \\
\hline $\begin{array}{l}\text { 1B/strong recommendation, } \\
\text { moderate-quality evidence }\end{array}$ & $\begin{array}{l}\text { Benefits clearly outweigh risk } \\
\text { and burdens or vice versa }\end{array}$ & $\begin{array}{l}\text { RCTs with important limitations (inconsistent } \\
\text { results, methodological flaws, indirect or } \\
\text { imprecise) or exceptionally strong evidence } \\
\text { from observational studies }\end{array}$ & $\begin{array}{l}\text { Strong recommendation, can apply to most } \\
\text { patients in most circumstances without } \\
\text { reservation }\end{array}$ \\
\hline $\begin{array}{l}\text { 1C/strong recommendation, } \\
\text { low-quality or very low- } \\
\text { quality evidence }\end{array}$ & $\begin{array}{l}\text { Benefits clearly outweigh risk } \\
\text { and burdens or vice versa }\end{array}$ & Observational studies or case series & $\begin{array}{l}\text { Strong recommendation but may change } \\
\text { when higher quality evidence becomes } \\
\text { available }\end{array}$ \\
\hline $\begin{array}{l}\text { 2A/weak recommendation, } \\
\text { high-quality evidence }\end{array}$ & $\begin{array}{l}\text { Benefits closely balanced with } \\
\text { risks and burden }\end{array}$ & $\begin{array}{l}\text { RCTs without important limitations or } \\
\text { overwhelming evidence from observational } \\
\text { studies }\end{array}$ & $\begin{array}{l}\text { Weak recommendation, best action may differ } \\
\text { depending on circumstances, patients' or } \\
\text { social values }\end{array}$ \\
\hline $\begin{array}{l}\text { 2B/weak recommendation, } \\
\text { moderate-quality evidence }\end{array}$ & $\begin{array}{l}\text { Benefits closely balanced with } \\
\text { risks and burden }\end{array}$ & $\begin{array}{l}\text { RCTs with important limitations (inconsistent } \\
\text { results, methodological flaws, indirect or } \\
\text { imprecise) or exceptionally strong evidence } \\
\text { from observational studies }\end{array}$ & $\begin{array}{l}\text { Weak recommendation, best action may differ } \\
\text { depending on circumstances, patients' or } \\
\text { social values }\end{array}$ \\
\hline $\begin{array}{l}\text { 2C/weak recommendation, } \\
\text { low-quality or very low- } \\
\text { quality evidence }\end{array}$ & $\begin{array}{l}\text { Uncertainty in the estimates of } \\
\text { benefits, risks and burden; } \\
\text { benefits, risk and burden may } \\
\text { be closely balanced }\end{array}$ & Observational studies or case series & $\begin{array}{l}\text { Very weak recommendations; other } \\
\text { alternatives may be equally reasonable }\end{array}$ \\
\hline
\end{tabular}

Adapted from reference 11. RCTs Randomized controlled trials

strength of the evidence was assessed and recommendations were graded as outlined in Table 2 .

Accordingly, health benefits of the intervention, adverse effects, the burden to the patient, including cost, associated with adherence to the recommendations, morbidity, mortality and quality of life (QoL) were considered by the committee. The strength of the recommendations was agreed on by consensus from the full committee through open and extensive discussions within the working groups assigned to each question. Final consensus on the recommendations by the full committee was achieved via an anonymous voting process. When no evidence was available, the committee made a recommendation when consensus was reached.

\section{External expert commentary and review}

Clinical and methodology experts were identified by the Asthma Clinical Assembly Steering Committee and invited to review the draft document. Reviewers used the AGREE II $(5,6)$ checklist to document their appraisal and enhance the usability of the document. Feedback was gathered and relevant suggestions were incorporated into the document.

The Asthma Clinical Assembly will regularly review and update the asthma CPG, including the questions and content of the present publication, and identify and address new/emerging gaps and priorities. At minimum, the literature will be reviewed every two years for new evidence to inform revisions and update the guideline recommendations.

\section{REFERENCES}

1. Lougheed MD, Lemiere C, Dell SD, et al. Canadian Thoracic Society Asthma Management Continuum - 2010 Consensus Summary for children six years of age and over, and adults.

Can Respir J 2010;17:15-24.

2. Lougheed MD, Lemiere C, Dell S, et al. Canadian Thoracic Society Asthma Committee commentary on long-acting beta-2 agonist use for asthma in Canada. Can Respir J 2010;17:57-60.

3. Lemiere C, Bai T, Balter M, et al. Adult Asthma Consensus Guidelines Update 2003. Can Respir J 2004;11(Suppl A):9A-18A.

4. Global Strategy for the Diagnosis and Management of Asthma in Children 5 Years and Younger. Global Initiative for Asthma (GINA), 2009. <www.ginasthma.org>
5. Brouwers MC, Kho ME, Browman GP, et al. Development of the AGREE II, part 1: Performance, usefulness and areas for improvement. CMAJ 2010;182:1045-52.

6. Brouwers MC, Kho ME, Browman GP, et al. Development of the AGREE II, part 2: Assessment of validity of items and tools to support application. CMAJ 2010;182:E472-8.

7. The ADAPTE Collaboration (2009). The ADAPTE Process: Resource Toolkit for Guideline Adaptation. Version 2.0. <www.g-i-n.net> (Accessed November 21, 2011).

8. British Guideline on the Management of Asthma: A national clinical guideline. Scottish Intercollegiate Guidelines Network (SIGN); British Thoracic Society, 2008.

9. Higgins JP, Genn S. Assessing risk of bias in included studies. In: Higgins JP, Green S, eds. Cochrane Handbook for Systematic Reviews of Interventions: Cochrane Book series. Chichester: John wiley \& Sons, 2008.

10. Shea BJ, Grimshaw JM, Wells GA, et al. Development of AMSTAR: A measurement tool to assess the methodological quality of systematic reviews. BMC Med Res Methodol 2007;7:10.

11. Guyatt G, Gutterman D, Baumann MH, et al. Grading strength of recommendations and quality of evidence in clinical guidelines: Report from an American College of Chest Physicians Task Force. Chest 2006;129:174-81.

\section{SECTION I}

\section{NONINVASIVE MEASUREMENTS OF AIRWAY INFLAMMATION}

Question

1. Does the use of noninvasive measurements of airway inflammation (A: sputum cell counts, B: FeNO), either in addition to, or instead of standard measures of asthma control for the adjustment of anti-inflammatory therapy, improve asthma outcomes in preschoolers (under 6 years of age), children (6 to 11 years of age), and adults ( 12 years of age and over) with asthma?

\section{Introduction}

The definition of asthma has evolved over the past 20 years. Asthma was once defined as a "clinical syndrome characterized by increased responsiveness of the tracheobronchial tree to a variety of stimuli" (1). However, recent iterations of the Global Initiative for Asthma 
(GINA) guidelines (2), and the CTS consensus guidelines (3) and consensus summary (4) now recognize that airway inflammation, and its resultant effects on airway structure, are important mechanisms underlying the pathophysiology of asthma. Moreover, these guidelines acknowledge that treatment of this airway inflammation results in better clinical outcomes. However, although airway inflammation is currently considered to be a characteristic feature of asthma, the majority of international asthma guidelines have not yet unequivocally endorsed the use of noninvasive measurements of airway inflammation in the diagnosis and management of the condition.

\section{Sputum cell counts}

Sputum cell count analysis is a noninvasive method of objectively assessing the presence and nature of airway inflammation. It has been shown to be a reproducible, valid and responsive clinical outcome measure $(5,6)$. Sputum is spontaneously produced or induced by the inhalation of varying concentrations of hypertonic saline solution according to a standardized protocol, and is subsequently processed using either the whole expectorate or the selected method to generate total cell counts. Cytospins are then prepared and stained to obtain differential cell counts (5).

Sputum eosinophils are not normally present in healthy, nonatopic individuals, but are increased in individuals with asthma following exposure to common aeroallergens (7) or reduction of steroid treatment (8). Sputum eosinophil counts decline within three to seven days of initiating regular ICS or systemic corticosteroid treatment in the majority of individuals with asthma $(9,10)$. Sputum eosinophilia is also present in eosinophilic bronchitis without asthma (11), and in a subgroup of chronic obstructive pulmonary disease patients $(12,13)$. Normal sputum eosinophil counts are considered to be $<2 \%$ to $3 \%$ of a differential sputum cell count $(14,15)$. It is possible to safely induce sputum in cooperative children as young as six to eight years of age (16). Induced sputum cell counts have been increasingly used in the management of asthma since clinical studies have shown that titrating ICS maintenance treatment to normalize sputum eosinophil counts resulted in significant reductions in asthma exacerbations (17-19). Therefore, there is evidence that sputum cell count analysis may be useful in guiding management decisions in clinical practice.

FeNO levels

Nitric oxide $(\mathrm{NO})$ is a biological mediator that is produced in the airways and is present in exhaled breath $(20,21)$. NO is formed through a reaction catalyzed by inducible $\mathrm{NO}$ synthases, which in turn are upregulated in the presence of airway inflammation (22). Consequently, the fractional concentration of exhaled NO (ie, FeNO) is increased in a variety of inflammatory airway diseases, including asthma $(23,24)$. FeNO has been shown to correlate closely with eosinophilic airway inflammation in both adults (25) and children (26) with asthma. Measurement of FeNO has attracted a great deal of attention as a potential noninvasive method to diagnose asthma and to monitor the response to anti-inflammatory therapy. The test has now been standardized for clinical use (27), and devices for measuring FeNO have been approved by the United States Food and Drug Administration (FDA) and Health Canada. Numerous studies have provided information about the performance characteristics, as well as the potential applications of FeNO measurements to clinical practice (28).

Advantages of FeNO measurements include the noninvasive nature of the test, its repeatability, the relative simplicity of performing the test and the immediate availability of the results. These latter two issues are often put forward as reasons to favour using FeNO measurements over performing more technically demanding and time consuming induced sputum cell counts. It is feasible to measure FeNO in preschool children and infants (27), which is another relative advantage over sputum cell counts. The high initial cost of purchasing a chemiluminescence analyzer, the relative lack of sensitivity and specificity of FeNO as a biomarker of eosinophilic airway inflammation in asthma (29,30), and the confounding effects of atopic status, smoking and concurrent ICS treatment on FeNO measurements, have all been relative impediments to the broad adoption of FeNO in clinical practice to date. Recent development of non-chemiluminescence-based analyzers, such as the NIOX MINO or NIOX Flex (Aerocrine Inc, Sweden) that use electrochemical sensors to measure FeNO have significantly reduced the cost of purchasing an FeNO analyzer; however, the other limitations identified above remain.

\section{Methods}

Practice guidelines, systematic reviews of RCTs and RCTs comparing the use of $\mathrm{FeNO}$ or sputum eosinophil count to measure airway inflammation versus standard measures of asthma control for the adjustment of anti-inflammatory therapy for preschoolers, children, and adults in the primary or tertiary care setting were included. Outcomes of interest were asthma exacerbations, dose of anti-inflammatory medication (eg, ICS), pulmonary function and quality of life.

Asthma search terms were combined with the following $\mathrm{MeSH}$ and text words in OVID MEDLINE and EMBASE: nitric oxide OR exhaled nitric oxide OR nitric\$ OR eno OR feno OR sputum $\$$ or mucus $\$$ or phlegm $\$$. Systematic reviews were included if they were published in 2005 or later. RCTs were included if they were published after the search date of the most recent systematic review.

\section{Key evidence}

Four guidelines were used to inform recommendations on noninvasive measurements of airway inflammation $(25,28,30,36)$. The search strategy identified a total of 86 systematic review citations and 799 RCT citations. Of these, 14 systematic reviews and $46 \mathrm{RCTs}$ were identified for further analysis by full-text review. Two methodologically rigorous Cochrane systematic reviews were used to inform recommendations $(29,31)$. No RCTs were identified that met the criteria for inclusion and were published after the literature search date of the two systematic reviews.

\section{A) Sputum cell counts \\ Guidelines}

Regarding the role of induced sputum cell counts in asthma management, the British Thoracic Society Guideline (BTS-SIGN) on the management of asthma published in 2008 and updated in 2009 (31) stated, "In patients [adults] with difficult asthma, consider monitoring induced sputum eosinophil counts to guide steroid treatment". No other recent guideline has provided clear recommendations on the use of sputum cell count in clinical practice.

\section{Systematic reviews}

A 2009 Cochrane review analyzed three RCTs that compared the effect of the adjustment of the asthma therapy according to the results of sputum cell counts (sputum strategy) or according to the traditional parameters (symptoms, and respiratory function tests [forced expiratory volume in $1 \mathrm{~s}\left(\mathrm{FEV}_{1}\right)$ or peak expiratory flow $(\mathrm{PEF})$ ]: clinical strategy) on asthma exacerbations in adult asthmatic subjects (32). To date, there are no relevant published studies involving children. The primary outcome of the Cochrane review was the proportion of participants who experienced any asthma exacerbations during the follow-up period. There was a significant reduction in the number of subjects who experienced one or more asthma exacerbations when treated according to the sputum strategy compared with the clinical strategy. The pooled odds ratio (OR) was 0.49 (95\% CI 0.28 to 0.87 ) with a number needed to treat to benefit of 6 (95\% CI 4 to 32), favouring the sputum strategy $\mathrm{arm}$. The frequency of exacerbation (per participant-month) was significantly lower in the sputum strategy arm (rate ratio [RR] 0.54 [95\% CI 0.37 to 0.78$]$ ). The number of hospitalizations between groups was not statistically different $(\mathrm{P}=0.08)$ but tended to favour the sputum strategy group (OR 0.14 [ $95 \%$ CI 0.02 to 1.25]). The rate of severe exacerbations requiring rescue oral steroids was lower in the sputum strategy group ( $R R$ 0.33 [95\% CI 0.19 to 0.57]). Only one trial reported the occurrence of mild exacerbations; therefore, the data could not be combined. Only 
one study (18) reported the type of airway inflammation associated with asthma exacerbations (eosinophilic versus noneosinophilic) in each group. In cases where sputum could be obtained at the time of exacerbation (39 of 47 in the sputum strategy group, and 63 of 79 in the clinical strategy group), the overall reduction in exacerbation rates were largely due to a reduction in eosinophilic exacerbations. There was no statistically significant difference in the maintenance dose of ICS between the two treatment strategies (difference in dose of ICS per person per day $=$ 78.99 [95\% CI -90.13 to 248.11]). Pulmonary function, as measured by the PEF amplitude and $\mathrm{FEV}_{1}$ after bronchodilator, were studied in one of the three trials and found no difference between groups (17). FEV was similar between groups in the study by Chlumsky et al. (19), whereas it was not reported in the study by Jayaram et al. (18). The quality of life and cost per patient of the two strategies were reported in only one trial (Green et al. [17]) and was not different between groups.

\section{B) $\mathrm{FeNO}$}

\section{Guidelines}

With regard to the role of FeNO in asthma management, the BTSSIGN Guideline concludes that there is insufficient evidence to support a role for $\mathrm{FeNO}$ in the diagnosis or monitoring of asthma in either children or adults (31). It adds that more experience and information are required before FeNO can be recommended for use in clinical practice. Similarly, the NHLBI Expert Panel Report 3 (2007) concluded that "...further evaluation in adults and children [is needed] before [FeNO] can be recommended as a clinical tool for routine asthma management" (33). A similar recommendation was made by the European Academy of Allergy and Clinical Immunology (EAACI)/ American Academy of Allergy, Asthma and Immunology (AAAAI) PRACTALL consensus report (2008) (34). To date, the only guideline statement that has offered any endorsement for the use of FeNO in clinical practice is the recently published American Thoracic Society clinical practice guideline on interpretation of FeNO for clinical applications (28). It provides strong recommendations for the use of FeNO in the diagnosis of eosinophilic airway inflammation and in determining the likelihood of patient responsiveness to corticosteroid treatment. However, it should be noted that these recommendations are based on a moderate quality of evidence (for diagnostic use) and low quality of evidence (for prediction of response), respectively, and the guideline recommendation that FeNO be used in monitoring airway inflammation in patients with asthma should be interpreted in that context.

\section{Systematic reviews}

A 2009 Cochrane review (35) analyzed six RCTs (two adult, four pediatric/adolescent) that evaluated the efficacy of tailoring asthma interventions based on FeNO compared with clinical symptoms (with or without spirometry/peak flow) for asthma-related outcomes in children and adults. The primary outcomes identified by the review were asthma exacerbations during follow-up or exacerbation rates. Doses of ICS used for treatment were described in a post hoc analysis; however, quality of life and health care cost per patient for the two strategies were not reported in any of the trials. In the meta-analysis of the six trials, involving 215 adults and 838 children with asthma, there was no significant difference between FeNO strategy group compared with control group for the primary outcome of asthma exacerbations (adults OR 0.85 [95\% CI 0.30 to 2.43]); children OR 0.75 (95\% CI 0.55 to 1.01), or for other outcomes (clinical symptoms, FeNO level and spirometry). In one of the pediatric trials studying 546 inner city American children (36), post hoc analyses showed that the FeNO strategy was effective in subsets of children with a high body mass index $\left(\geq 30 \mathrm{~kg} / \mathrm{m}^{2}\right)$, severe atopy ( $\geq 10$ positive skin tests out of 14 allergens tested) or high serum immunoglobulin E levels ( $>460 \mathrm{kU} / \mathrm{L}$ ). With regard to impact on ICS dose, in a post hoc analysis, a significant reduction in mean final daily dose of ICS in adults was found in the FeNO group compared with the standard management group (mean difference [MD] -450 mcg; $95 \% \mathrm{CI}-677 \mathrm{mcg}$ to $-223 \mathrm{mcg}$ budesonide equivalent/day). The total amount of ICS used in one of the adult studies (37) was $11 \%$ greater in the FeNO arm. In contrast, in the pediatric studies, there was a significant increase in ICS dose in the FeNO strategy arm (MD $140 \mathrm{mcg}$ [95\% CI $29 \mathrm{mcg}$ to $251 \mathrm{mcg}$ ], budesonide equivalent/day). Thus, while tailoring medications based on FeNO has been advocated in the literature (38), the results of this Cochrane review indicate that using this strategy results in only a modest benefit at best, and could potentially result in increased ICS use in children compared with a standard strategy. The conclusion, therefore, is that using FeNO measurements to tailor the dose of ICS cannot be routinely recommended for clinical practice at this time. It should be noted that the failure of previous clinical trials to show a benefit from monitoring $\mathrm{FeNO}$ to guide asthma management may be related to study design and the clinical outcomes evaluated, which should be addressed in future clinical trials (39).

\section{Conclusions}

Treating asthma according to the results of sputum cell counts is an effective strategy to reduce severe eosinophilic asthma exacerbations in adults with moderate to severe asthma. While the three studies reported in the Cochrane review (35) compared treatment strategies based on sputum eosinophil counts versus best practice strategies using standard measures of asthma control, it should be noted that the sputum strategy cohort in the largest of these studies (18) still permitted assessment of symptoms and spirometry to identify clinical control, exacerbations and other treatment options. Thus, based on current evidence, it seems prudent to advocate monitoring sputum eosinophil counts in addition to, and not instead of, standard measures of asthma control to adjust anti-inflammatory therapy in adults with moderate to severe asthma. In contrast, while FeNO measurements are noninvasive and relatively easy to obtain in both children and adults, there is still insufficient evidence to recommend the use of FeNO to tailor the dose of ICS compared with titrating ICS dose based on clinical symptoms alone. As such, the routine use of FeNO measurements as a guide to tailor the dose of ICS in asthma cannot be endorsed for clinical practice at this time.

\section{Question 1 \\ Does the use of noninvasive measurements of airway inflammation (A: sputum cell counts, B: FeNO), either in addition to, or instead of standard measures of asthma control for the adjustment of anti- inflammatory therapy improve asthma outcomes in preschoolers (under 6 years of age), children (6 to 11 years of age), and adults (12 years of age and over) with asthma?}

The following recommendations are based on evidence from four guidelines, two systematic reviews and the consensus of the CTS Asthma Clinical Assembly Expert Panel.

\section{Recommendation 1A}

We recommend the monitoring of sputum eosinophil counts, in addition to standard measures of asthma control, to adjust antiinflammatory therapy of individuals 18 years of age and over with moderate to severe asthma in tertiary care or specialized centres. (GRADE 1B)

\section{Recommendation 1B}

We do not suggest the routine use of FeNO, either in addition to or instead of standard measures of asthma control, to adjust anti-inflammatory therapy in children or adults with asthma. (GRADE 2B)

There is insufficient evidence to recommend for or against the monitoring of sputum eosinophil counts to adjust the anti-inflammatory treatment of children and adolescents (12 to 17 years of age) with asthma.

There is insufficient evidence to make a recommendation regarding the use of FeNO either in addition to or instead of standard measures of asthma control to adjust anti-inflammatory therapy in preschoolers. 
Future research needs

Based on the evidence reviewed, the Clinical Assembly identifies the following research needs:

- to evaluate the benefit of monitoring sputum eosinophil counts in the management of children and adolescents with severe asthma and in assessing patient adherence to ICS medications;

- to develop and validate surrogate biomarkers of sputum eosinophilic inflammation that are both practical and feasible to use in a broad range of health care settings, especially in children; and

- to evaluate the role of FeNO using study designs that may be more reflective of intraindividual changes in airway inflammation; and subpopulations of asthma phenotypes, including inner-city children, obese patients, and those with severe atopy or moderatesevere asthma who might be expected to benefit from using FeNO to guide clinical decision making.

\section{REFERENCES}

1. Standards for the diagnosis and care of patients with chronic obstructive pulmonary disease (COPD) and asthma. This official statement of the American Thoracic Society was adopted by the ATS Board of Directors, November 1986. Am Rev Respir Dis $1987 ; 136: 225-44$

2. Gobal Strategy for Asthma Management and Prevention. Global Initiative for Asthma (GINA), 2008. <www.ginasthma.org> (Accessed September 24, 2010).

3. Lemiere C, Bai T, Balter M, et al. Adult Asthma Consensus Guidelines update 2003. Can Respir J 2004;11(Suppl A):9A-18A

4. Lougheed MD, Lemiere C, Dell SD, et al. Canadian Thoracic Society Asthma Management Continuum - 2010 Consensus Summary for children six years of age and over, and adults. Can Respir J 2010;17:15-24.

5. Pizzichini E, Pizzichini M, Efthimiadis A, et al. Indices of airway inflammation in induced sputum: Reproducibility and validity of cell and fluid-phase measurements. Am J Respir Crit Care Med 1996;154:308-17.

6. Djukanovic R, Sterk PJ, Fahy JV, Hargreave FE. Standardised methodology of sputum induction and processing. Eur Respir J 2002;20(37 Suppl):1s-55s

7. Fahy J, Liu J, Wong H, Boushey H. Analysis of cellular and biochemical constituents of induced sputum after allergen challenge: A method for studying allergic airway inflammation. J Allergy Clin Immunol 1994;93:1031-9.

8. Gibson P, Wong B, Hepperle M, et al. A research method to induce and examine a mild exacerbation of asthma by withdrawal of inhaled corticosteroid. Clin Exper Allergy 1992;22:525-32.

9. Hargreave FE. Induced sputum and response to glucocorticoids. J Allergy Clin Immunol 1998;102:S102-5.

10. Kelly MM, Leigh R, Jayaram L, Goldsmith CH, Parameswaran K, Hargreave FE. Eosinophilic bronchitis in asthma: A model for establishing dose-response and relative potency of inhaled corticosteroids. J Allergy Clin Immunol 2006;117:989-94.

11. Gibson PG, Dolovich J, Denburg J, Ramsdale EH, Hargreave FE. Chronic cough: Eosinophilic bronchitis without asthma. Lancet 1989;1:1346-8

12. Brightling CE, Monteiro W, Ward R, et al. Sputum eosinophilia and short-term response to prednisolone in chronic obstructive pulmonary disease: A randomised controlled trial. Lancet 2000;356:1480-5

13. Leigh R, Pizzichini MM, Morris MM, Maltais F, Hargreave FE, Pizzichini E. Stable COPD: Predicting benefit from high-dose inhaled corticosteroid treatment. Eur Respir J 2006;27:964-71.

14. Belda J, Leigh R, Parameswaran K, O'Byrne PM, Sears MR, Hargreave FE. Induced sputum cell counts in healthy adults. Am J Respir Crit Care Med 2000;161:475-8.

15. Spanevello A, Confalonieri M, Sulotto F, et al. Induced sputum cellularity. Reference values and distribution in normal volunteers. Am J Respir Crit Care Med 2000;162:1172-4.

16. Gibson PG, Grootendorst DC, Henry R, et al. Sputum induction in children. Eur Respir J 2002;20(37 Suppl):44s-6s.

17. Green R, Brighting C, McKenna S, et al. Asthma exacerbations and sputum eosinophil counts: A randomised controlled trial. Lancet 2002;360:1715-21.

18. Jayaram L, Pizzichini MM, Cook RJ, et al. Determining asthma treatment by monitoring sputum cell counts: effect on exacerbations. Eur Respir J 2006;27:483-94.
19. Chlumsky J, Striz I, Terl M, Vondracek J. Strategy aimed at reduction of sputum eosinophils decreases exacerbation rate in patients with asthma. J Int Med Res 2006;34:129-39.

20. Palmer RM, Ashton DS, Moncada S. Vascular endothelial cells synthesize nitric oxide from L-arginine. Nature 1988;333:664-6.

21. Gustafsson LE, Leone AM, Persson MG, Wiklund NP, Moncada S. Endogenous nitric oxide is present in the exhaled air of rabbits, guinea pigs and humans. Biochem Biophys Res Comm 1991;181:852-7.

22. Nathan C, Xie QW. Nitric oxide synthases: Roles, tolls, and controls. Cell 1994;78:915-8.

23. Alving $\mathrm{K}$, Weitzberg E, Lundberg JM. Increased amount of nitric oxide in exhaled air of asthmatics. Eur Respir J 1993;6:1368-70.

24. Kharitonov SA, Yates D, Robbins RA, Logan-Sinclair R, Shinebourne EA, Barnes PJ. Increased nitric oxide in exhaled air of asthmatic patients. Lancet 1994;343:133-5.

25. Berry MA, Shaw DE, Green RH, Brightling CE, Wardlaw AJ, Pavord ID. The use of exhaled nitric oxide concentration to identify eosinophilic airway inflammation: An observational study in adults with asthma. Clin Exp Allergy 2005;35:1175-9.

26. Warke TJ, Fitch PS, Brown V, et al. Exhaled nitric oxide correlates with airway eosinophils in childhood asthma. Thorax 2002;57:383-7.

27. ATS/ERS Recommendations for standardized procedures for the online and offline measurement of exhaled lower respiratory nitric oxide and nasal nitric oxide, 2005. Am J Respir Crit Care Med 2005;171:912-30.

28. Dweik RA, Boggs PB, Erzurum SC, et al. An official ATS clinical practice guideline: Interpretation of exhaled nitric oxide levels (FENO) for clinical applications. Am J Respir Crit Care Med 2011;184:602-15.

29. Leuppi JD, Salome CM, Jenkins CR, et al. Markers of airway inflammation and airway hyperresponsiveness in patients with wellcontrolled asthma. Eur Respir J 2001;18:444-50.

30. Lex C, Ferreira F, Zacharasiewicz A, et al. Airway eosinophilia in children with severe asthma: Predictive values of noninvasive tests. Am J Respir Crit Care Med 2006;174:1286-91.

31. British Guideline on the Management of Asthma. Scottish Intercollegiate Guidelines Network (SIGN); British Thoracic Society, 2008. <www.sign.ac.uk?>.

32. Petsky H, Kynaston J, Turner C, et al. Tailored Interventions based on sputum eosinophils versus clinical symptoms for asthma in children and adults. Cochrane Database of Syst Rev 2007(2);CD005603.

33. National Asthma Education Prevention Program (NAEPP). Expert Panel Report 3: Guidelines for the diagnosis and management of asthma. Bethesda: National Heart, Lung, and Blood Institute (NHLBI), 2007.

34. Bacharier LB, Boner A, Carlsen KH, et al. Diagnosis and treatment of asthma in childhood: A PRACTALL consensus report. Allergy 2008;63:5-34.

35. Petsky HL, Cates CJ, Li A, Kynaston JA, Turner C, Chang AB. Tailored interventions based on exhaled nitric oxide versus clinical symptoms for asthma in children and adults. Cochrane Database Syst Rev 2009(4):CD006340.

36. Szefler SJ, Mitchell H, Sorkness CA, et al. Management of asthma based on exhaled nitric oxide in addition to guideline-based treatment for inner-city adolescents and young adults: A randomised controlled trial. Lancet 2008;372:1065-72.

37. Shaw DE, Berry MA, Thomas M, et al. The use of exhaled nitric oxide to guide asthma management: a randomized controlled trial. Am J Respir Crit Care Med 2007;176:231-7.

38. Szefler SJ. Facing the challenges of childhood asthma: What changes are necessary? J Allergy Clin Immunol 2005;115:685-8.

39. Gibson PG. Using fractional exhaled nitric oxide to guide asthma therapy: Design and methodological issues for ASthma TReatment ALgorithm studies. Clin Exp Allergy 2009;39:478-90.

\section{SECTION II ADJUNCT THERAPY WITH LABAs AND LTRAs}

\section{Questions}

2. At which ICS dose should adjunct therapy (LABA or LTRA) be added in children ( 6 to 11 years of age) and adults (12 years of age and over) with uncontrolled asthma who are on ICS monotherapy?

3. Which adjunct therapy (LABA or LTRA) should be added to ICS in children (6 to 11 years of age) and adults (12 years of age and over) with uncontrolled asthma who are on ICS monotherapy? 
TABLE 3

Comparative inhaled corticosteroids (ICS) dosing categories in children and adults

\begin{tabular}{|c|c|c|c|c|c|c|c|}
\hline \multirow[b]{3}{*}{ Corticosteroid } & \multirow[b]{3}{*}{ Trade name } & \multicolumn{6}{|c|}{ Daily ICS dose, mcg } \\
\hline & & \multicolumn{3}{|c|}{ Pediatric (6 to 11 years of age) } & \multicolumn{3}{|c|}{ Adult (12 years of age and over) } \\
\hline & & Low & Medium & High & Low & Medium & High \\
\hline Beclomethasone dipropionate HFA & $\mathrm{QVAR}^{\dagger}$ & $\leq 200$ & $201-400^{a}$ & $>400^{\mathrm{a}}$ & $\leq 250$ & $251-500$ & $>500$ \\
\hline Ciclesonide $^{*}$ & Alvesco ${ }^{\S}$ & $\leq 200$ & $201-400^{\mathrm{a}}$ & $>400^{\mathrm{a}}$ & $\leq 200$ & $201-400$ & $>400$ \\
\hline Fluticasone & Flovent MDI and spacer; Flovent Diskus" & $\leq 200$ & $201-400$ & $>400^{\mathrm{a}}$ & $\leq 250$ & $251-500$ & $>500$ \\
\hline Mometasone & Asmanex Twisthaler** & & & & 200 & $\geq 400-800$ & $>800^{\mathrm{b}}$ \\
\hline
\end{tabular}

Dosing categories are approximate, based on a combination of approximate dose equivalency as well as safety and efficacy data rather than available product formulations. *Licensed for once daily dosing in Canada (a: Daily doses of beclomethasone dipropionate HFA >200 mcg/day, ciclesonide >200 mcg/day and fluticasone $>400$ mcg/day are not approved for use in children in Canada [highlighted]); ${ }^{\dagger}$ Graceway Pharmaceuticals, Canada; ${ }^{\ddagger}$ AstraZeneca Inc, Canada; ${ }^{\S}$ Nycomed Canada Inc; "GlaxoSmithKline Inc, Canada; **Merck \& Co Inc, USA (b: Daily doses of mometesone >800 mg/day are not approved for use in adults in Canada [highlighted]). Adapted from reference 1

\section{Introduction}

ICS are the foundation of chronic maintenance pharmacotherapy for asthma. Most patients can achieve asthma control using relatively low doses of ICS. Failure to demonstrate a clinical response to ICS therapy often relates to one of five factors: erroneous diagnosis of asthma; poor inhaler device technique; poor adherence with maintenance ICS treatment; ongoing exposure to environmental triggers; and comorbidities (1). If, after reviewing these factors, asthma remains uncontrolled on low-dose ICS, there are three initial options for escalating pharmacological therapy: increasing to medium or high doses of ICS; adding a LABA; or adding an LTRA. The available literature was reviewed to determine at what dose of ICS therapy adjunct therapy should be considered and to determine which adjunct therapy (LABA or LTRA) demonstrates the greatest clinical benefit.

\section{Methods}

Question 2: Practice guidelines, systematic reviews of RCTs and RCTs comparing the addition of LABA or LTRA to the same ICS dose with increased ICS dose alone in the treatment of children and adults with uncontrolled asthma who are on ICS monotherapy were included. Outcomes of interest were asthma exacerbations, pulmonary function,

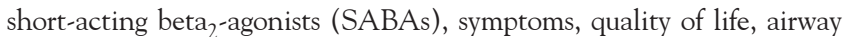
inflammatory markers, asthma control, withdrawals and adverse effects. Question 3: Practice guidelines, systematic reviews of RCTs and RCTs comparing the addition of LABA versus LTRA in the treatment of children and adults with uncontrolled asthma who are on ICS monotherapy were included. Outcomes of interest included asthma exacerbations, pulmonary function, quality of life, airway inflammatory markers, asthma control and adverse effects.

Asthma search terms were combined with the following $\mathrm{MeSH}$ and text words in OVID MEDLINE and EMBASE: (beta\$ AND agonist\$ AND long-acting) OR (beta $\$$ AND adrenergic\$ AND long-acting) OR salmeterol OR formoterol OR eformoterol OR advair OR symbicort OR leucotrien\$ OR leukotrien\$ OR anti-leucotrien\$ OR anti-leukotrien\$ AND (steroid\$ OR glucocorticoid\$ OR corticosteroid $\$$ AND inhal\$ OR budesonide OR beclomethasone OR fluticasone $\mathrm{OR}$ triamcinolone $\mathrm{OR}$ flunisolide). Systematic reviews were included if they were published in 2005 or later. RCTs were included if they were published after the search date of the most recent systematic review.

\section{Key evidence: Adjunct therapy - ICS dosage}

The search identified a total of 289 systematic review citations and 1777 RCT citations. Of these, 12 systematic reviews and 55 RCTs were selected for full-text review. A total of six guidelines, four systematic reviews and six RCTs were used to inform the recommendations. There were insufficient data identified for children under 6 years of age.

\section{Guidelines}

Six guidelines were identified that addressed the ICS dose at which adjunct therapy should be added (1-6). All six guidelines recommended the addition of adjunct therapy with LABA or LTRA when asthma is not controlled at low or medium doses of ICS. None of the guidelines recommend escalating to high-dose ICS before initiating combination therapy. The recommendations differed for children 6 to 11 years of age compared with individuals 12 years of age and over.

In adults 12 years of age and over, two guidelines (GINA), the 2003 CTS Adult and the CTS Asthma Management Continuum 2010 Consensus Summary for children six years of age and over, and adults $(1,3,5)$ recommended adjunct therapy as the preferred choice if low-dose ICS does not result in controlled asthma, whereas NHLBI/ NAEPP recommended adjunct therapy after low- or medium-dose ICS (6).

In children 6 to 11 years of age, the GINA, NHLBI/NAEPP, 2004 CTS Pediatric Asthma, and South African Childhood Asthma Working Group (SACAWG) Guidelines, and the CTS Asthma Management Continuum 2010 Consensus Summary, all recommend initiation of adjunct therapy only after patients fail to achieve control on a medium dose of ICS $(1,2,4-6)$.

ICS dosing categories (low-, medium- and high-dose ICS) for children and adults are presented in Table 3.

\section{Systematic reviews}

Four systematic reviews that compared combination therapy of ICS plus LABA, or ICS plus LTRA with higher doses of ICS monotherapy (7-11) were identified. The evidence was examined to identify the optimal ICS dose range for initiation of adjunct therapies.

Ducharme et al. (8) identified 48 trials including 15,155 participants (14,000 adults and 1515 children) that compared ICS/LABA combination therapy at a median dose of $400 \mathrm{mcg}$ beclomethasone diproprionate (BDP) equivalent to an increased dose of ICS median dose 1000 mcg BDP (8). In adults, combination therapy with ICS/ LABA resulted in decreased exacerbations requiring oral steroids (RR 0.88 [95\% CI 0.78 to 0.98], improved $\mathrm{FEV}_{1} 0.08$ L (95\% CI 0.03 to 0.13 ) and improved asthma control (change in rescue inhalations over $24 \mathrm{~h}$ : -20 puff/day (95\% CI -0.29 to -0.11 ), compared with higher dose ICS. In children, there was no statistically significant difference between the comparators when evaluating exacerbations requiring oral corticosteroids (RR 1.24 [95\% CI 0.58 to 2.66]) and exacerbations requiring hospitalization (RR 2.21 [95\% CI 0.74 to 6.64]). Notably however, although the results are not statistically significant in children, the RR point estimates are greater than one and the CIs are wide, indicating low precision of these estimates (8).

$\mathrm{Ni}$ Chroinin et al. (10) evaluated seven trials that randomly assigned 1021 children 2 to 18 years of age initially on a median of 400 mcg BDP equivalent or less to ICS/LABA combination therapy versus increased dose ICS. There was no statistically significant difference in the risk of exacerbation requiring oral corticosteroids between the groups (OR 1.5 [95\% CI 0.65 to 3.48]) and no significant difference in the risk of hospitalization (OR 2.2 [95\% CI 0.74 to 6.64]). Morning PEF was significantly better in the ICS/LABA combination group. Linear growth was significantly greater in the ICS/LABA combination group by $1.2 \mathrm{~cm} /$ year ( $95 \%$ CI 0.72 to 1.7 ). 
TABLE 4

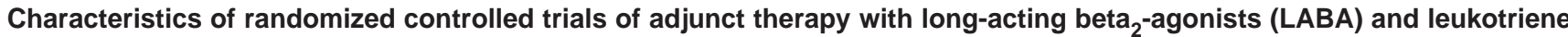
receptor antagonists (LTRAs)

\begin{tabular}{|c|c|c|c|c|c|}
\hline Trial, year & Patients, $\mathbf{n}$ & Age, years & Intervention(s) & Comparator & Outcomes \\
\hline \multicolumn{6}{|c|}{ Combination ICS plus LABA versus increased ICS dose } \\
\hline $\begin{array}{l}\text { Menezes et al. } \\
(12), 2008\end{array}$ & 32 & $18-60$ & $\begin{array}{l}\text { BUD } 400 \mathrm{mcg} / \\
\text { FORM } 24 \mathrm{mcg}\end{array}$ & $\begin{array}{l}\text { BUD } \\
800 \mathrm{mcg}\end{array}$ & $\begin{array}{l}\text { Combination group: significant decrease in the rate of exacerbations } \\
(\mathrm{P}<0.05) \text { and increase in morning }(435 \pm 162 \mathrm{~L} / \mathrm{min} \text { to } 489 \pm 169 \mathrm{~L} / \mathrm{min}) \text { and } \\
\text { evening }(428 \pm 160 \mathrm{~L} / \mathrm{min} \text { to } 496 \pm 173 \mathrm{~L} / \mathrm{min}) \mathrm{PEF}(\mathrm{P}<0.01)\end{array}$ \\
\hline $\begin{array}{l}\text { O'Byrne et al. } \\
\text { (16), } 2008\end{array}$ & 852 & $18-70$ & $\begin{array}{l}\text { BUD } 200 \mathrm{mcg} / F O R M \\
24 \mathrm{mcg} ; \\
\text { BUD } 800 \mathrm{mcg} ; \\
\text { BUD } 800 \mathrm{mcg} / \\
\text { FORM } 24 \mathrm{mcg} / \text { day }\end{array}$ & $\begin{array}{l}\text { BUD } \\
200 \mathrm{mcg}\end{array}$ & 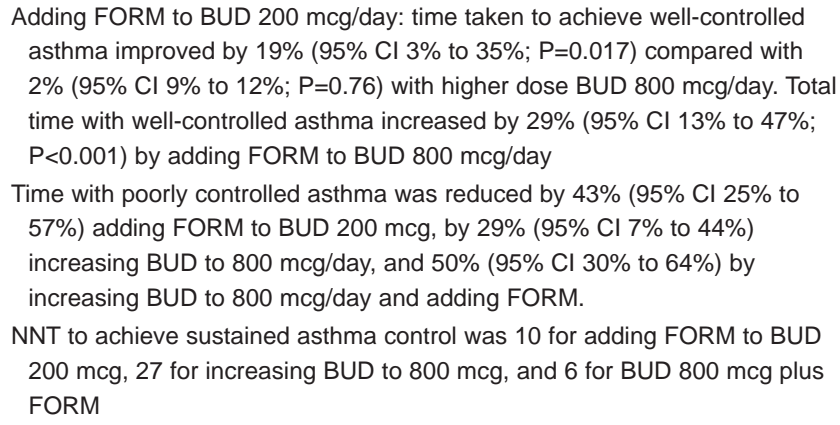 \\
\hline $\begin{array}{l}\text { de Blic et al. } \\
\text { (13), } 2009\end{array}$ & 321 & $4-11$ & $\begin{array}{l}\text { Fluticasone } 200 \mathrm{mcg} / \\
\text { salmeterol } 100 \mathrm{mcg}\end{array}$ & $\begin{array}{l}\text { Fluticasone } \\
400 \text { mcg }\end{array}$ & $\begin{array}{l}\text { PEF better in combination (difference } 7.6 \mathrm{~L} / \mathrm{min} \text { ) } \\
\text { Proportion achieving control same in both groups }\end{array}$ \\
\hline $\begin{array}{l}\text { Gappa et al. } \\
\text { (14), } 2009\end{array}$ & 283 & $4-16$ & $\begin{array}{l}\text { Fluticasone } 200 \mathrm{mcg} / \\
\text { salmeterol } 100 \mathrm{mcg}\end{array}$ & $\begin{array}{l}\text { Fluticasone } \\
400 \mathrm{mcg}\end{array}$ & $\begin{array}{l}\text { Combination: morning PEF higher }(8.6 \mathrm{~L} / \mathrm{min},) \text {, greater number of weeks of } \\
\text { good asthma control }(3.4 \pm 2.7 \text { weeks versus } 2.7 \pm 2.7 \text { weeks; } P=0.02)\end{array}$ \\
\hline \multicolumn{6}{|c|}{ ICS plus LTRA versus increased ICS dose } \\
\hline $\begin{array}{l}\text { Yildirim et al. } \\
\text { (17), } 2004\end{array}$ & 30 & 37 (mean) & $\begin{array}{l}\text { BUD } 400 \mathrm{mcg}+ \\
\text { montelukast } 10 \mathrm{mg}\end{array}$ & $\begin{array}{l}\text { BUD } \\
800 \mathrm{mcg}\end{array}$ & No differences in early morning, daytime or evening symptom scores \\
\hline $\begin{array}{l}\text { Barnes et al. } \\
(12), 2007\end{array}$ & 75 & $15-70$ & $\begin{array}{l}\text { BUD } 800 \mathrm{mcg}+ \\
\text { montelukast } 10 \mathrm{mg}\end{array}$ & $\begin{array}{l}\text { BUD } \\
1600 \mathrm{mcg}\end{array}$ & PEF and QoL improved in both arms but no significant differences \\
\hline
\end{tabular}

BUD Budesonide; FORM Formoterol; NNT Number needed to treat; PEFR Peak expiratory flow rate; QoL Quality of life

Ducharme et al. (7) identified seven trials in adults comparing ICS (400 to 800 mcg BDP equivalent) plus LTRA combination therapy to double-dose ICS therapy. However, only four studies contributed data in a way that could be used in the meta-analysis, and one of these did not use licensed doses of LTRA. Therefore, only three studies contributed to the final analysis. There was no significant group difference between LTRA/ICS combination therapy and double-dose ICS at reducing exacerbations requiring oral steroids (RR 0.92 [95\% CI 0.56 to 1.51], data from two trials) (7).

Masoli et al. (9) identified 12 studies involving 4576 adolescents 12 years of age and over and adult subjects in which combination therapy ICS (fluticasone $200 \mathrm{mcg}$ or equivalent) plus salmeterol was compared with at least a doubling of the baseline dose of ICS. Compared with combination therapy, ICS monotherapy was associated with more moderate or severe exacerbations (OR 1.35 [95\% CI 1.10 to 1.66]) and lower morning and evening PEF (9). The publication of a report on the high cost of the initial therapy by combination therapy was also reviewed (11).

\section{RCTs}

Six additional RCTs that were published after the systematic reviews addressed above (12-17) were identified. The studies are summarized in Table 4.

i) Combination ICS/LABA versus increased ICS dose

Four RCTs compared the combination of ICS/LABA to increasing the ICS dose. Menezes et al. (15) compared BUD $400 \mathrm{mcg} /$ day plus FORM $24 \mathrm{mcg} /$ day with BUD $800 \mathrm{mcg} /$ day in 32 adult patients. There was a significant decrease in the rate of exacerbations in the combination group $(\mathrm{P}<0.05)$, as well as an increase in morning and evening mean PEF from $435 \pm 162 \mathrm{~L} / \mathrm{min}$ to $489 \pm 169 \mathrm{~L} / \mathrm{min}$, and $428 \pm 160 \mathrm{~L} / \mathrm{min}$ to $496 \pm 173 \mathrm{~L} / \mathrm{min}$, respectively $(\mathrm{P}<0.01)$.

O'Byrne et al. (16) compared BUD $200 \mathrm{mcg}$ per day, BUD $200 \mathrm{mcg}$ plus FORM $24 \mathrm{mcg} /$ day, and BUD $800 \mathrm{mcg} /$ day, to BUD $800 \mathrm{mcg}$ plus FORM $24 \mathrm{mcg} /$ day, in a multicentre study including 852 subjects 18 to 70 years of age. The time taken to achieve well-controlled asthma was improved by $19 \%$ (95\% CI $3 \%$ to $35 \%$; $\mathrm{P}=0.017$ ) by adding FORM to
BUD $200 \mathrm{mcg} /$ day compared with 2\% (95\% CI 9\% to 12\%; P=0.76) with higher dose BUD $800 \mathrm{mcg} /$ day alone. The addition of FORM to BUD was significantly more effective at increasing the time with wellcontrolled asthma in comparison to increasing the BUD dose by a factor of four. Total time with well-controlled asthma increased by $29 \%$ (95\% CI $13 \%$ to $47 \%$; $\mathrm{P}<0.001$ ), by adding FORM to BUD 800 $\mathrm{mcg} /$ day. The time with poorly controlled asthma was reduced by $43 \%$ (95\% CI 25\% to 57\%) adding FORM to BUD $200 \mathrm{mcg}$, by 29\% (95\% CI $7 \%$ to $44 \%$ ) increasing BUD to $800 \mathrm{mcg} / \mathrm{day}$, and $50 \%$ (95\% CI $30 \%$ to $64 \%$ ) by increasing BUD to $800 \mathrm{mcg} /$ day and adding FORM. The number needed to treat (NNT) to achieve sustained asthma control was 10 for adding FORM to BUD $200 \mathrm{mcg}, 27$ for increasing BUD to $800 \mathrm{mcg}$, and six for increasing BUD $800 \mathrm{mcg}$ and adding FORM (16).

de Blic et al. (13) compared fluticasone $200 \mathrm{mcg} /$ day plus salmeterol $100 \mathrm{mcg} /$ day to fluticasone $400 \mathrm{mcg} /$ day in 321 children 4 to 11 years of age with asthma that was not controlled despite beclomethasone $400 \mathrm{mcg} / \mathrm{day}$ or equivalent. The fluticasone/salmeterol group had improved PEF compared with the higher dose fluticasone group; however, the mean difference between the two groups was only $7.6 \mathrm{~L} / \mathrm{min}$.

Gappa et al. (14) compared fluticasone $200 \mathrm{mcg} /$ day plus salmeterol $100 \mathrm{mcg} /$ day to fluticasone $400 \mathrm{mcg} /$ day in 283 subjects 4 to 16 years of age with symptomatic asthma despite beclomethasone $200 \mathrm{mcg}$ to 400 mcg or equivalent. Combination therapy was not inferior to monotherapy with fluticasone. The mean improvement in morning PEF in the intent to treat population was $8.6 \mathrm{~L} / \mathrm{min}$ higher in the fluticasone/ salmeterol group $(24.6 \pm 39.8)$ versus the fluticasone group $(16.0 \pm 33.3$ [95\% CI 1.3 to $\infty]$ ). During the eight-week treatment interval, combination therapy achieved a greater mean number of weeks of good asthma control $(3.4 \pm 2.7$ weeks $)$ compared with monotherapy with fluticasone $(2.7 \pm 2.7$ weeks; $\mathrm{P}=0.02)(14)$.

In summary, ICS/LABA combination therapy decreased the rate of exacerbations, increased morning and evening PEF (15), decreased the time taken to achieve well-controlled asthma (16), versus increasing the dose of ICS in adults with asthma. Two studies involving children $(13,14)$ demonstrated minimal improvement in PEF with combination 
therapy, but the proportion of children achieving asthma control was the same. Neither study reported effects on exacerbations.

\section{ii) ICS plus LTRA versus increased ICS dose}

Two studies of montelukast added to low to medium doses of ICS showed no differences in any major outcomes in adults with asthma $(12,17)$. Yildirim et al. (17) compared budesonide $400 \mathrm{mcg} /$ day plus $10 \mathrm{mg}$ of montelukast with budesonide $800 \mathrm{mcg} /$ day in 30 subjects with a mean age of 37 years, who had moderate persistent asthma (17). There were no significant differences in any of the major outcome measures. Barnes et al. (12) compared budesonide $800 \mathrm{mcg} /$ day plus $10 \mathrm{mg}$ of montelukast with budesonide $1600 \mathrm{mcg} /$ day in 75 subjects 15 to 70 years of age with moderate persistent asthma (12). There were improvements in PEF and quality of life in both arms, but no significant differences between the comparator arms.

\section{Key evidence: Type of adjunct therapy (LABA or LTRA)}

The search identified a total of 59 systematic review citations and 297 RCT citations. Of these, four systematic reviews were selected for full-text review. A total of four guidelines, one systematic review and one RCT were used to inform recommendations. There were no data identified for children less than 6 years of age.

\section{Guidelines}

Three guideline documents and a consensus summary addressed the choice of LABA versus LTRA as adjunct therapy: The Global Initiative for Asthma 2010; National Heart, Lung, and Blood Institute (NHLBI)/National Asthma Education and Prevention Program (NAEPP); CTS 2003 Adult guidelines; and the CTS Asthma Management Continuum - 2010 Consensus Summary $(1,3,5,6)$. The GINA guidelines recommended that adults and adolescents 12 years of age and over not achieving asthma control on a low dose of ICS add a LABA (based on eight trials) as the first choice for adjunct therapy. Alternative options include adding an LTRA (nine trials) or increasing to a medium dose of ICS (5).

For children, the GINA guideline recommendation (5) is sequenced differently, with the first choice to increase to medium-dose ICS and alternative options including the addition of a LABA or LTRA.

The 2003 Canadian Asthma Consensus Guidelines and the CTS Asthma Management Continuum - 2010 Consensus Summary collectively reached the same conclusions recommending that adjunct therapy be initiated after low-dose ICS therapy in adults 12 years of age and over and after medium dose therapy in children 6 to 11 years of age; that LABA be considered as the preferred adjunct choice with LTRA as an alternate in individuals 12 years of age and over; and that either a LABA or LTRA be added in individuals 6 to 11 years of age $(1,3)$. In contrast, the NHLBI/NAEPP expert panel assesses equal weighting to the option of increasing to medium-dose ICS and to the addition of a LABA in adults and adolescents (6).

\section{Systematic reviews}

Ducharme et al. (18) identified 16 adult and adolescent studies (12 years of age and over) and one pediatric trial including 7032 patients. The reported results are from adult and adolescent patients. The combination of ICS and LABA was superior to ICS and LTRA on all measures examined including: the risk of exacerbation requiring oral corticosteroids $11 \%$ verasus $9 \%$ (95\% CI 0 to $3 \%$ ), OR 0.83 (95\% CI 0.71 to 0.97 ); quality of life 0.11 (95\% CI 0.05 to 0.17 ), rescue-free days $9.2 \%(95 \%$ CI $5.4 \%$ to $13.0 \%$ ), symptom-free days $7.3 \%$ (95\% CI $4.7 \%$ to $9.8 \%$ ); and PEF $15.4 \mathrm{~L} / \mathrm{min}$ (95\% CI 11.35 to 19.37 ) (18).

\section{RCTs}

No RCTs were identified after the publication date of the systematic review; however, because the systematic review by Ducharme et al. (18) identified only one pediatric RCT and, therefore, could not be considered in the systematic review, it is summarized in this section. Lemanske et al. (19) included 126 subjects 6 to 11 years of age and 56 subjects 12 to 17 years of age. The authors used rank-order logistic regression to predict which step-up therapy was significantly more likely to be the best response as defined by a composite outcome of exacerbations, asthma control days and $\mathrm{FEV}_{1}$, specifically whether the frequency of a differential response to the step-up regimens was more than $25 \%$. LABA step-up was significantly more likely to be the best response, compared with the response to LTRA step-up (relative probability, 1.6 [95\% CI 1.1 to 2.3]; P=0.004) and the response to ICS step-up (relative probability 1.7 [95\% CI 1.2 to 2.4]; $\mathrm{P}=0.002$ ). It should be noted that this was a small study and could only assess current control and, thus, did not have the power to detect a difference in future risk (i.e. exacerbations). In addition, the results were generated by a regression analysis and the clinical relevance of the results is uncertain.

\section{Conclusions}

All treatment decisions should be based on individual characteristics, which depending on local resources, could include clinical characteristics, objective measure of pulmonary function and inflammatory markers. The effectiveness of each treatment decision should be carefully evaluated for its impact on current control, future risk (in particular asthma exacerbations) and side effects.

A large body of evidence is available to guide treatment recommendations in adults 12 years of age and over; however, relatively little evidence is available to guide recommendations for children 6 to 11 years of age. Notably, the limited evidence available for children suggests that the findings in individuals 12 years of age and over cannot be extrapolated to this population.

Adults 12 years of age and over not achieving asthma control on a low dose of ICS benefit more from combination therapy with LABA than increasing the maintenance dose of ICS. Combination therapy with ICS and LABA is superior to combination therapy with ICS and LTRA with respect to exacerbation reduction, quality of life, symptom control and pulmonary function. Two guidelines and a consensus summary (GINA 2010 guideline [5], CTS Adult 2003 Guideline [3] and the CTS Asthma Management Continuum - 2010 Consensus Summary [1]) recommended adjunct therapy as the preferred choice if low-dose ICS does not result in controlled asthma.

In response to recent concerns about LABA safety, the NHLBI/ NAEPP expert panel changed its recommendation in 2007 assessing equal weighting to the option of increasing to medium-dose ICS and combination therapy with a LABA in adults and adolescents (6). The revised recommendation takes into consideration the FDA black-box warning on LABA safety identifying a reported excess of asthmarelated deaths and severe exacerbations in subjects on LABA versus placebo. While acknowledging that the reported LABA mortality risk is an area of controversy, and that LABA is a more efficacious option, the NHLBI/NAEPP 2007 panel recommended that the potential side effects of LABA be weighed against the benefits in treatment decisions. The LABA controversy has led the FDA to recommend that if patients are controlled on a combination of an ICS/LABA, therapy should be adjusted with the withdrawal of the LABA. There are no asthma CPGs that recommend the approach outlined by the FDA. We identify the safety of this approach as an important area for future research.

For children 6 to 11 years years of age, the evidence is not clear with respect to the next best option when low-dose ICS does not result in asthma control. Consistent with four other guideline documents, we suggest that the best option in children not achieving control on lowdose ICS is to increase to medium-dose ICS. Contrary to the clear evidence in adults 12 years of age and over, the meta-analyses by $\mathrm{Ni}$ Chroinin et al. (10) and Ducharme et al. (8) in children did not find a significant difference between ICS/LABA combination therapy and medium-dose ICS monotherapy. Consistent with these systematic reviews, the RCT by Gappa et al. (14), a noninferiority trial, demonstrated that combination therapy with a LABA was not inferior to higher dose monotherapy. Of particular concern in both systematic reviews is the possibility that, although the risk estimates are not statistically significant different between the treatment arms, the wide confidence limits around the RR point estimates may be masking a greater risk of exacerbations requiring oral corticosteroids and hospitalization in 
children treated with ICS/LABA combination therapy compared with those treated with medium-dose ICS $(8,10)$. Of note, there is no clear evidence of the benefit of ICS and LABA combination therapy in the pediatric population.

\section{Question 2}

At which ICS dose should adjunct therapy (LABA or LTRA) be added in children ( 6 to 11 years of age) and adults (12 years of age and over) with uncontrolled asthma who are on ICS monotherapy?

The following recommendations are based on evidence from six guidelines, four systematic reviews, six RCTs and the consensus of the CTS Asthma Clinical Assembly Expert Panel.

\section{General recommendations}

Regular need for a reliever (of any kind) merits re-evaluation to identify the reason(s) for poor asthma control. For SABA, regular use is defined as more than three doses per week. (Consensus)

All treatment decisions should be based on individual characteristics which, depending on resources, could include clinical characteristics, objective measures of pulmonary function, and inflammatory markers. (Consensus)

The effectiveness of each treatment decision should be carefully evaluated for its impact on current control, future risk (in particular) asthma exacerbations, and side effects. (Consensus)

\section{Recommendation 2A}

We recommend initiation of adjunct therapy in adults with asthma uncontrolled despite adherence to a low dose of ICS. (GRADE 1A)

\section{Recommendation 2B}

We recommend initiation of adjunct therapy in children with asthma uncontrolled despite adherence to a medium dose of ICS. (GRADE 1A)

\section{Question 3}

Which adjunct therapy (LABA or LTRA) should be added to an ICS in children (6 to 11 years of age) and adults (12 years of age and over) with uncontrolled asthma who are on ICS monotherapy?

The following recommendations are based on evidence from four guidelines, one systematic review, one RCT and the consensus of the CTS Asthma Clinical Assembly Expert Panel.

\section{Recommendation 3A}

In adults with asthma not achieving control despite adherence to a low dose of ICS, we recommend the addition of a LABA (GRADE 1A).

Alternative third-line options include adding an LTRA or increasing to a medium dose of ICS. (Consensus)

\section{Recommendation 3B}

In children with asthma not achieving control despite adherence to a low dose of ICS, we recommend increasing to a medium dose of ICS. (GRADE 1A)

\section{Recommendation 3C}

In children not achieving asthma control on a medium dose of ICS, we suggest the addition of a LABA or LTRA. (GRADE 2B)

\section{Recommendation 3D}

Children who fail to achieve control on a medium dose of ICS should be referred to a specialist. (Consensus)

\section{Future research needs}

Based on the evidence reviewed, the Clinical Assembly identifies the following research needs:

- To formally review ICS dose equivalencies and dosing categories;

- To determine the efficacy of addition of LTRA in individuals with uncontrolled asthma on ICS and a LABA;

- To determine the role of tiotropium bromide as adjunct therapy in moderate to severe asthma in adults;

- To determine the optimum strategy for additional controller therapy in children 6 to 11 years of age who are not controlled on low-dose ICS;
- To determine the efficacy of step-up with LTRA in children;

- To compare efficacy of step-up with LABA plus ICS versus LTRA plus ICS in children poorly controlled on medium-dose ICS; and

- To determine the safest dose-reduction strategy in individuals controlled on a combination of an ICS plus LABA;

- To determine the safety of discontinuation of LABA in individuals with asthma controlled on ICS/LABA combination therapy.

\section{REFERENCES}

1. Lougheed MD, Lemiere C, Dell SD, et al. Canadian Thoracic Society Asthma Management Continuum - 2010 Consensus Summary for children six years of age and over, and adults. Can Respir J 2010;17:15-24.

2. Becker A, Berube D, Chad Z, et al. Canadian Pediatric Asthma Consensus guidelines, 2003 (updated to December 2004): introduction. CMAJ 2005;173(6 Suppl):S12-S14.

3. Lemiere C, Bai T, Balter M, et al. Adult Asthma Consensus Guidelines Update 2003. Can Respir J 2004;11(Suppl A):9A-18A.

4. Motala C, Green RJ, Manjra AI, Potter PC, Zar HJ. Guideline for the management of chronic asthma in children - 2009 update. S Afr Med J 2009;99:898-912.

5. Global Strategy for Asthma Management and Prevention. Global Initiative for Asthma. Global Initiative for Asthma (GINA), 2010. $<$ www.ginasthma.org>.

6. National Asthma Education Prevention Program (NAEPP). Expert Panel Report 3: Guidelines for the diagnosis and management of asthma. Bethesda: National Heart, Lung, and Blood Institute (NHLBI), 2007.

7. Ducharme FM. Addition of anti-leukotriene agents to inhaled corticosteroids for chronic asthma. Cochrane Database of Syst Rev 2004(1):CD003133.

8. Ducharme FM, Ni Chroinin M. Greenstone I, Lasserson TJ. Addition of long-acting beta 2 -agonists to inhaled steroids versus higher dose inhaled steroids in adults and children with persistent asthma. Cochrane Database Syst Rev 2010(4):CD005533.

9. Masoli M, Weatherall M, Holt S, Beasley R. Moderate dose inhaled corticosteroids plus salmeterol versus higher doses of inhaled corticosteroids in symptomatic asthma. Thorax 2005;60:730-4.

10. Ni Chroinin M, Lasserson TJ, Greenstone I, Ducharme FM. Addition of long-acting beta-agonists to inhaled corticosteroids for chronic asthma in children. Cochrane Database Syst Rev 2009(3):CD007949.

11. Lemiere $\mathrm{C}$, Bond $\mathrm{K}$, Coyle $\mathrm{D}$, et al. Long-acting beta 2 -agonist and inhaled corticosteroid combination therapy for adult persistent asthma: Systematic Review of Clinical Outcomes and Economic Evaluation. [Technology Report Number 122] Ottawa: Canadian Agency for Drugs and Technologies in Health, 2009.

12. Barnes N, Laviolette M, Allen D, et al. Effects of montelukast compared to double dose budesonide on airway inflammation and asthma control. Respir Med 2007;101:1652-8.

13. de Blic J, Ogorodova L, Klink R, et al. Salmeterol/fluticasone propionate vs. double dose fluticasone propionate on lung function and asthma control in children. Pediatr Allergy Immunol 2009;20:763-771.

14. Gappa M, Zachgo W, Von BA, Kamin W, Stern-Strater C, Steinkamp G. Add-on salmeterol compared to double dose fluticasone in pediatric asthma: A double-blind, randomized trial (VIAPAED). Pediatr Pulmonol 2009;44:1132-42.

15. Menezes MB, Teixeira AL, Terra FJ, Vianna EO. Inflammatory and functional effects of increasing asthma treatment with formoterol or double dose budesonide. Respir Med 2008;102:1385-91.

16. O’Byrne PM, Naya IP, Kallen A, Postma DS, Barnes PJ. Increasing doses of inhaled corticosteroids compared to adding long-acting inhaled beta ${ }_{2}$-agonists in achieving asthma control. Chest 2008; 134:1192-9.

17. Yildirim Z, Ozlu T, Bulbul Y, Bayram H. Addition of montelukast versus double dose of inhaled budesonide in moderate persistent asthma. Respirology 2004;9:243-8.

18. Ducharme FM, Lasserson TJ, Cates CJ. Addition to inhaled corticosteroids of long-acting beta ${ }_{2}$-agonists versus anti-leukotrienes for chronic asthma. Cochrane Database Syst Rev 2011(5):CD003137.

19. Lemanske RF Jr, Mauger DT, Sorkness CA, et al. Step-up therapy for children with uncontrolled asthma receiving inhaled corticosteroids. N Engl J Med 2010;362:975-85. 


\section{SECTION III \\ SINGLE INHALER ICS/LABA COMBINATION AS A RELIEVER AND SINGLE INHALER ICS/LABA COMBINATION AS A RELIEVER AND A CONTROLLER}

\section{Questions}

4. What is the efficacy of using a single inhaler ICS/LABA combination as a reliever compared with a FABA as a reliever as part of a self-management plan in children and adults experiencing an acute loss of asthma control?

5. What is the efficacy of using a single inhaler of BUD/FORM as a reliever and a controller as part of a self-management plan for individuals 12 years of age and over, compared with the following:

a. the usual dose of controller (either ICS monotherapy or fixeddose ICS/LABA combination) with a FABA as a reliever?

b. 'guideline best practice' (defined as a practitioner adjusting controller therapy based upon regular review) with a FABA as a reliever?

\section{Introduction}

In 2003, Canadian Asthma Consensus Guidelines broadened the recommended class of reliever medication from short-acting bronchodilator to fast-acting bronchodilator (1). While one LABA (FORM) is also a FABA, the use of FORM alone as a reliever in asthma is contraindicated because of concerns that LABAs increase the risk of asthmarelated deaths. Whether concomitant use of an ICS mitigates that risk is the subject of ongoing research. As such, the role of ICS/LABA combination products as reliever and controller medication merits review.

Health Canada has approved the use of FORM in combination with BUD (BUD/FORM) in a single inhaler for use in individuals with asthma 12 years of age and over as both a controller and a reliever. Three approaches of use of a single inhaler of BUD/FORM have been evaluated in clinical trials: a fixed-dose strategy and two approaches to adjusting the dose in response to loss of asthma control (outlined in Table 5). In the fixed-dose strategy, a separate reliever is to be used as needed. In the adjustable maintenance dose (AMD) strategy, the BUD/ FORM combination may be temporarily increased for loss of control to a maximum daily dose, and a separate reliever is also to be used as needed. The Health Canada-approved terminology for this dosing is 'Symbicort (AstraZeneca Inc, Canada) Maintenance Therapy'. The third approach is use of the BUD/FORM inhaler both as the controller and the reliever (termed Symbicort (AstraZeneca Inc, Canada) as maintenance and reliever therapy [SMART]; also known as single inhaler therapy [SiT]). The difference between AMD and SMART is the reliever medication (see Table 5). These represent specific selfmanagement approaches to acute loss of control that permit the patient to adjust use of the combination product on a day-to-day basis according to symptoms (within the limits set by maximum approved daily doses). It is important to note that mometasone/FORM (Zenhale, Merck Canada, Inc) is only approved by Health Canada for use as a controller (not as a reliever) in individuals 12 years of age and over.

We reviewed the evidence examining the efficacy of: i) a single inhaler of BUD/FORM as a reliever compared with a FABA (either SABA or fast-acting LABA) as a reliever in individuals with asthma on no ICS, on ICS monotherapy, or on fixed-dose ICS/LABA combination therapy; and ii) a single inhaler of BUD/FORM as a reliever and a controller compared with the usual maintenance dose of controller (ICS, lower fixed-dose ICS/LABA or best practice) with a FABA as reliever. The AMD strategy is functionally a traditional action plan approach (of doubling the dose for acute loss of control), which is addressed in Section IV Part 3 of the present guideline.

\section{Methods}

Practice guidelines, systematic reviews of RCTs and RCTs addressing one or more of the clinical questions as part of a self-management strategy in children and adults with acute loss of asthma control were included. Outcomes of interest were the use of systemic steroids, ED visits, hospitalization, duration of symptoms, quality of life and adverse effects.

Asthma search terms were combined with the following $\mathrm{MeSH}$ and text words in OVID MEDLINE and EMBASE to identify systematic reviews: exacerbat: or acut: or status: or sever: or emergenc: or crisis: or worsen: or attack: and terms for ICS and LABA. Systematic reviews were included if they were published in 2005 or later.

The Cochrane Airways Group "asthma and wheez*" database was searched from September 2008 to September 2011 using the search strategy of the most recent systematic review to identify any new RCTs. The following search terms were used: "single inhaler therapy" or SiT or SMART or relie: or "as need:" or as-need: or prn or flexible or titrat: AND combin: or symbicort or viani or steroid: or corticosteroid: or ICS or budesonide or BUD or Pulmicort or beclomethasone or BDP or becotide AND "beta agonist:" or "adrenergic beta-agonist:" or formoterol or eformoterol or oxis or foradil.

\section{Key evidence}

A total of two guidelines, four systematic reviews and four primary trials informed the recommendations (Tables 6 and 7).

\section{Guidelines}

Two guidelines addressed the second question only. Based on four RCTs (2-5) (Table 7), the 2010 GINA Guideline for Adults (6) states the following:

The use of the combination of a rapid and long-acting beta agonist (formoterol) and an inhaled glucocorticosteroid (budesonide) in a single inhaler both as a controller and reliever is effective in maintaining a high level of asthma control and reduces exacerbations requiring systemic glucocorticosteroids and hospitalization (Evidence A).

The May 2011 Update of the SIGN British Guideline on The Management of Asthma introduced a new section on the use of a single combination inhaler (7). Citing five RCTs $(2,3,5,8,9)$ (Table 7$)$, it states the following:

In selected adult patients at step 3 who are poorly controlled or in selected adult patients at step 2 (above BDP [beclomethasone dipropionate] 400 micrograms/day and poorly controlled), the use of budesonide/formoterol in a single inhaler as rescue medication instead of a short-acting beta ${ }_{2}$-agonist, in addition to its regular use as controller therapy has been shown to be an effective treatment regimen. When this management option is introduced, the total regular dose of daily ICS should not be decreased. The regular maintenance dose of inhaled steroids may be budesonide 200 mcg twice daily or budesonide $400 \mathrm{mcg}$ twice daily. Patients taking rescue budesonide/formoterol once a day or more on a regular basis should have their treatment reviewed. Careful education of patients about the specific issues around this management strategy is required.

Systematic reviews

After identification of relevant systematic reviews of RCTs published by April 2009, we used the same search strategy as used in the systematic reviews to update the literature search for additional trials until September 2011 using the CAGR "asthma and wheez*" database. No new systematic reviews were identified. Four new trials were identified which addressed use of a single inhaler of BUD/FORM as a reliever and a controller (10-13) (Table 8). Post hoc subgroup or pooled analyses of previously published trials (14-17) were excluded due to risk of bias and over-representation of trials already included in the systematic reviews.

1) Single inhaler of an ICS/LABA compared with a FABA as a reliever One systematic review (18) identified three RCTs $(2,4,9)$ involving 5905 participants (including one RCT involving 341 children 4 to 11 years of 
TABLE 5

Single inhaler of budesonide/formoterol: Dosing strategies evaluated in clinical trials

\begin{tabular}{|c|c|c|}
\hline & Controller therapy & Reliever therapy \\
\hline Fixed-dose BUD/FORM & $\begin{array}{l}1 \text { or } 2 \text { inhalations of BUD/FORM } 100 \mathrm{mcg} / 6 \mathrm{mcg} \text { or } \\
200 \mathrm{mcg} / 6 \mathrm{mcg} \text { once daily, or twice daily }\end{array}$ & Separate FABA inhaler as needed \\
\hline $\begin{array}{l}\text { BUD/FORM adjustable maintenance dose strategy } \\
\text { (also termed Symbicort* Maintenance Therapy) }\end{array}$ & $\begin{array}{l}1 \text { or } 2 \text { inhalations of BUD/FORM } 100 \mathrm{mcg} / 6 \mathrm{mcg} \text { or } \\
200 \mathrm{mcg} / 6 \mathrm{mcg} \text { once daily, or twice daily; AND may } \\
\text { temporarily increase to a maximum of } 4 \\
\text { inhalations twice daily for worsening of asthma }\end{array}$ & Separate FABA inhaler as needed \\
\hline $\begin{array}{l}\text { BUD/FORM as a reliever and controller (Symbicort* } \\
\text { Maintenance and Reliever Therapy; also termed } \\
\text { Single Inhaler Therapy) }\end{array}$ & $\begin{array}{l}1 \text { or } 2 \text { inhalations of BUD/FORM } 100 \mathrm{mcg} / 6 \mathrm{mcg} \text { or } \\
200 \mathrm{mcg} / 6 \mathrm{mcg} \text { twice daily, or } 2 \text { inhalations once } \\
\text { daily }\end{array}$ & $\begin{array}{l}\text { BUD/FORM } 100 \mathrm{mcg} / 6 \mathrm{mcg} \text { or } 200 \mathrm{mcg} / 6 \mathrm{mcg} \\
1 \text { inhalation as needed; maximum } 6 \text { inhalations/dose } \\
\text { AND maximum } 8 \text { inhalations/day (including } \\
\text { maintenance dose[s]) }\end{array}$ \\
\hline
\end{tabular}

*AstraZeneca Inc, Canada. BUD Budesonide; FABA Fast-acting beta ${ }_{2}$-agonist; FORM Formoterol

age [2]), in which the only planned difference between treatment arms was use of a combination inhaler of BUD/FORM as reliever compared with a FABA as a reliever. In the systematic review, these trials were stratified according to the maintenance therapy and whether the comparator was a SABA (terbutaline) or fast-acting LABA (FORM).

a) No controller maintenance therapy

One trial in the systematic review involved 92 participants 15 years of age and over with mild intermittent asthma not receiving any maintenance controller therapy. Use of a single inhaler of BUD/FORM as a reliever compared with FORM alone as a reliever was not associated with statistically significant reductions in any of the outcomes of interest including reliever use, symptom-free days, morning or evening PEF, or proportion of rescue-free days (18). There were no hospitalizations or exacerbations requiring oral corticosteroids in either arm of the trial. A $2.7 \%$ (95\% CI $0.7 \%$ to $4.7 \%$ ) difference between groups in the change in $\mathrm{FEV}_{1}$ at 24 weeks was found favouring the BUD/FORM group, which is of uncertain clinical relevance.

b) ICS monotherapy as maintenance therapy

No trials comparing BUD/FORM as a reliever with a FABA reliever in children or adults on ICS monotherapy at the same dose in the treatment and control groups were identified (18). Furthermore, no controlled trials on this topic were identified in the updated search to September 2011.

c) Fixed-dose ICS/LABA maintenance therapy

Two trials included in the systematic review recruited individuals 12 years of age and over or children 4 to 11 years of age with uncontrolled asthma despite maintenance high-dose ICS monotherapy (approximately $700 \mathrm{mcg} /$ day) who had experienced one or more exacerbations in the past year (18). At randomization, they were switched to a maintenance, fixed-dose ICS/LABA combination in which the total daily ICS dose was reduced by $50 \%$ to $66 \%$ (to $200 \mathrm{mcg} / \mathrm{day}$ to $400 \mathrm{mcg} / \mathrm{day}$ ) compared with the prerandomization dosage. In participants 12 years of age and over, use of BUD/FORM as a reliever was superior to terbutaline or FORM as a reliever for reducing the risk of exacerbations requiring oral corticosteroids (when compared with terbutaline: OR 0.54 [ $95 \%$ CI 0.44 to 0.65]; and when compared with FORM OR 0.74 [95\% CI 0.56 to 0.99]) (18). There were no significant reductions in hospitalizations in the group using BUD/FORM as a reliever compared with terbutaline or formoterol as a reliever in patients 12 years of age and over (OR 0.68 [95\% CI 0.40 to 1.16]; OR 0.71 [95\% CI 0.37 to 1.35], respectively) or compared with terbutaline as a reliever in children 4 to 11 years of age (OR 0.06 [95\% CI 0.00 to 1.10]). There were no differences in nonfatal serious adverse events (SAEs) using fixeddose BUD/FORM maintenance and BUD/FORM reliever compared with fixed dose BUD/FORM maintenance and either terbutaline or formoterol as a reliever in patients 12 years of age and over (OR 1.04 [ $95 \%$ CI 0.80 to 1.37]; OR 1.33 [95\% CI 0.92 to 1.91]). There were fewer nonfatal SAEs in children 4 to 11 years of age using fixed lowdose BUD/FORM maintenance $(100 \mathrm{mcg} / 6 \mathrm{mcg}$ once daily) and
TABLE 6

Evidence/trials evaluating the efficacy of a single inhaler of ICS/LABA combination as a reliever, and as a reliever and controller

\begin{tabular}{|c|c|c|}
\hline $\begin{array}{l}\text { Maintenance } \\
\text { treatment }\end{array}$ & $\begin{array}{l}\text { ICS/LABA } \\
\text { (versus } \\
\text { FABA) as a } \\
\text { reliever }\end{array}$ & $\begin{array}{l}\text { BUD/FORM as a reliever and a } \\
\text { controller versus same or } \\
\text { increased maintenance treatment } \\
\text { (versus ICS, fixed-dose ICS/LABA } \\
\text { or 'Guideline best practice') with } \\
\text { FABA as reliever }\end{array}$ \\
\hline No ICS & $\begin{array}{l}\text { Cates and } \\
\text { Lasserson } \\
(18), 2009 \\
\cdot 1 \text { trial }\end{array}$ & \\
\hline ICS monotherapy & $\begin{array}{l}\text { No trials with } \\
\text { same ICS } \\
\text { dose in both } \\
\text { arms of trial }\end{array}$ & $\begin{array}{l}\text { Compared with usual or increased } \\
\text { ICS } \\
\text { Agarwal et al. (19), } 2009 \\
\text { - } 3 \text { trials } \\
\text { Edwards et al. (21), } 2010 \\
\text { - } 3 \text { trials } \\
\text { Cates and Lasserson (20), } 2010 \\
\text { - } 3 \text { trials }\end{array}$ \\
\hline Fixed-dose ICS/LABA & $\begin{array}{l}\text { Cates and } \\
\text { Lasserson } \\
(18), 2009 \\
\cdot 2 \text { trials }\end{array}$ & $\begin{array}{l}\text { Compared with usual ICS dose in } \\
\text { maintenance ICS/LABA } \\
\text { Agarwal et al. (19), } 2009 \\
\text { • } 6 \text { trials } \\
\text { Edwards et al. (21), } 2010 \\
\text { • } 2 \text { trials of same dose } \\
\text { - } 1 \text { trial of higher dose } \\
\text { Stallberg et al (10), } 2008 \\
\text { Compared with ‘Guideline best } \\
\text { practice’ } \\
\text { Cates and Lasserson (20), } 2010 \\
\text { • } 9 \text { trials } \\
\text { Louis et al. (11), 2009 } \\
\text { Soes-Pedersen et al. (13), } 2011 \\
\text { Riemersma et al. (12), 2011 }\end{array}$ \\
\hline
\end{tabular}

BUD Budesonide; FABA Fast-acting beta ${ }_{2}$-agonist; FORM Formoterol; ICS Inhaled corticosteroid; LABA Long-acting beta $_{2}$-agonist

BUD/FORM as reliever (OR 0.11 [95\% CI 0.02 to 0.48]) and no significant differences in growth compared with use of terbutaline as a reliever. Data were not available on exacerbations needing oral steroids in children 4 to 11 years of age.

The authors of the systematic review of these three trials concluded the following:

In mild asthma, it is not yet known whether patients who use a budesonide/formoterol inhaler for relief of asthma symptoms derive any clinically important benefits. In more severe asthma, two studies enrolled patients who were not controlled 
TABLE 7

Characteristics of trials cited in GINA and BTS/SIGN guidelines, included in three systematic reviews on the use of a single inhaler of budesonide/formoterol as a reliever and a controller and/or identified in updated searches

\begin{tabular}{|c|c|c|c|c|c|c|c|c|c|c|c|}
\hline \multirow[b]{2}{*}{$\begin{array}{l}\text { First author } \\
\text { (reference), year }\end{array}$} & \multirow{2}{*}{$\begin{array}{l}\text { Trial } \\
\text { acronym } \\
\text { (if available) }\end{array}$} & \multirow[b]{2}{*}{$\mathbf{n}$} & \multirow{2}{*}{$\begin{array}{c}\text { Age, } \\
\text { years }\end{array}$} & \multicolumn{3}{|c|}{$\begin{array}{c}\text { Comparison of a single inhaler of } \\
\text { budesonide/formoterol as a reliever and a } \\
\text { controller versus: }\end{array}$} & \multicolumn{2}{|c|}{ Guidelines } & \multicolumn{3}{|c|}{ Systematic reviews } \\
\hline & & & & $\begin{array}{l}\text { Fixed-dose } \\
\text { ICS }\end{array}$ & $\begin{array}{l}\text { Fixed-dose } \\
\text { ICS/LABA }\end{array}$ & $\begin{array}{c}\text { Guideline } \\
\text { best practice }\end{array}$ & GINA 2010 & $\begin{array}{c}\text { BTSISIGN } \\
2011\end{array}$ & $\begin{array}{l}\text { Agarwal } \\
\text { et al. (19) }\end{array}$ & $\begin{array}{l}\text { Edwards } \\
\text { et al. (21)e }\end{array}$ & $\begin{array}{l}\text { Cates } \\
\text { et al. (20) }\end{array}$ \\
\hline Scicchitano (9), 2004 & & 1890 & $\geq 12$ & $\checkmark$ & & & & $\checkmark$ & $\checkmark$ & $\checkmark$ & $\checkmark$ \\
\hline O’Byrne (2), 2005 & STAY-All & 2753 & $\geq 4$ & $\checkmark$ & $\checkmark$ & & $\checkmark$ & $\checkmark$ & $\checkmark$ & $\checkmark$ & $\checkmark$ \\
\hline Rabe (4), 2006 & STEAM & 696 & $\geq 12$ & $\checkmark$ & & & $\checkmark$ & & $\checkmark$ & $\checkmark$ & $\checkmark$ \\
\hline Rabe (3), 2006 & SMILE & 2245 & $\geq 12$ & & $\checkmark$ & & $\checkmark$ & $\checkmark$ & $\checkmark$ & $\checkmark$ & \\
\hline Vogelmeir (5),2005 & cosmos & 2143 & $\geq 12$ & & $\checkmark$ & & $\checkmark$ & $\checkmark$ & $\checkmark$ & & \\
\hline Bousquet (24), 2007 & & 2304 & $\geq 12$ & & $\checkmark$ & & & & $\sqrt{ }$ & $\checkmark$ & \\
\hline Kuna (15), 2007 & COMPASS & 3321 & $\geq 12$ & & $\checkmark$ & & & $\checkmark$ & $\checkmark$ & $\checkmark$ & \\
\hline Sears (25), 2008 & SOLO & 1538 & $\geq 12$ & & $\checkmark$ & $\checkmark$ & & & $\checkmark$ & & $\checkmark$ \\
\hline NCT00252863* & De-SOLO & $1800^{\dagger}$ & $\geq 18$ & & & $\checkmark$ & & & & & $\checkmark$ \\
\hline NCT00242411 & MONO & 1854 & $>12$ & & & $\checkmark$ & & & & & $\checkmark$ \\
\hline NCT00235911* & & $100^{\dagger}$ & N/A & & & $\checkmark$ & & & & & $\checkmark$ \\
\hline NCT00290264 & SALTO & 908 & $\geq 12$ & & & $\checkmark$ & & & & & $\checkmark$ \\
\hline Sovani (22), 2008 & & 71 & $\geq 18$ & $\checkmark$ & & & & & & & $\checkmark$ \\
\hline NCT00252824 & STYLE & $1000^{\dagger}$ & $\geq 12$ & & & $\checkmark$ & & & & & $\checkmark$ \\
\hline Stallberg (10), 2008 & & 1776 & $\geq 12$ & & $\checkmark$ & & & & & & \\
\hline Louis (11), 2009 & & 908 & $\geq 12$ & & & $\sqrt{ }$ & & & & & \\
\hline $\begin{array}{l}\text { Soes-Petersen (13), } \\
2011\end{array}$ & & 1835 & $\geq 12$ & & & $\checkmark$ & & & & & \\
\hline Riemersma (12), 2011 & & 102 & $\geq 18$ & & & $\checkmark$ & & & & & \\
\hline
\end{tabular}

${ }^{\dagger}$ Estimated or planned sample size. Definition of abbreviations: BTS/SIGN British Thoracic Society/Scottish Intercollegiate Guidelines Network; GINA Global Initiative for Asthma; ICS Inhaled corticosteroid; LABA Long-acting beta ${ }_{2}$-agonist; N/A Not available. *Unpublished at the time Cates (2010) was last updated

on inhaled corticosteroids and had suffered an exacerbation in the previous year, and then had their maintenance inhaled corticosteroids reduced in both arms of the study. Under these conditions, the studies demonstrated a reduction in the risk of exacerbations that require oral corticosteroids with budesonide/formoterol for maintenance and relief in comparison with budesonide/formoterol for maintenance and terbutaline or formoterol for relief (18).

2) Single inhaler of BUD/FORM as a reliever and controller compared with usual dose of controller (ICS monotherapy, fixed-dose ICS/LABA or 'guideline best practice'), with FABA as reliever

Two guidelines (GINA [6] and BTS/SIGN [7]) and three systematic reviews (19-21) addressed the use of a single inhaler of BUD/FORM as a reliever and a controller, one of which (21) was sponsored by a pharmaceutical company and authored by its employees. The trials cited in the guidelines and included in the systematic reviews are outlined in Tables 6 and 7. Most trials included individuals 12 years of age and over. Only one trial (2) evaluated children 4 years of age and over, and two trials evaluated only adults 18 years of age and over (22 and NCT00252863). Collectively, the reviews addressed comparisons of the use of a single inhaler of BUD/FORM as a reliever and a controller (intervention) to: i) fixed-dose ICS monotherapy at the same or higher maintenance ICS dose as in the intervention arm; ii) usual maintenance fixed-dose ICS/LABA; or iii) 'guideline best practice' in accordance with existing national/international guidelines including the addition of a LABA to ICS if indicated. Agarwal et al. (19) included all trials included in the Edwards et al. (21) review plus two additional trials, and the primary outcome in both reviews was severe exacerbations. The Cochrane review (20) included four trials cited in at least one of the other two reviews, plus six other trials comparing use of a single inhaler of BUD/FORM as a reliever and a controller to 'guideline best practice'. Severe exacerbations were defined by Edwards et al. (21) as ED visit or hospitalization or need for oral steroid for at least three days (21). Agarwal et al. (19) included trials with various definitions of severe exacerbations including combinations of the ED visits, hospitalizations, need for oral steroid, plus or minus the need to escalate ICS, specification of duration of steroid use, or specification of a decline in PEF from baseline (19). In the Cochrane review by Cates et al. (20), severe exacerbations were defined as an ED visit, a hospitalization, or the need for oral steroid. It also analyzed exacerbations requiring hospitalization and exacerbations requiring oral corticosteroids as separate outcomes. In some instances, trials were sorted according to whether the ICS dose was the same or higher in the control arm.

Four new RCTs were identified in the updated search, comparing the use of a single inhaler of BUD/FORM as a reliever and a controller with fixed-dose ICS/LABA (10) or 'guideline best practice' (11-13) (Table 7).

a) Single inhaler of BUD/FORM as a reliever and a controller versus usual maintenance dose ICS

One trial (22) included in the Cochrane review by Cates et al. (20) compared the use of a single inhaler of BUD/FORM as a reliever and a controller to the same dose of ICS (400 mcg BUD/day) in adults 18 years of age and over, and this trial failed to identify a significant difference in exacerbations treated with oral steroids 
TABLE 8

Characteristics of trials of a single inhaler of budesonide/formoterol as a reliever and a controller compared with fixed-dose ICS/LABA and 'Guideline best practice'

\begin{tabular}{|c|c|c|c|c|}
\hline $\begin{array}{l}\text { Author } \\
\text { (ref), year n }\end{array}$ & Study design & Population & Intervention & Control \\
\hline \multicolumn{5}{|c|}{ Compared with fixed-dose ICS/LABA } \\
\hline $\begin{array}{l}\text { Stallberg et } 1776 \\
\text { al. (10), } \\
2008\end{array}$ & $\begin{array}{l}\text { Randomized, } \\
\text { open-label trial }\end{array}$ & $\begin{array}{l}\text { Age } \geq 12 \text { years, } \\
\text { using a constant } \\
\text { dose of ICS ( } \geq 400 \\
\text { mcg/day) for } \geq 30 \\
\text { days, persistent } \\
\text { asthma, receiving } \\
\text { daily maintenance } \\
\text { ICS and LABA or } \\
\text { symptomatic } \\
\text { despite regular } \\
\text { use of ICS }\end{array}$ & $\begin{array}{l}\text { BUD/FORM } \\
\text { 160/4.5 mcg or } \\
\text { 80/4.5 mcg } \\
\text { (depending on } \\
\text { previous ICS } \\
\text { dose), one } \\
\text { inhalation twice } \\
\text { daily or two } \\
\text { inhalations once } \\
\text { daily for } \\
\text { maintenance } \\
\text { plus additional } \\
\text { inhalations as } \\
\text { needed }\end{array}$ & $\begin{array}{l}\text { a) free adjustable } \\
\text { combination BUD } \\
\text { (100-400 mcg/ } \\
\text { inhalation) and } \\
\text { FORM (4.5 or } \\
9 \text { mcg/inhalation) } \\
\text { plus terbutaline as } \\
\text { needed } \\
\text { b) fixed-dose BUD/ } \\
\text { FORM } 160 / 4.5 \text { mcg } \\
\text { or } 80 / 4.5 \text { mcg } \\
\text { (depending on } \\
\text { previous ICS dose), } \\
\text { two inhalations } \\
\text { twice daily plus } \\
\text { terbutaline as } \\
\text { needed }\end{array}$ \\
\hline
\end{tabular}

Duration Outcomes

12 months Systemic steroid use not reported. No significant difference in ED visits or hospitalizations between groups. No significant difference in time to first exacerbation, rate of severe exacerbation, or reported reliever medication use. Number and type of SAEs similar between groups.

Economic evaluation: Significant reduction in annual direct costs per patient $(-13 \%$, $\mathrm{P}<0.001$ compared with freely adjustable BUD/FORM and $-20 \%, P<0.001$ compared with fixed-dose BUD/FORM plus terbutaline) mostly due to lower cost of using less drug. There were no differences in TOTAL costs (ie, hospitalizations $[\mathrm{P}<0.001]$ and indirect costs $(P=0.094)$ were higher in BUD/FORM as reliever and controller vs fixed-dose BUD/FORM, so the effect balanced out in terms of total cost. (This is not mentioned in the abstract. See Table 4 of article, page 1376)

Compared with 'Guideline best practice'

\begin{tabular}{|c|c|c|c|c|c|c|c|}
\hline $\begin{array}{l}\text { Louis et al. } \\
\text { (11), } \\
2009\end{array}$ & 908 & $\begin{array}{l}\text { Randomized, } \\
\text { open-label, } \\
\text { parallel-group } \\
\text { multicentre trial }\end{array}$ & $\begin{array}{l}\text { Age } \geq 12 \text { years, } \\
\text { asthma diagnosis } \\
\geq 3 \text { months, on ICS } \\
\text { at } \geq 500 \text { mcg/day } \\
\text { BDP equivalent } \\
\pm \text { any other } \\
\text { controller } \\
\text { therapies. If only } \\
\text { on ICS, use } \\
\geq 3 \text { inhalations of } \\
\text { as-needed meds } \\
\text { in previous } 7 \text { days }\end{array}$ & $\begin{array}{l}\text { BUD/FORM } \\
\text { 160/4.5 mcg } \\
\text { twice daily + as } \\
\text { needed } \\
\text { (maximum as } \\
\text { needed to } \\
10 \text { inhalations/ } \\
\text { day) }\end{array}$ & $\begin{array}{l}\text { Conventional best } \\
\text { practice as per } \\
\text { GINA guidelines. }\end{array}$ & 26 weeks & $\begin{array}{l}\text { No statistically significant differences in } \\
\text { systemic steroid ( } 2.4 \text { versus 3.5\%), ED } \\
\text { visits ( } 1 \text { versus } 4 \text { ), hospitalizations (3 versus } \\
\text { 1), time to first severe exacerbation } \\
\text { ( } P=0.75 \text { ) or number of exacerbations }(2.7 \% \\
\text { versus } 4.1 \% \text { ) between groups. Lower ICS } \\
\text { dose in BUD/FORM as reliever and } \\
\text { controller versus conventional best practice } \\
\text { (749 versus } 1050 \text { mcg/day BDP eq, } \\
P<0.0001 \text { ) and lower cost (P<0.0001). No } \\
\text { clinically important differences in AEs. }\end{array}$ \\
\hline $\begin{array}{l}\text { Soes- } \\
\text { Petersen } \\
\text { et al. } \\
(13) \text {, } \\
2010\end{array}$ & 1854 & $\begin{array}{l}\text { Randomized, } \\
\text { open-label, } \\
\text { non-blinded trial. } \\
\text { Prescriptions for } \\
\text { both arms } \\
\text { dispensed via } \\
\text { normal local } \\
\text { practice using } \\
\text { community } \\
\text { pharmacies }\end{array}$ & $\begin{array}{l}\text { Age } \geq 12 \text { years, } \\
\text { asthma as per } \\
\text { ATS definition for } \\
\geq 3 \text { months, on } \\
\text { ICS dose of } \\
\geq 320 \text { mcg/day } \\
\text { (any ICS) } \pm \\
\text { LABA; or on ICS } \\
\text { alone and } \\
\text { suboptimal control } \\
\text { with use of } \\
\geq 3 \text { inhalations of } \\
\text { reliever in } \\
\text { previous week }\end{array}$ & $\begin{array}{l}\text { BUD/FORM } \\
\text { 160/4.5 mcg } \\
1 \text { inhalation } \\
\text { twice daily and } \\
\text { as needed } \\
\text { (maximum as } \\
\text { needed } \\
\text { inhalations } \\
\text { limited to } \\
\text { 10/day) }\end{array}$ & $\begin{array}{l}\text { Conventional best } \\
\text { standard treatment } \\
\text { as per GINA } \\
\text { guidelines. }\end{array}$ & 6 months & $\begin{array}{l}\text { No significant differences in systemic steroids } \\
\text { (5.5 verus } 7.0 \%) \text {, ED visits (1.8 versus } \\
2.3 \% \text { ), or hospitalizations ( } 0.5 \text { versus } 0.8 \%) \text {. } \\
\text { No significant difference in time to first } \\
\text { exacerbation, number of exacerbations/ } \\
\text { year, severe exacerbations. Statistically but } \\
\text { not clinically relevant greater improvement } \\
\text { in ACQ score in BUD/FORM as reliever and } \\
\text { controller. Lower ICS dose ( } 753 \text { mcg/day } \\
\text { versus } 1092 \text { mcg/day; P<0.0001) and } \\
\text { greater increase in well-controlled asthma in } \\
\text { SMART. Similar SAEs but more stopped } \\
\text { study drug in BUD/FORM as reliever and } \\
\text { controller (21) versus Guideline best } \\
\text { practice group (9). }\end{array}$ \\
\hline $\begin{array}{l}\text { Riemersma } \\
\text { et al. } \\
\text { (12), } \\
\text { 2011) }\end{array}$ & 102 & $\begin{array}{l}\text { Randomized, } \\
\text { open-label, } \\
\text { multicentre trial }\end{array}$ & $\begin{array}{l}\text { Age } \geq 18 \text { years, } \\
\text { mild to moderate } \\
\text { asthma, daily ICS } \\
\text { use in last months } \\
\text { before enrollment, } \\
\text { FEV }_{1} \geq 60 \% \text { of } \\
\text { expected normal }\end{array}$ & $\begin{array}{l}\text { BUD/FORM } \\
80 / 4.5 \mathrm{mcg} \\
2 \text { inhalations } \\
\text { once daily plus } \\
\text { additional } \\
\text { inhalations as } \\
\text { needed }\end{array}$ & $\begin{array}{l}\text { Usual care treatment } \\
\text { as per GINA } \\
\text { guidelines. }\end{array}$ & 12 months & $\begin{array}{l}\text { Systemic steroid use, ED visits and } \\
\text { hospitalizations were not reported. There } \\
\text { was no significant difference in mild } \\
\text { exacerbations. AEs were similar }\end{array}$ \\
\hline
\end{tabular}

AE Adverse event; ACQ Asthma Control Questionnaire; AMD Adjustable maintenance dose; ATS American Thoracic Society; BDP Beclomethasone dipropionate; BUD Budesonide; ED Emergency department; eq Equivalent; FEV 1 Forced expiratory volume in 1 s; FORM Formoterol; GINA Global Initiative for Asthma; ICS Inhaled corticosteroid; LABA Long-acting beta ${ }_{2}$-agonist; ref Reference; SABA Short-acting beta ${ }_{2}$-agonist; SAE Serious adverse event; SMART Symbicort (AstraZeneca Inc, Canada) Maintenance and Reliever Therapy 
(OR 1.42 [95\% CI 0.20 to 6.86]). The adults recruited to this trial had uncontrolled asthma and a history of poor adherence with 400 $\mathrm{mcg} /$ day to $1000 \mathrm{mcg} /$ day of ICS before enrollment. Steroid load increased more in the single inhaler BUD/FORM group than in the BUD group (mean between group difference $196 \mathrm{mcg} / \mathrm{day}, 95 \% \mathrm{CI}$ $13 \mathrm{mcg} /$ day to $279 \mathrm{mcg} /$ day). No trials of children treated with the same dose of ICS as administered by single inhaler BUD/FORM were identified.

\section{b) Single inhaler of BUD/FORM as a reliever and a controller versus higher than usual maintenance dose ICS}

Compared with higher dose ICS, systematic reviews found that use of a single inhaler of BUD/FORM as a reliever and a controller reduced the odds of a severe exacerbation in individuals 12 years of age and over (Agarwal et al. [19] OR 0.52 [95\% CI 0.45 to 0.61]; Edwards et al. [21], RR 0.59 [95\% CI 0.51 to 0.68]). In the Cochrane review, the use of a single inhaler of BUD/FORM as a reliever and a controller was associated with a reduction in exacerbations treated with oral steroids (OR 0.53 [95\% CI 0.44 to 0.63$]$ ) and a reduction in the rate of severe exacerbations (HR 0.59 [95\% CI 0.49 to 0.70]). However, no significant difference in hospitalizations was identified (OR 0.56 [95\% CI 0.28 to 1.09$]$ ) (20). The steroid load was reduced in all three trials in the single inhaler of BUD/FORM group compared with higher than usual maintenance dose ICS.

One trial, which compared use of a single inhaler of BUD/FORM as a reliever and a controller to higher than maintenance dose ICS in children four to 11 years of age (2), reported a reduction in severe exacerbations (defined as ED visit or hospitalization, or need for oral corticosteroid or increase in ICS use, or decline in morning PEF to $\leq 70 \%$ of baseline) (OR 0.33 [95\% CI 0.15 to 0.77$]$ ). Hospitalizations were infrequent and use of rescue oral corticosteroid was not reported, precluding firm conclusions regarding either outcome (20). Use of a single inhaler of BUD/FORM as a reliever and a controller was associated with an average difference in height advantage of $1 \mathrm{~cm}$ over the one year study ( $95 \% \mathrm{CI} 0.3 \mathrm{~cm}$ to $1.7 \mathrm{~cm}$ ), and a lower corticosteroid load (both lower mean daily dose of ICS and fewer days spent on oral corticosteroids) (20).

c) Single inhaler of BUD/FORM as a reliever and a controller versus usual fixed-dose ICS/LABA

Two of the systematic reviews analyzed data from trials comparing use of a single inhaler of BUD/FORM as a reliever and a controller with fixed-dose ICS/LABA therapy. Agarwal et al. (19) evaluated six trials of 14,536 individuals 12 years of age and over and adults (19). Use of a single inhaler of BUD/FORM as a reliever and a controller was associated with a lower rate of severe exacerbations (six trials, 14,536 participants: OR 0.65 [95\% CI 0.53 to 0.80]) and exacerbations requiring an $\mathrm{ED}$ visit or hospitalization (five trials, 12,702 participants: OR 0.89 [95\% CI 0.58 to 0.83$]$ ). There were no significant differences in the risk of total or SAEs (OR 1.02 [95\% CI 0.92 to 1.13], and OR 0.93 [95\% CI 0.79 to 1.09], respectively). Mean ICS (BDPeq) dose was $5931 \mathrm{mcg} /$ day in the ICS/LABA trials compared with $4890 \mathrm{mcg} /$ day in the BUD/FORM as a reliever and controller trials; however, a ststistical comparison was not reported. Edwards et al. (21) subgrouped these same six trials according to whether the ICS dose within the ICS/LABA control arm was the same or higher compared with the single inhaler of BUD/FORM as reliever and controller group. Compared with same-dose BUD/FORM, use of a single inhaler of BUD/FORM as a reliever and a controller was associated with fewer SAEs (RR fixed effects 0.57 [95\% CI 0.49 to 0.66]), hospitalizations and ED visits (RR 0.62 95\% CI [0.46 to 0.83]), and oral corticosteroid use (RR 0.58 [95\% CI 0.49 to 0.67]), and fewer withdrawals because of any reason, asthma, adverse events or SAEs. Compared with higherdose BUD/FORM, use of a single inhaler of BUD/FORM as a reliever and a controller was associated with reduced risk of severe exacerbations (RR 0.74 [95\% CI 0.58 to 0.96]) and rescue systemic corticosteroids (RR 0.68 [95\% CI 0.51 to 0.90]); however, there were no significant differences in hospitalizations or ED visits (RR 0.96 [95\% CI 0.64 to 1.44]) or any of the four withdrawal outcomes (21).

One recent RCT was an economic evaluation of use of a single inhaler of BUD/FORM (160/4.5 mcg or $80 / 4.5 \mathrm{mcg}$ depending on previous ICS dose), one inhalation twice daily or two inhalations once daily for maintenance plus additional inhalations as needed compared with: a) adjustable combination of separate inhalers containing BUD (100 mcg/inhalation to $400 \mathrm{mcg} /$ inhalation $)$ and FORM (4.5 mcg/inhalation or $9 \mathrm{mcg} /$ inhalation) plus terbutaline reliever; and b) fixed-dose BUD/FORM $160 / 4.5 \mathrm{mcg}$ or $80 / 4.5 \mathrm{mcg}$ (depending on previous ICS dose), two inhalations twice daily plus rescue terbutaline as reliever (10). ED visits, hospitalizations, and the number and type of adverse events were comparable between groups. Rescue systemic steroid use was not reported. There was a significant reduction in direct costs $(13 \%$ to $20 \%)$ compared with either control arm, primarily as a result of lower total asthma medication use. However, the cost of hospitalizations was higher for the single inhaler of BUD/FORM as a reliever and a controller intervention arm than the fixed-dose BUD/FORM control arm $(\mathrm{P}<0.001)$, and there were no significant differences between any groups for total (direct plus indirect) costs.

iii) Single inhaler of BUD/FORM as a reliever and a controller versus current guideline best practice

RCTs that compare use of a single inhaler of BUD/FORM as a reliever and a controller with fixed doses of controllers for the trial duration have limited generalizability to 'real-life' clinical practice because guidelines recommend that clinicians regularly assess asthma control and adjust maintenance therapy to achieve control. Thus, more recent RCTs have compared this intervention to 'guideline best practice' in which a clinician regularly reviews the patient and is allowed to adjust maintenance controller therapy according to current guidelines. Most of these trials were conducted in Europe and clinicians adjusted therapy in the control arm according to existing GINA guidelines.

The Cochrane review (20) addressed the comparison of use of a single inhaler of BUD/FORM as a reliever and a controller with current best practice for adjustment of controller therapy and FABA as reliever, by analyzing five RCTs involving 5378 individuals 12 years of age and over. There were no significant differences in hospitalizations (OR 0.59 [95\% CI 0.24 to 1.45]) or systemic corticosteroids (based upon four RCTs of 4470 individuals; OR 0.83 [95\% CI 0.66 to 1.03]). Use of a single inhaler of BUD/FORM as a reliever and a controller was associated with a lower daily ICS dose of $267 \mathrm{mcg}$ (95\% CI $308 \mathrm{mcg} /$ day to $226 \mathrm{mcg} /$ day) in all three published trials. Although there were no significant differences in fatal or nonfatal SAEs (in three trials involving 4282 individuals), the authors caution that infrequent events limited the power to detect differences that may be clinically important. Furthermore, there were significantly more discontinuations due to adverse events in individuals using a single inhaler of BUD/FORM as a reliever and a controller (OR 2.92 [95\% CI 1.70 to 5.01]). At the time of publication, the Cochrane review (20) identified five large trials on this topic that were underway.

As of October 2011, results from two publications pertaining to one of these trials (NCT00463866, known as the "EuroSMART" Study) are available. These compared different maintenance doses of BUD/FORM combination inhaler as a reliever and controller and were excluded from our analysis. The updated search identified three additional publications pertaining to two trials (11-13) (Table 8). Both trials were open-label design comparing use of a single inhaler of BUD/FORM as a reliever and a controller to conventional best practice (as per GINA guidelines) in individuals 12 years of age and over $(11,13)$ or 18 years of age and over $(12)$. There were no statistically significant differences in any of the trials in systemic steroid use (13), ED visits or hospitalizations $(11,13)$, number of severe exacerbations $(11,13)$ or mild exacerbations $(12)$, time to severe 
exacerbations $(11,13)$ or adverse events. Two trials reported these comparable outcomes were achieved at an average lower daily ICS doses using a single inhaler of BUD/FORM as a reliever and a controller: $747 \mathrm{mcg} / \mathrm{day}$ versus $1059 \mathrm{mcg} /$ day BDP equivalent; $\mathrm{P}<0.0001$ (11); and $753 \mathrm{mcg} / \mathrm{day}$ versus $1092 \mathrm{mcg} /$ day BDP equivalent; $\mathrm{P}<0.0001$ ) (13). These two trials also reported statistically significantly greater improvements in Asthma Control Questionnaire scores with the single inhaler, which were less than the minimum important difference of 0.5 and, therefore, not clinically relevant.

\section{Conclusions}

Combination inhalers of reliever and controller medication offer theoretical advantages both for maintenance of control, and as part of guided asthma self-management strategies and action plans, which prompt patient-initiated adjustments to reliever and controller therapy. In response to safety concerns regarding LABAs and adverse outcomes, specifically severe exacerbations requiring hospitalization in children and adults, and increased risk of death in some patients, the CTS Asthma Committee published a commentary on LABA use in asthma in Canada (23). It focused on maintenance therapy, stating the following:

LABAs should never be used alone (as monotherapy) for asthma in any age group. LABAs should only be used as add-on therapy to an anti-inflammatory controller (such as an inhaled corticosteroid [ICS], ideally, in the same inhaler device) in any age group. If a LABA is used in children, a combination inhaler of an ICS plus a LABA is preferred over separate inhalers of each to preclude the use of a LABA without an ICS, which may arise due to adherence issues.

Regarding use of a single inhaler of BUD/FORM as a reliever and a controller, it was noted that:

Use of a single inhaler of budesonide and formoterol for maintenance and relief is only approved for use [in Canada] in individuals 12 years of age and over. (23)

Until now, the CTS had not formally reviewed the efficacy of the use of combination inhalers of ICS/LABA as a reliever or as both a reliever and a controller.

\section{1) Single inhaler of ICS/LABA compared with a FABA as a reliever}

Trials have examined the use of a single inhaler of an ICS/LABA as a reliever during periods of loss of asthma control compared with either a SABA or LABA reliever. There is currently no evidence of benefit in individuals with mild intermittent asthma who are not on regular controller therapy. In addition, systematic reviews have not identified trials examining ICS/LABA combination products compared with FABA as relievers in patients on the same dose of maintenance ICS in both treatment arms. Evidence of benefit of ICS/LABA reliever compared with FABA reliever has only been shown in a highly selected population of individuals 12 years of age and over whose asthma was uncontrolled despite regular high-dose ICS, with a recent exacerbation and who were switched to ICS/LABA as controller therapy at approximately one-half the previous ICS dose. The benefit demonstrated was a reduction in the risk of exacerbations requiring oral corticosteroids, but not in hospitalizations. The reduction in ICS dosage when switching to ICS/LABA maintenance is not currently recommended in national or international guidelines. The potential for overestimating the treatment effect is therefore high, limiting the quality of the evidence.

In summary, there is no evidence to support use of a single inhaler of an ICS/LABA (BUD/FORM) instead of a FABA as a reliever in children or adults who are not on maintenance controller therapy or who are on ICS monotherapy at the same dose in the treatment and control groups. There is evidence from clinical trials that BUD/FORM as a reliever may be of benefit in individuals 12 years of age and over with moderate asthma and poor asthma control on ICS/LABA combination maintenance therapy.
2) Single inhaler of BUD/FORM as a reliever and a controller compared with usual dose of controller (ICS monotherapy, fixed-dose ICS/LABA, or 'guideline best practice'), with FABA as a reliever Two guidelines have recently made formal recommendations regarding use of a single inhaler of BUD/FORM as a reliever and a controller therapy. Both the GINA and SIGN guidelines have deemed it to be an effective treatment regimen for maintenance of control and reduction of exacerbations. The SIGN guideline cautions against reducing the daily dose of ICS when patients are started on this regimen. We concur with the SIGN guideline cautionary statement that regular need for reliever (of any kind) merits re-evaluation.

Our recommendations are based on the GINA (6) and SIGN (7) guidelines, and evidence from three systematic reviews (19-21) of a total of 14 RCTs plus four additional RCTs (10-13). Only one study was identified that compared low-dose ICS monotherapy (up to $400 \mathrm{mcg}$ BUD/day) at the same ICS dose as in the single inhaler of BUD/FORM used as a reliever and controller in individuals 18 years of age and over with a history of poor adherence to ICS, and found no evidence that the latter is superior. Use of a single inhaler of BUD/FORM as a reliever and a controller appears to be of benefit compared with higher maintenancedose ICS (up to $800 \mathrm{mcg} /$ day) in individuals 12 years of age and over in reducing severe exacerbations and steroid load. It also has reduced impedance of growth in children 4 to 11 years of age. We note, however, that the apparent benefit demonstrated in a number of the trials included in systematic reviews may have been related to loss of asthma control in the control arm due to a reduction in controller therapy (withdrawal of LABA or reduction in maintenance ICS dose).

Compared with fixed-dose ICS/LABA, benefits have been demonstrated in meta-analyses of open-label trials compared with the same or higher-dose ICS in severe exacerbations, and exacerbations needing oral corticosteroids. However, there is considerable heterogeneity of results in the systematic reviews. Although not formally included as evidence, we note that Bateman et al. (16) found similar reductions in the risk of future exacerbations in a post hoc analysis of individual patient data from five of the RCTs (all of which were included in one or more of the systematic reviews) favouring use of a single inhaler of BUD/FORM as a reliever and a controller compared with higher dose ICS plus SABA, and same dose ICS/LABA plus SABA but not higher dose ICS/LABA plus SABA.

The Cochrane review by Cates and Lasserson (20) was the only systematic review to include a comparison with current 'guideline best practice' in individuals 12 years of age and over. Use of a single inhaler of BUD/FORM as a reliever and a controller was comparable in effectiveness with conventional guideline-based care (which often includes fixed combination therapy with an ICS and LABA) at decreasing hospitalizations (five trials) or preventing exacerbations needing rescue oral steroids (four trials) and was associated with a lower daily dose of ICS compared with conventional guideline-based strategy. There were no differences in fatal or nonfatal SAEs (three trials), although the power was insufficient to rule out clinically important differences in the latter. However, use of a single inhaler of BUD/FORM as a reliever and a controller was associated with a twofold increase in discontinuation due to adverse effects, which were primarily in individuals switching from a metered-dose inhaler to dry powder inhaler. The additional three trials we reviewed that were published subsequent to the Cochrane review contribute similar findings, in terms of comparable effectiveness for most outcomes and lower ICS daily dose. Although there were no statistically significant differences in SAEs in these three additional trials, individual trials have limited power in this regard. It is worth noting that guideline-based best practice, as achieved within the context of a clinical trial, still likely exceeds every day practice, where adherence to best practice is often suboptimal. Which treatment strategy is most effective in community settings is not known.

In summary, there is no evidence that use of a single inhaler of BUD/FORM as a reliever and controller is superior to the same dose of ICS monotherapy. The former appears to be superior to increasing the ICS dose above the usual maintenance and to using the same or a 
higher fixed dose of ICS/LABA including BUD/FORM-AMD during loss of control in adults. It is also associated with lower cost of medication but higher costs related health care resources utilization. However, limitations in the trial designs raise concerns regarding the external validity of these findings. There is no evidence that use of a single inhaler of BUD/FORM as a reliever and controller is more efficacious than 'current guidelines best practice', but it is consistently associated with lower daily ICS dose.

We conclude that using a single inhaler of BUD/FORM as a reliever and controller may be an appropriate self-management strategy compared with increasing to higher-dose ICS monotherapy, increasing the ICS dose of fixed-dose ICS/LABA combination or 'guideline best practice' (titration of controller medication during regular review by a practitioner) for selected subgroups. In particular, it may be of value in exacerbation-prone individuals 12 years of age and over with uncontrolled asthma, who are on high maintenance doses of ICS or ICS/LABA combination therapy. Additional safety data are needed to clarify the risk-benefit compared with conventional best practice.

\section{Question 4}

What is the efficacy of using a single inhaler of an ICS/LABA combination as a reliever compared with a FABA as a reliever as part of a self-management plan in children and adults experiencing an acute loss of asthma control?

The following recommendations are based on review of evidence from one systematic review and the consensus of the CTS Asthma Clinical Assembly Expert Panel.

\section{Recommendation 4A}

We do not recommend the use of an ICS/LABA combination as a reliever in lieu of a FABA as a reliever in individuals 16 years of age and over with mild intermittent asthma on no maintenance controller therapy. (GRADE 1B)

There is insufficient evidence to make a recommendation regarding the efficacy of an ICS/LABA combination as a reliever in individuals under 16 years of age on no maintenance controller therapy.

There is insufficient evidence to make a recommendation regarding the efficacy of an ICS/LABA combination as a reliever in children and adults on ICS monotherapy.

\section{Recommendation 4B}

We recommend the use of a SABA instead of either a LABA (GRADE $1 \mathrm{~A}$ ) or an ICS/LABA combination inhaler (GRADE 1B) as a reliever in individuals with mild intermittent asthma on no maintenance controller therapy.

\section{Recommendation 4C}

We suggest the use of a SABA, instead of an ICS/LABA combination inhaler as a reliever in individuals with mild asthma on ICS monotherapy. (Consensus)

\section{Recommendation 4D}

In exacerbation-prone individuals 12 years of age and over with moderate asthma and poor control on a fixed-dose maintenance ICS/ LABA combination, we suggest the use of budesonide/formoterol as a reliever be considered at the same maintenance ICS dose.

\section{Question 5}

What is the efficacy of using a single inhaler of BUD/FORM as a reliever and a controller as part of a self-management plan for individuals 12 years of age and over, compared with the following:

a) the usual dose of controller (either ICS monotherapy or fixeddose ICS/LABA combination) with a FABA as a reliever?

b) 'guideline best practice' (defined as a practitioner adjusting controller therapy based on regular review) with a FABA as a reliever?
The following recommendations are based on adaptation of two guidelines, review of evidence from three systematic reviews, four RCTs and the consensus of the CTS Asthma Clinical Assembly Expert Panel.

\section{Recommendation 5A}

We do not suggest the use of a single inhaler of budesonide/formoterol as a reliever and a controller as a self-management strategy in lieu of ensuring adherence to low-dose ICS (400 mcg/day CFC-BDP equivalent) and use of a FABA as a reliever in individuals 12 years of age and over. (GRADE 2B)

There is insufficient evidence to make a recommendation regarding the use of a single inhaler of budesonide/formoterol as a reliever and a controller as a self-management strategy compared with fixed-dose ICS/LABA in individuals who are exacerbation prone despite adherence to low-dose ICS.

\section{Recommendation 5B}

We do not currently suggest the use of a single inhaler of budesonide/ formoterol as a reliever and a controller as a self-management strategy in children 4 to 11 years of age (GRADE 2B), and this approach is not approved in Canada in this age group.

\section{Recommendation $5 \mathrm{C}$}

We suggest the use of a single inhaler of budesonide/formoterol as a reliever and a controller at the same ICS dose be considered in individuals 12 years of age and over with asthma uncontrolled on fixed-dose ICS/LABA combination therapy in lieu of increasing the ICS dose of the combination therapy. (GRADE 2B)

\section{Recommendation 5D}

Use of a single inhaler of budesonide/formoterol as a reliever and a controller and 'guideline best practice' of a practitioner titrating controller medication according to current control are both effective therapeutic options in individuals 12 years of age and over. We suggest that the choice between these therapeutic strategies be individualized based on patient preferences and steroid load. (GRADE 2B)

\section{Future research needs}

Based on the evidence reviewed, the Clinical Assembly identifies the following research needs:

- To determine the risk-benefit of use of a single inhaler of BUD/ FORM as a reliever and a controller versus 'guideline best practice';

- To determine the efficacy and safety of use of a single inhaler of BUD/FORM as a reliever and a controller self-management strategy in children 4 to 11 years of age and adults; and

- To determine how to assess asthma control (specifically frequency of reliever use) in individuals using a single inhaler of an ICS/ LABA as a reliever or as a reliever and a controller.

\section{REFERENCES}

1. Lemiere C, Bai T, Balter M, et al. Adult Asthma Consensus Guidelines Update 2003. Can Respir J 2004;11(Suppl A):9A-18A.

2. O'Byrne PM, Bisgaard H, Godard PP, et al. Budesonide/formoterol combination therapy as both maintenance and reliever medication in asthma. Am J Respir Crit Care Med 2005;171:129-36.

3. Rabe KF, Atienza T, Magyar P, Larsson P, Jorup C, Lalloo UG. Effect of budesonide in combination with formoterol for reliever therapy in asthma exacerbations: A randomised controlled, double-blind study. Lancet 2006;368:744-53.

4. Rabe KF, Pizzichini E, Stallberg B, et al. Budesonide/formoterol in a single inhaler for maintenance and relief in mild-to-moderate asthma: A randomized, double-blind trial. Chest 2006;129:246-56.

5. Vogelmeier C, D’Urzo A, Pauwels R, et al. Budesonide/formoterol maintenance and reliever therapy: an effective asthma treatment option? Eur Respir J 2005;26:819-28.

6. Global Strategy for Asthma Management and Prevention. Global Initiative for Asthma (GINA), 2010. <www.ginasthma.org>

7. British Guideline on the Management of Asthma: A national clinical guideline. Scottish Intercollegiate Guidelines Network (SIGN): British Thoracic Society, 2008. 
8. Kuna P, Peters MJ, Manjra AI, et al. Effect of budesonide/formoterol maintenance and reliever therapy on asthma exacerbations. Int J Clin Pract 2007;61:725-36.

9. Scicchitano R, Aalbers R, Ukena D, Manjra A, Fouquert L, Centanni S, et al. Efficacy and safety of budesonide/formoterol single inhaler therapy versus a higher dose of budesonide in moderate to severe asthma. Curr Med Res Opin 2004;20:1403-18.

10. Stallberg B, Ekstrom T, Neij F, et al. A real-life cost-effectiveness evaluation of budesonide/formoterol maintenance and reliever therapy in asthma. Respir Med 2008;102:1360-70.

11. Louis R, Joos G, Michils A, Vandenhoven G. A comparison of budesonide/formoterol maintenance and reliever therapy vs. conventional best practice in asthma management. Int J Clin Pract 2009;63:1479-88.

12. Riemersma RA, Postma D, van der Molen T. Budesonide/formoterol maintenance and reliever therapy in primary care asthma management: Effects on bronchial hyperresponsiveness and asthma control. Prim Care Respir J 2011; 12:50-6.

13. Soes-Petersen U, Kava T, Dahle R, Lei Y, Dam N. Budesonide/ formoterol maintenance and reliever therapy versus conventional best standard treatment in asthma in an attempted 'real life' setting. Clin Respir J 2011;5:173-82.

14. Aalbers R. Fixed or adjustable maintenance-dose budesonide/ formoterol compared with fixed maintenance-dose salmeterol/ fluticasone propionate in asthma patients aged $>$ or $=16$ years: Post hoc analysis of a randomized, double-blind/open-label extension, parallel-group study. Clin Drug Investig 2010;30:439-51.

15. Kuna P. Treatment comparison of budesonide/formoterol with salmeterol/fluticasone propionate in adults aged $>$ or $=16$ years with asthma: post hoc analysis of a randomized, double-blind study. Clin Drug Investig 2010;30:565-79.

16. Bateman ED, Reddel HK, Eriksson G, et al. Overall asthma control: The relationship between current control and future risk. J Allergy Clin Immunol. 2010;125:600-8.

17. Demoly P, Louis R, Soes-Petersen U, et al. Budesonide/formoterol maintenance and reliever therapy versus conventional best practice. Respir Med 2009;103:1623-32.

18. Cates CJ, Lasserson TJ. Combination formoterol and inhaled steroid

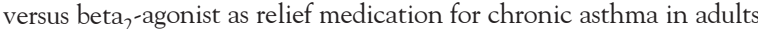
and children. Cochrane Database Syst Rev 2009(1):CD007085.

19. Agarwal R, Khan A, Aggarwal AN, Gupta D. Is the SMART approach better than other treatment approaches for prevention of asthma exacerbations? A meta-analysis. Monaldi Arch Chest Dis 2009;71:161-9.

20. Cates CJ, Lasserson TJ. Combination formoterol and budesonide as maintenance and reliever therapy versus inhaled steroid maintenance for chronic asthma in adults and children. Cochrane Database Syst Rev 2009(2):CD007313.

21. Edwards SJ, von Maltzahn R, Naya IP, Harrison T. Budesonide/ formoterol for maintenance and reliever therapy of asthma: A meta analysis of randomised controlled trials. Int J Clin Pract 2010;64:619-27.

22. Sovani MP, Whale CI, Oborne J, et al. Poor adherence with inhaled corticosteroids for asthma: can using a single inhaler containing budesonide and formoterol help? Br J Gen Pract 2008;58:37-43.

23. Lougheed MD, Lemiere C, Dell S, et al. Canadian Thoracic Society Asthma Committee commentary on long-acting beta-2 agonist use for asthma in Canada. Can Respir J 2010;17:57-60.

24. Bousquet J, Boulet L-P, Peters MJ, et al. Budesonide/formoterol for maintenance and relief in uncontrolled asthma vs. high-dose salmeterol/fluticasone. Respir Med 2007;101:2437-46.

25. Sears MR, Boulet L-P. Laviolette M, et al. Budesonide/formoterol maintenance and reliever therapy: Impact on airway inflammation in asthma. Eur Respir J 2008;31:982-9.

\section{SECTION IV}

\section{CONTROLLER THERAPY FOR ACTION PLANS}

\section{Introduction}

Asthma education is an essential component of care for all individuals with asthma and their caregivers (1). Written action plans are the foundation of guided self-management, and are particularly effective when combined with self-monitoring and regular medical review (2-5). Action plans outline strategies to achieve and maintain control, when and how to adjust reliever and controller therapy in response to acute loss of asthma control, and when to seek urgent medical attention. Written action plans typically use three or four zones to describe the level of asthma control according to traffic light colors: green, yellow and red (plus or minus orange, or extra red). Specific instructions regarding the symptom thresholds that define a deterioration of asthma control and/or the severity of decline in lung function parameters that should prompt a change in medication vary somewhat among published action plans. In addition, although all major guidelines recommend the use of written action plans, specific evidencebased recommendations regarding the adjustment of controller therapy in the yellow zone are either absent or unclear.

The CTS Asthma Assembly Expert Panel, therefore, undertook to review the literature and provide guidance regarding how to escalate controller therapy for acute loss of control (in the 'yellow zone'), based on the maintenance ('green zone') medication. Specifically, we reviewed the evidence examining the efficacy of escalation of controller medication as part of a written action plan for preschoolers, children and adults with acute loss of asthma control in patients not on regular controller therapy, ICS monotherapy, LTRA monotherapy or ICS plus LABA.

\section{REFERENCES}

1. Lougheed MD, Lemiere C, Dell SD, et al.. Canadian Thoracic Society Asthma Management Continuum - 2010 Consensus Summary for children six years of age and over, and adults. Can Respir J 2010;17:15-24.

2. Toelle BG, Ram FS. Written individualised management plans for asthma in children and adults. Cochrane Database Syst Rev 2004(2):CD002171.

3. Gibson PG, Powell H, Coughlan J, et al.. Self-management education and regular practitioner review for adults with asthma. Cochrane Database Syst Rev 2003(1):CD001117.

4. Powell H, Gibson PG. Options for self-management education for adults with asthma. Cochrane Database Syst Rev 2003(1):CD004107.

5. Zemek RL, Bhogal SK, Ducharme FM. Systematic review of randomized controlled trials examining written action plans in children: what is the plan? Arch Pediatr Adolesc Med 2008;162:157-63.

\section{SECTION IV CONTROLLER THERAPY FOR ACTION PLANS}

\section{Part 1 - Intermittent ICS}

\section{Question}

6. In mild persistent asthma, is the strategy of taking no daily controller therapy but initiating ICS as part of a written action plan at the onset of acute loss of asthma control as effective as taking daily ICS for preschoolers (under 6 years of age), children (6 to 11 years of age) and adults ( 12 years of age and over)?

\section{Introduction}

Major national and international asthma guidelines recommend daily controller therapy as the mainstay of treatment of children and adults with mild persistent asthma. Daily ICS therapy is recommended at the minimal effective dose. In practice, due to poor adherence to daily therapy, patients often initiate ICS only at the onset of a loss of asthma control. This strategy is also a popular recommendation by some physicians for guided self-management. Several trials have been recently published to examine the efficacy of this strategy.

\section{Methods}

Practice guidelines, systematic reviews of RCTs and RCTs comparing intermittent ICS versus daily ICS with or without step-up therapy for acute loss of asthma control in preschoolers, children and adults were included. Outcomes of interest included the use of systemic steroids, emergency department visits, hospitalizations, duration of symptoms, rescue beta ${ }_{2}$-agonist use, quality of life and adverse effects.

Asthma search terms were combined with the following $\mathrm{MeSH}$ and text words in OVID MEDLINE and EMBASE to identify 
systematic reviews: exacerbate*: or acut*: or status*: or sever*: or emergenc*: or crisis*: or worsen*: or attack*: and terms for inhaled corticosteroids. Systematic reviews were included if they were published in 2005 or later.

Because no existing systematic reviews on this topic were identified, a Cochrane systematic review was commissioned to explore the safety and efficacy of intermittent versus daily ICS. The search strategy of CAGR, which included all records in the CAGR coded as 'asthma', were searched using the following terms: (intermittent* or as-needed* or "as needed" or prn or irregular* or occasional* or sporadic* or short-course*) and (daily* or regular* or routine*).

\section{Key evidence}

One practice guideline (1) and one systematic review (2) of six RCTs informed the recommendations.

\section{Guidelines}

There is no mention of intermittent controller therapy in patients with persistent asthma in the GINA and BTS Guidelines $(3,4)$. The NHLBI (1) recommends that step-down to intermittent ICS may be considered for infants and young children who are well controlled on ICS.

Therefore, it is the opinion of the Expert Panel that low-dose ICS is the preferred daily long-term control therapy for infants and young children who have never before been treated with long-term control therapy. This medication should be prescribed in the form of a therapeutic trial, and response should be monitored carefully. Treatment should be stopped if a clear beneficial effect is not obvious within 4-6 weeks, and the patient/family medication technique and adherence are satisfactory. If a clear and positive response exists for at least 3 months (and given the high rates of spontaneous remission of symptoms in this age group), the need for ICS therapy should be re-evaluated. A step down to intermittent therapy, as needed for symptoms, may then be considered' (Evidence D).

With regard to adults, the NHLBI also suggested the following:

A recent study has suggested that some patients who have mild persistent asthma may be successfully managed with intermittent use of low-dose ICS, because study participants taking daily budesonide, daily zafirlukast, or intermittent treatment with ICS and SABA (according to a symptom-based action plan) had similar improvement in morning PEF and a similarly low number of exacerbations (Boushey et al.. 2005). However, other outcomes in this study were significantly better in patients taking regular versus intermittent ICS therapy (symptom-free days, prebronchodilator $\mathrm{FEV}_{1}$, airway hyperresponsiveness, and inflammatory markers). Currently, data are insufficient to recommend intermittent use of ICS for most patients who have mild persistent asthma, although it may be considered as a step-down therapy strategy for patients who are well controlled on step 2 therapy. Further studies are needed to evaluate the use of intermittent therapy with either ICSs or leukotriene modifiers.

\section{Systematic review}

Because no existing systematic reviews were identified, a Cochrane review was conducted (Chauhan et al., unpublished data). The reviewers identified six relevant trials comparing intermittent versus daily ICS in children and adults. In the daily ICS group, five trials used a daily low dose $(100 \mathrm{mcg} /$ day to $500 \mathrm{mcg} /$ day $)$ of inhaled beclomethasone, inhaled BUD or nebulized BUD while the remaining trial used moderate doses ( $800 \mathrm{mcg} / \mathrm{day}$ ) of nebulized BUD) (Table 9) (5-12). Only one identified trial was previously cited in the above-mentioned guidelines, namely Boushey et al. (9), which was cited in the NHLBI guidelines.

The trials were stratified in two subgroups based on whether the ICS dose during exacerbations was similar in both groups (pre-emptive initiation or escalation of ICS in both groups) or only in the intermittent ICS group (pre-emptive ICS initiation only); one trial by Martinez et al. (5) contributed data to both comparisons, yielding a total of seven comparisons.

Comparing the intermittent ICS with the daily ICS groups, there was no significant difference in the risk of patients with one or more exacerbations requiring oral corticosteroids $(n=7, \mathrm{RR} 1.07$ [95\% CI 0.87 to 1.32$]$ ), withdrawals ( $n=7$, OR 1.14 [95\% CI 0.75 to 1.73$]$ ), time to first exacerbation requiring oral corticosteroids $(n=3, O R$ 1.02 [95\% CI 0.77 to 1.36]) and in withdrawals due to poor asthma control or exacerbations ( $n=5$, OR 1.66 [95\% CI 0.54 to 5.13]). Use of pre-emptive ICS initiation or escalation in both groups versus only in the intermittent group did not significantly affect findings. However, with regard to asthma control, the intermittent ICS group experienced a significantly lower percent improvement from baseline in PEF $(n=3$, mean difference [MD] $-2.56 \%$ [95\% CI $-4.49 \%$ to $-0.63 \%)$, in asthma control days $(n=2, M D-0.07$ days $[95 \% \mathrm{CI}$ -0.14 days to -0.01 days]), a higher daily use of beta 2 -agonists (puffs/ day) (n=3, MD 0.15 puffs/day [95\% CI 0.00 puffs/day to 0.29 puffs/ day]) as well as a lower proportion of asthma control days ( $n=3, M D$ $-0.09 \%$ [ $95 \%$ CI $-0.15 \%$ to $-0.04 \%]$ ). The intermittent ICS group experienced a statistically significant increase in exhaled nitric oxide during the study period compared with the daily ICS ( $n=2, M D$ 16.80 [95\% CI 11.95 to 21.64]); no group differences were observed in other lung function tests, markers of asthma control or other inflammatory markers. The growth velocity in children was significantly higher in the intermittent compared with daily ICS groups $(\mathrm{n}=4, \mathrm{MD} 0.41 \mathrm{~cm}[95 \% \mathrm{CI} 0.13 \mathrm{~cm}$ to $0.69 \mathrm{~cm}])$. No group differences in other safety profile indicators were observed including overall and specific adverse effects and withdrawals due to adverse effects.

\section{Conclusions}

In preschoolers, children and adults with persistent asthma, the metaanalysis failed to identify statistically significant group differences in the risk of exacerbations requiring rescue oral corticosteroids, time to first exacerbations requiring rescue corticosteroids, withdrawals and withdrawals due to poor control. The step-up protocol did not appear to significantly influence results. Several markers of control were in favour of daily over intermittent ICS therapy. In children, however, the growth velocity was significantly higher in the intermittent compared with daily ICS groups. Of note, all trials used budesonide or beclomethasone; none used fluticasone or ciclesonide. The data must be interpreted with caution given the lack of precision of the results based on six trials (seven comparisons) and 1211 participants. In this review, the absence of group difference did not meet the definition of equivalence.

\section{Question 6 \\ In mild persistent asthma, is the strategy of taking no daily controller therapy but initiating ICS as part of a written action plan at the onset of acute loss of asthma control as effective as taking daily ICS for preschoolers (under 6 years of age), children (6 to 11 years of age) and adults (12 years of age and over)?}

The following recommendations are based on evidence from one guideline, one systematic review and the consensus of the CTS Asthma Clinical Assembly Expert Panel.

\section{Recommendation 6A}

We recommend daily ICS in lieu of starting intermittent ICS at the onset of an episode of acute loss of asthma control in patients with mild persistent asthma. (GRADE 1B)

\section{Recommendation 6B}

We recommend that the safest and minimal effective ICS dose be prescribed to minimize side effects in all age groups, particularly in children to address the concern regarding growth velocity. (GRADE 1B) 
TABLE 9

Characteristics of controlled trials of intermitted versus daily ICS in children and adults

\begin{tabular}{|c|c|c|c|c|c|c|c|c|c|c|}
\hline Trial & $\begin{array}{c}\text { Patients, } \\
\mathbf{n}\end{array}$ & $\begin{array}{l}\text { Mean } \\
\text { age, } \\
\text { years }\end{array}$ & $\begin{array}{l}\text { beginning of } \\
\text { daily versus } \\
\text { intermittent ICS }\end{array}$ & Phenotype definition & Trigger for action plan & $\begin{array}{r}\text { Daily } \\
\text { Standard }\end{array}$ & Intermittent & $\begin{array}{r}\text { Exace } \\
\text { Standard }\end{array}$ & $\frac{\text { rbations }}{\text { intervention }}$ & $\begin{array}{c}\text { Study } \\
\text {-duration, } \\
\text { weeks }\end{array}$ \\
\hline \multicolumn{11}{|c|}{ Same ICS step-up dose during exacerbation in both groups } \\
\hline $\begin{array}{l}\text { Turpeinen } \\
\text { et al. (8), } \\
2008\end{array}$ & 116 & 6.9 & $\begin{array}{l}\text { BUD } 800 \text { mcg/ } \\
\text { day } \times 1 \text { month } \\
\text { then BUD } \\
400 \text { mcg/day } \\
\times 5 \text { months }\end{array}$ & $\begin{array}{l}\text { According to the symptoms } \\
\text { and lung function test, the } \\
\text { majority of patients were } \\
\text { categorized as mild } \\
\text { persistent asthma: } 20 \% \\
\text { diurnal variation in PEF or } \\
\text { at least } 15 \% \text { increased in } \\
\text { PEF at least } 3 \text { times within } \\
2 \text { weeks or at least } 15 \% \\
\text { increase in FEV } 15 \text { min } \\
\text { after beta } 2 \text {-agonists. The } \\
\text { rest were categorized as } \\
\text { moderate persistent } \\
\text { asthma }\end{array}$ & $\begin{array}{l}\text { At increase in symptoms } \\
\text { that were not controlled } \\
\text { with six doses of rescue } \\
\text { terbutaline per } 24 \mathrm{~h} \text { that } \\
\text { caused the parents } \\
\text { contact the clinic. } \\
\text { Physician decided the } \\
\text { occurrence of } \\
\text { exacerbation }\end{array}$ & $\begin{array}{c}\text { BUD } \\
200 \mathrm{mcg} / \\
\text { day }\end{array}$ & - & $\begin{array}{c}\text { BUD } 800 \\
\text { mcg/day } \times \\
2 \text { weeks }\end{array}$ & $\begin{array}{l}\text { BUD } 800 \\
\text { mcg/day } \times \\
2 \text { weeks }\end{array}$ & 52 \\
\hline $\begin{array}{l}\text { Boushey } \\
\text { et al. } \\
(9) \\
2008\end{array}$ & 149 & 33 & $\begin{array}{l}\text { Placebo } \\
\text { controller for } \\
4 \text { weeks + prn } \\
\text { albuterol }\end{array}$ & $\begin{array}{l}\text { Mild persistent asthma } \\
\text { defined as self-treatment } \\
\text { with beta }{ }_{2} \text {-agonists more } \\
\text { than } 2 \text { days per week, } \\
\text { nighttime awakening } \\
\text { related to asthma more } \\
\text { than } 2 \text { days/month, or } \\
\text { variability in PEF } 20 \%- \\
30 \% \text {. All had FEV } 1 \geq 70 \% \\
\text { of predicted }\end{array}$ & Not reported & $\begin{array}{l}\text { BUD } 400 \\
\text { mcg/day }\end{array}$ & - & $\begin{array}{c}\text { BUD } 1600 \\
\text { mcg/day } \times \\
2 \text { weeks }\end{array}$ & $\begin{array}{l}\text { BUD } 1600 \\
\text { mcg/day } \times \\
2 \text { weeks }\end{array}$ & 52 \\
\hline $\begin{array}{l}\text { Martinez } \\
\text { et al. (5), } \\
2011\end{array}$ & 143 & 11 & $\begin{array}{l}\text { HFA-BDP } 100 \\
\text { mcg/day for } \\
4 \text { weeks + prn } \\
\text { albuterol }\end{array}$ & $\begin{array}{l}\text { Mild persistent asthma } \\
\text { defined as on average } \\
\text { more than } 2 \text { days a week } \\
\text { with symptoms (eg, } \\
\text { wheezing) or with use of } \\
\text { albuterol to control } \\
\text { symptoms, or more than } \\
2 \text { awakenings a night per } \\
\text { month when not using a } \\
\text { controller medication or, } \\
\text { if they had to use daily } \\
\text { controller treatment to } \\
\text { keep their disorder well } \\
\text { controlled. }\end{array}$ & $\begin{array}{l}\text { Use of more than } 12 \text { puffs } \\
\text { of albuterol in } 24 \mathrm{~h} \text {, a } \\
\text { PEF less than } 70 \% \text { of } \\
\text { reference value before } \\
\text { albuterol use, symptoms } \\
\text { that led to inability to } \\
\text { sleep or do daily } \\
\text { activities for } 2 \text { or more } \\
\text { consecutive days, a PEF } \\
\text { less than } 50 \% \text { of } \\
\text { reference value despite } \\
\text { relief medication, ED visit } \\
\text { due to worsening of } \\
\text { asthma symptoms. } \\
\text { Excessive ICS use, or } \\
\text { ICS + rescue CS }\end{array}$ & $\begin{array}{l}\text { HFA-BDP } \\
100 \mathrm{mcg} / \\
\text { day }\end{array}$ & - & $\begin{array}{l}\text { HFA-BDP } \\
100 \mathrm{mcg} / \\
\text { day }\end{array}$ & $\begin{array}{l}\text { HFA-BDP } \\
\text { 50/S100 } \\
2 \text { puffs prn }\end{array}$ & 44 \\
\hline \multicolumn{11}{|c|}{ Higher ICS dose during exacerbation in intermittent group } \\
\hline $\begin{array}{l}\text { Martinez } \\
\text { et al. } \\
(5) \\
2011\end{array}$ & 71 & 11 & $\begin{array}{l}\text { HFA-BDP } \\
100 \text { mcg/day } \\
\text { for } 4 \text { weeks + } \\
\text { prn albuterol }\end{array}$ & $\begin{array}{l}\text { Mild persistent asthma } \\
\text { defined as on average } \\
\text { more than } 2 \text { days a week } \\
\text { with symptoms (eg, } \\
\text { wheezing) or with use of } \\
\text { albuterol to control } \\
\text { symptoms, or more than } \\
2 \text { awakenings a night per } \\
\text { month when not using a } \\
\text { controller medication or, if } \\
\text { they had to use daily } \\
\text { controller treatment to } \\
\text { keep their disorder well } \\
\text { controlled }\end{array}$ & $\begin{array}{l}\text { Use of more than } 12 \text { puffs } \\
\text { of albuterol in } 24 \mathrm{~h} \text {, a } \\
\text { PEF less than } 70 \% \text { of } \\
\text { reference value before } \\
\text { albuterol use, symptoms } \\
\text { that led to inability to } \\
\text { sleep or do daily } \\
\text { activities for } 2 \text { or more } \\
\text { consecutive days, a } \\
\text { PEF less than } 50 \% \text { of } \\
\text { reference value despite } \\
\text { relief medication, ED visit } \\
\text { due to worsening of } \\
\text { asthma symptoms. } \\
\text { Excessive ICS use, or } \\
\text { ICS + rescue CS }\end{array}$ & $\begin{array}{l}\text { HFA-BDP } \\
100 \mathrm{mcg} / \\
\text { day }\end{array}$ & - & $\begin{array}{l}\text { HFA-BDP } \\
100 \mathrm{mcg} / \\
\text { day }\end{array}$ & $\begin{array}{l}\text { HFA-BDP } \\
50 / S 100 \\
2 \text { puffs prn }\end{array}$ & 44 \\
\hline
\end{tabular}


TABLE 9 - CONTINUED

\begin{tabular}{|c|c|c|c|c|c|c|c|c|c|c|}
\hline $\begin{array}{l}\text { Papi et al. } \\
\text { (6), } \\
2007\end{array}$ & 234 & 38 & $\begin{array}{l}\text { BDP } 500 \text { mcg/ } \\
\text { day x } 4 \text { weeks } \\
+ \text { prn albuterol }\end{array}$ & $\begin{array}{l}\text { Mild persistent asthma } \\
\text { according to published } \\
\text { guidelines for at least } \\
6 \text { months and } \\
\text { prebronchodilator } \mathrm{FEV}_{1} \text { of } \\
\geq 75 \% \text { of predicted, with } \\
\text { either an increase in } \mathrm{FEV}_{1} \\
\text { of } \geq 12 \% \text { post } \\
\text { bronchodilation or a } \\
\text { positive methacholine } \\
\text { challenge. }\end{array}$ & $\begin{array}{l}\text { Awakening at night } \\
\text { due to asthma or } \\
\text { as a decrease in the } \\
\text { morning PEF to more } \\
\text { than three additional } \\
\text { puffs per day of rescue } \\
\text { medication (either } \\
\text { albuterol or } \\
\text { beclomethasone + } \\
\text { albuterol) compared to } \\
\text { baseline for } 2 \text { or more } \\
\text { consecutive days or } \\
\text { both. (Single isolated } \\
\text { days on which mild } \\
\text { exacerbation occurred } \\
\text { were not counted.) }\end{array}$ & $\begin{array}{c}\text { BDP } \\
500 \text { mcg/ } \\
\text { day }\end{array}$ & - & $\begin{array}{l}\text { BDP } 500 \\
\text { mcg/day }\end{array}$ & $\begin{array}{l}\text { BDP 250/ } \\
\text { S100 } 1 \text { puff } \\
\text { prn }\end{array}$ & 24 \\
\hline $\begin{array}{l}\text { Papi et al. } \\
\text { (7), } \\
2009\end{array}$ & 220 & 2.4 & $\begin{array}{l}\text { Placebo } \\
\text { controller for } \\
2 \text { weeks + prn } \\
\text { albuterol } \\
2500 \text { mcg/ } \\
\text { nebule }\end{array}$ & $\begin{array}{l}\text { Frequent wheezing defined } \\
\text { as a documented history } \\
\text { of at least } 3 \text { episodes of } \\
\text { wheezing requiring } \\
\text { medical attention in the } \\
\text { previous } 6 \text { months. }\end{array}$ & $\begin{array}{l}\text { Episode of progressive } \\
\text { increase in shortness } \\
\text { of breath, cough or } \\
\text { wheezing (or } \\
\text { combination of these } \\
\text { symptoms) that required } \\
\text { a change in medication. } \\
\text { Exacerbation was } \\
\text { confirmed by study } \\
\text { investigator. }\end{array}$ & $\begin{array}{l}\text { BDP } 800 \\
\text { mcg/day }\end{array}$ & - & $\begin{array}{l}\text { BDP } 800 \\
\text { mcg/day }\end{array}$ & $\begin{array}{c}\text { BDP 800/ } \\
\text { S1600 } \\
1 \text { nebule prn }\end{array}$ & 12 \\
\hline $\begin{array}{l}\text { Zeiger et } \\
\text { al (10), } \\
2011\end{array}$ & 278 & $\begin{array}{l}\text { 12-53 } \\
\text { months }\end{array}$ & $\begin{array}{l}\text { Placebo } \\
\text { controller for } 2 \\
\text { weeks + prn } \\
\text { albuterol }\end{array}$ & $\begin{array}{l}\text { Frequent wheezing defined } \\
\text { as } \geq 4 \text { episodes of } \\
\text { wheezing (or } \geq 3 \text { episodes } \\
\text { of wheezing and controller } \\
\text { use for } \geq 3 \text { months) AND at } \\
\text { least one exacerbation } \\
\text { requiring the use of } \\
\text { systemic glucocorticoids, } \\
\text { urgent or emergency care, } \\
\text { or hospitalization in the } \\
\text { preceding year AND in the } \\
2 \text {-week run-in on placebo, } \\
<3 \text { days per week of } \\
\text { albuterol use AND } \\
<2 \text { nights with awakening }\end{array}$ & $\begin{array}{l}\text { Onset of symptoms or } \\
\text { signs of a respiratory } \\
\text { tract illness that they } \\
\text { identified as their } \\
\text { t child's usual starting } \\
\text { point before } \\
\text { development of } \\
\text { wheezing. These } \\
\text { 'individualized' } \\
\text { symptoms or signs - } \\
\text { reassessed at each } \\
\text { visit. }\end{array}$ & $\begin{array}{l}\text { BUD } \\
0.5 \mathrm{mg} / \\
\text { day }\end{array}$ & - & $\begin{array}{l}\text { BUD } 0.5 \\
\text { mg/day }\end{array}$ & $\begin{array}{l}\text { BUD } 1 \mathrm{mg} \\
\text { bid } \times 7 \text { days }\end{array}$ & 52 \\
\hline
\end{tabular}

bid Twice daily; BUD Budesonide; ED Emergency department; FEV Forced expiratory volume in 1 sec; HFA-BDP Hydrofluoroalkane beclomethasone dipropionate; ICS Inhaled corticosteroids; PEF Peak expiratory flow; prn As needed; S Salbutamol

Future research needs

Based on the evidence reviewed, the Clinical Assembly identifies the following research needs:

- Comparative evaluation of the efficacy and side effect profile of intermittent versus daily ICS using various ICS molecules separately: - in individuals with mild persistent asthma; and ○ in individuals with mild intermittent asthma.

\section{REFERENCES}

1. National Asthma Education and Prevention Program (NAEPP). Expert Panel Report 3: Guidelines for the diagnosis and management of asthma. Bethesda: National Heart, Lung, and Blood Institute (NHLBI), 2007.

2. Chauhan BF, Chartrand C, Ducharme FM. Intermittent versus daily inhaled corticosteroids for persistent asthma in children and adults [Protocol]. Cochrane Database of Syst Rev 2012(2);CD009611.

3. British Guideline on the Management of Asthma - A national clinical guideline. Scottish Intercollegiate Guidelines Network (SIGN); British Thoracic Society, 2011.

4. Global Strategy for Asthma Management and Prevention. Global Initiative for Asthma (GINA), 2009. <www.ginasthma.org>

5. Martinez FD, Chinchilli VM, Morgan WJ, et al. Use of beclomethasone dipropionate as rescue treatment for children with mild persistent asthma (TREXA): A randomised, double-blind, placebo-controlled trial. Lancet 2011;377:650-7.
6. Papi A, Canonica GW, Maestrelli P, et al. Rescue use of beclomethasone and albuterol in a single inhaler for mild asthma. N Engl J Med 2007;356:2040-52.

7. Papi A, Nicolini G, Baraldi E, et al; on behalf of the BEclomethasone and Salbutamol Treatment (BEST) for Children Study Group. Regular vs prn nebulized treatment in wheeze preschool children. Allergy 2009;64:1463-71.

8. Turpeinen M, Nikander K, Pelkonen AS, et al. Daily versus as-needed inhaled corticosteroid for mild persistent asthma (The Helsinki early intervention childhood asthma study). Arch Dis Child 2008;93:654-9.

9. Boushey HA, Sorkness CA, King TS, et al. National Heart, Lung, and Blood Institute's Asthma Clinical Research Network. Daily versus as-needed corticosteroids for mild persistent asthma. N Engl J Med 2005;352:1519-28.

10. Zeiger RS, Mauger D, Bacharier LB, et al. Daily or intermittent budesonide in preschool children with recurrent wheezing. N Engl J Med 2011;365:1990-2001.

11. Turpeinen M, Pelkonen AS, Nikander K, et al. Bone mineral density in children treated with daily or periodical inhaled budesonide: The Helsinki early intervention childhood asthma study. Pediatr Res 2010;68:169-73.

12. Turpeinen M, Raitio H, Pelkonen AS, et al. Skin thickness in children treated with daily or periodical inhaled budesonide for mild persistent asthma. The Helsinki early intervention childhood asthma study. Pediatr Res 2010;67:221-5. 


\section{SECTION IV}

\section{CONTROLLER THERAPY FOR ACTION PLANS}

\section{Part 2 - Escalating ICS}

\section{Question}

7. In individuals with asthma on ICS monotherapy, what is the efficacy of escalating the ICS dose as part of a written action plan for children (6 to 11 years of age) and adults (12 years of age and over) with acute loss of asthma control?

\section{Introduction}

Escalation of the usual dose of ICS by patients at the onset of an asthma exacerbation has been a popular recommendation for guided self-management as part of written action plans. Initially endorsed by several national and international consensus statements in the early 2000s, the publication of the first RCTs testing this strategy showed no evidence of effect (1-3). This has prompted several guideline groups to alter their original position (4-6). Recently, additional trials have suggested that higher than double dose ICS may have a beneficial effect $(7,8)$. Thus, we assessed the available evidence updated to November 2010 examining the efficacy of patient-initiated increase in the usual dose of ICS agents compared with no change in dose at the onset of loss of asthma control or upper respiratory tract infections on the severity and duration of the exacerbation.

\section{Methods}

Practice guidelines, systematic reviews of RCTs and RCTs comparing escalating ICS dose as part of a written action plan versus another strategy for acute loss of asthma control in preschoolers, children and adults were included. Outcomes of interest were use of systemic steroids, ED visits, hospitalization, duration of symptoms, quality of life and adverse effects.

Asthma search terms were combined with the following $\mathrm{MeSH}$ and text words in OVID MEDLINE and EMBASE to identify systematic reviews: exacerbat: or acut: or status: or sever: or emergenc: or crisis: or worsen: or attack: and terms for ICS. Systematic reviews were included if they were published in 2005 or later. RCTs were included if they were published after the search date of the most recent systematic review.

After the identification of a relevant systematic review of RCTs published in October 2009 (9), the same search strategy was used to update the literature search for additional trials until November 2010 in MEDLINE and EMBASE (Table 10). No new trials were identified.

\section{Key evidence}

Three guidelines and a Cochrane systematic review were selected to inform the recommendations $(4-6,9)$

\section{Guidelines}

Three guidelines addressed escalating the ICS dose as part of a written action plan. Based on two RCTs $(1,2)$, both the NHLBI and GINA guidelines concluded that doubling the dose of ICS was insufficient and no longer recommend this approach $(4,6)$. Referring to their 2002 guidelines, the 2011 BTS concluded the following:

Although recommended for both adults and children in previous guidelines and as part of asthma action plans, doubling the dose at the time of an exacerbation is of unproven value.

According to the 2007 NHLBI and 2011 BTS, "quadrupling ICS dose may be effective" and "quintupling dose from low dose BDP decreases severity of exacerbations in adults," respectively quoting the same trial (7). GINA reported on the "emerging evidence that quadrupling the dose of inhaled glucocorticosteroid might be effective when asthma control starts to deteriorate, if doubling the dose does not work" (4). Specifically, GINA stated that:
A four-fold or greater increase has been demonstrated to be equivalent to a short course of oral glucocorticosteroids in adult patients with an acute deterioration.

The statement was based on one placebo-controlled trial of quadrupling the dose of ICS (8) and a narrative review of various patient and physician-initiated strategies to treat exacerbations in different settings (10). No head-to-head trial was cited comparing patient escalation/initiation of high-dose ICS versus systemic corticosteroids as pre-emptive treatment; presumably, it was referring to a comparative study of high-dose fluticasone versus prednisone on discharge from the ED (11). GINA concluded that "The higher dose should be maintained for 7-14 days but more research is needed in both adults and children to standardize the approach;" but provided no reference (4).

\section{Systematic review}

The systematic review by Quon et al. (9), identified five relevant trials of patients who were on daily ICS, including one pediatric trial of 28 children and four adult trials $(1,2,7,8)$ totalling 1296 adults (Table 10). All identified trials were previously cited in the abovementioned guidelines. Overall, 435 exacerbations were managed with the step-up therapy. Three studies examined a doubling ICS dose from 50 to $1000 \mathrm{mcg} /$ day, to 100 to $2000 \mathrm{mcg} /$ day of hydrofluroalkane beclomethasone dipropionate or equivalent (HFA-BDPeq) $(1,2,12)$. Two adult placebo-controlled trials examining quadrupling (8) or quintupling (7) the ICS dose from 100 to $500 \mathrm{mcg} /$ day, to 200 to $1000 \mathrm{mcg} / \mathrm{day}$ of (HFA-BDPeq); one of these two trials also included adolescents (16 years of age and over) (7). One trial had a third group testing daily high dose ( $800 \mathrm{mcg} /$ day) of budesonide (7).

In adults with asthma on daily maintenance ICS, a self-initiated ICS increase to 100 to $2000 \mathrm{mcg} /$ day HFA-BDPeq at the onset of an exacerbation was not associated with a statistically significant reduction in the risk of exacerbations requiring rescue systemic corticosteroids (OR 0.85 [95\% CI 0.58 to 1.26]); there was no significant group difference between those who doubled (OR 1.07 [95\% CI 0.65 to 1.78]) compared with those who quadrupled or quintupled (OR 0.60 [95\% CI 0.32 to 1.13$]$ ) their ICS dose (Figure 1) (9). However, in a subgroup analysis of patients who used the study drug at least once (35\% of participants), quadrupling or quintupling the ICS dose was significantly more effective in reducing patient-initiated systemic corticosteroids (OR 0.27 [95\% CI 0.11 to 0.67]) compared with doubling (OR 1.02 [95\% CI 0.44 to 2.34]) (Figure 2) (9). There were insufficient data to examine other outcomes. More research is needed to determine whether age group, smoking status, maintenance ICS or achieved ICS dose, and number of days before stepping up therapy modify the effectiveness of increased ICS doses at the onset of asthma exacerbations, and whether this strategy has any impact on impact or duration of episodes, ED visits, hospital admissions, and adverse effects. The authors concluded the following (9):

There is insufficient evidence to confirm the efficacy of the widespread practice of increasing the dose of corticosteroids in the yellow zone (loss of control) of a written action plan. Equally the wide confidence intervals mean that the results cannot rule out possible benefits from this approach.

Of note, from the small pediatric trial of 28 children (9), there is scarce evidence to draw any conclusion regarding doubling - and none regarding quadrupling - the dose of ICS in children.

\section{Conclusions}

In children and adults already receiving ICS, increasing the dose of ICS (to between 100 and $2000 \mathrm{mcg} /$ day HFA-BDPeq) at the time of acute loss of asthma control has not been demonstrated to be effective to reduce the need for patient-initiated systemic corticosteroids, ED visits, hospital admissions, intensity or duration of episode.

When the fold-increase in ICS doses is considered, there is no evidence of benefit from doubling from 50 to $1000 \mathrm{mcg} / \mathrm{day}$, to 100 to $2000 \mathrm{mcg} / \mathrm{day}$ of HFA-BDPeq. There is limited evidence, however, 
TABLE 10

Characteristics of trials of escalating ICS as part of a written action plan in children and adults

\begin{tabular}{|c|c|c|c|c|c|c|c|c|c|c|c|c|c|c|c|}
\hline \multirow{3}{*}{\multicolumn{2}{|c|}{$\begin{array}{l}\text { Trial (ref) } \quad n \\
\text { Double doses }\end{array}$}} & \multirow{3}{*}{$\begin{array}{c}\text { Patients } \\
\text { started } \\
\text {, the study } \\
\text { inhaler }\end{array}$} & \multirow{3}{*}{$\begin{array}{c}\text { Mean age, } \\
\text { years }\end{array}$} & \multirow[b]{2}{*}{$\begin{array}{c}\text { Baseline } \\
\text { FEV }_{1} \text {, } \\
\text { \% predicted }\end{array}$} & \multirow[b]{2}{*}{$\begin{array}{l}\text { Asthma } \\
\text { control }\end{array}$} & \multirow[b]{2}{*}{$\begin{array}{l}\text { Usual ICS } \\
\text { dose, } \\
\text { mcg/day* }\end{array}$} & \multicolumn{5}{|c|}{ Step-up inhaled corticosteroids during exacerbations* } & \multicolumn{2}{|c|}{ At home rescue medication } & \multirow{3}{*}{$\begin{array}{c}\text { Duration } \\
\text { of } \\
\text { follow-up, } \\
\text { months }\end{array}$} & \multirow{3}{*}{$\begin{array}{l}\text { Intention } \\
\text { to treat } \\
\text { analysis }\end{array}$} \\
\hline & & & & & & & Criteria & Drug $^{\dagger}$ & $\begin{array}{l}\text { Intervention } \\
\text { group dose, } \\
\text { mcg/day* }\end{array}$ & $\begin{array}{l}\text { Control } \\
\text { group } \\
\text { dose, } \\
\text { mcg/day }\end{array}$ & $\begin{array}{c}\text { Duration, } \\
\text { days }\end{array}$ & $\begin{array}{c}\text { Beta }_{2} \\
\text {-agonists }\end{array}$ & $\begin{array}{l}\text { Oral } \\
\text { cortico- } \\
\text { steroids }\end{array}$ & & \\
\hline & & & & & & & & & & & & & & & \\
\hline $\begin{array}{l}\text { Garrett } \\
\text { et al. (12) }\end{array}$ & 28 & 18 & $\begin{array}{c}9 \text { (range } \\
6-14 \\
\text { years) }\end{array}$ & 99 & NR & $\leq 400$ & $\begin{array}{l}\text { Fall in PEF } \\
\text { to } \leq 80 \% \text { of } \\
\text { baseline for } \\
\geq 24 \text { hours or } \\
\text { woken at } \\
\text { night with } \\
\text { cough or } \\
\text { wheeze or } \\
\text { bronchodila- } \\
\text { tor require- } \\
\text { ment } \\
\text { doubled }\end{array}$ & $\begin{array}{l}\text { CFC- } \\
\text { BDP }\end{array}$ & $\leq 800$ & $\leq 400$ & 3 & Salbutamol & No & 6 & No \\
\hline $\begin{array}{l}\text { Harrison } \\
\text { et al. (2) }\end{array}$ & 390 & 207 & $\begin{array}{c}49 \\
(\geq 13 \\
\text { years })\end{array}$ & 80 & $\begin{array}{l}\geq 1 \text { exacerbation } \\
\text { requiring rescue } \\
\text { oral corticoster- } \\
\text { oids or double } \\
\text { dose of ICS in } \\
\text { past } 12 \text { months }\end{array}$ & 50-1000 & $\begin{array}{l}15 \% \text { fall in } \\
\text { PEF from } \\
\text { run-in or } \\
\text { 1-point } \\
\text { increase in } \\
\text { the 4-point } \\
\text { symptom } \\
\text { score }\end{array}$ & $\begin{array}{l}\text { CFC- } \\
\text { BDP }\end{array}$ & $100-2000$ & $50-1000$ & 14 days & NR & $\begin{array}{l}\text { Prednisolone } \\
30 \mathrm{mg} \text { daily } \\
\text { for } 10 \text { days if } \\
\text { fall in PEF } \\
\geq 40 \% \text { from } \\
\quad \text { run-in }\end{array}$ & f & Yes \\
\hline $\begin{array}{l}\text { Oborne } \\
\text { et al. (8) }\end{array}$ & 403 & 94 & $\begin{array}{c}54 \\
(\geq 16 \\
\text { years) }\end{array}$ & 83 & $\begin{array}{l}\geq 1 \text { exacerbation } \\
\text { requiring rescue } \\
\text { oral } \\
\text { corticosteroids } \\
\text { or increased } \\
\text { ICS dose in } \\
\text { past } 12 \text { months }\end{array}$ & 100-500 & $\begin{array}{l}\text { Signs of } \\
\text { upper respi- } \\
\text { ratory tract } \\
\text { infection or } \\
\geq 15 \% \text { fall in } \\
\text { PEF from } \\
\text { run-in period } \\
\text { for } 2 \text { consec- } \\
\text { utive days or } \\
\geq 30 \% \text { fall } \\
1 \text { day from } \\
\text { run-in }\end{array}$ & $\begin{array}{c}\text { BDP- } \\
\text { eq }\end{array}$ & $200-1000$ & $100-500$ & 7 to 14 & NR & $\begin{array}{l}\text { Prednisone } \\
30 \text { mg daily } \\
\text { under } \\
\text { medical } \\
\text { advice, if fall } \\
\text { in PEF by } \\
\geq 40 \% \text {, or if } \\
\text { would usually } \\
\text { start } \\
\text { prednisolone }\end{array}$ & $y$ & Yes \\
\hline
\end{tabular}

${ }^{*}$ Dose of inhaled corticosteroids reported in HFA-propelled beclomethasone-equivalent (approximated from the dose and distribution of inhaled corticosteroids [ICS] in each group); ${ }^{\dagger}$ Four inhaled corticosteroids: Beclomethasone (BDP); Budesonide (BUD). Beclomethasone was propelled by chlorofluorocarbon (CFC); FEV ${ }_{1}$ Forced expiratory volume in 1 sec (reported in \% predicted ['unless otherwise specified in litres]); NR Not reported; PEF Peak expiratory flow; ref Reference 


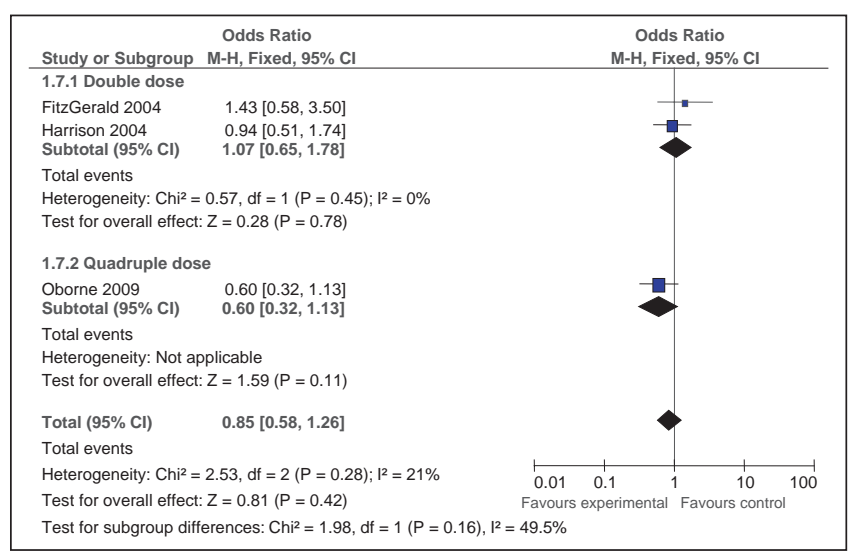

Figure 1) Pooled OR of patients experiencing one or more exacerbations requiring systemic glucocorticoids, comparing maintenance inhaled corticosteroid (ICS) dose to increased ICS dose during exacerbations and analysed by intention-to-treat. Trials are stratified according to the fold-increase in ICS dose from baseline at the onset of exacerbation (double dose versus quadruple dose). The width of the horizontal line represents the 95\% CI around the point estimate (black square). The size of the point estimate represents the relative weight (\% weight) of each trial in the pooled summary estimate (diamond). The vertical line is the line of no effect $(O R=1.0)$. (C) Cochrane Collaboration. Figure reproduced with permission from the authors and publisher

to indicate that adults on an adequate dose of ICS who required recent rescue systemic corticosteroids or dose changes during exacerbations may benefit from quadrupling or quintupling the ICS dose (from 100 to $500 \mathrm{mcg} / \mathrm{day}$, to 200 to $1000 \mathrm{mcg} /$ day) at the time of acute loss of control to reduce the risk for patient-initiated systemic corticosteroids. There is insufficient evidence to assess the impact on duration of episodes, ED visits, hospital admissions and safety profile. Of note, it was not possible to determine from the systematic review whether the dose increase or the maximal ICS dose reached explains the apparent benefit of a four- or fivefold increase. In addition, there is insufficient evidence to draw firm conclusions regarding the safety profile of a single or repeated increase in the dose of ICS. Moreover, use of double or higher dose of ICS represents 'off label' use that is not recommended in any product monographs of ICS.

There is no current evidence that children already receiving ICS benefit from increasing, by four-fold or more, the dose of ICS at the onset of an episode of acute loss of control. There is evidence in children that pre-emptive high-dose ICS at onset of a viral illness reduces the risk of physician-initiated rescue oral steroids at the cost of a small negative impact on growth (13). The data are derived from a trial of preschool-age children not receiving daily ICS, and it is not clear how it would apply to school-age children receiving daily maintenance ICS.

In summary, although self-management education programs that include provision of a written action plan have demonstrated efficacy, evidence of the efficacy of escalating ICS as part of written action plans is limited.

\section{Question 7}

In individuials with asthma on ICS monotherapy, what is the efficacy of escalating the ICS dose as part of a written action plan for children (6 to 11 years of age) and adults (12 years of age and over) with acute loss of asthma control?

The following recommendations are based on evidence from three guidelines, one systematic review and the consensus of the CTS Asthma Clinical Assembly Expert Panel.

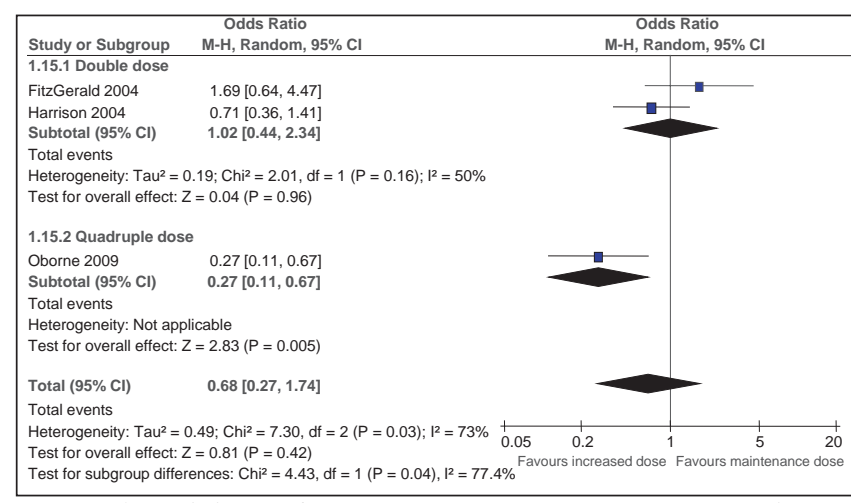

Figure 2) Pooled OR of patients experiencing one or more exacerbations requiring systemic glucocorticoids, comparing maintenance inhaled corticosteroid (ICS) dose to increased ICS dose during exacerbations; this subgroup analysis focuses only on patients who used the study drug at least once (35\% of participants) during the study period. Trials are stratified according to the fold-increase in ICS dose from baseline at the onset of exacerbation (double dose versus quadruple dose). The width of the horizontal line represents the 95\% CI around the point estimate (black square). The size of the point estimate represents the relative weight (\% weight) of each trial in the pooled summary estimate. The vertical line is the line of no effect $(\mathrm{OR}=1.0)$. (C) Cochrane Collaboration. Figure reproduced with permission from the authors and publisher

\section{Recommendation 7A}

We suggest that children and adults already on maintenance ICS monotherapy do not routinely double the dose of their ICS as part of a written action plan (or self-management plan) at the onset of an episode of acute loss of asthma control. (GRADE 2B)

\section{Recommendation 7B}

We suggest a trial of increasing the ICS maintenance dose by fouror five-fold for 7 to 14 days as part of an action plan (or self-management plan) for acute loss of asthma control in adults with a history of severe exacerbations in the past year requiring systemic steroids. (GRADE 2C)

\section{Recommendation 7C}

We recommend that children on maintenance ICS monotherapy do not routinely increase by four-fold or more the dose of their ICS as part of a self-management plan for acute loss of asthma control. (Consensus) There is no evidence of efficacy and there is evidence of potential harm.

\section{Future research needs}

Based on the evidence reviewed, the Clinical Assembly identifies the following research needs:

- to determine whether the fold-increase in ICS dose or actual ICS dose achieved determines the efficacy of ICS escalation within written action plans;

- to determine the efficacy of escalating ICS in individuals on maintenance ICS/LABA combination therapy;

- to determine the efficacy of adding ICS as part of a written action plan in individuals on LTRA monotherapy;

- to explore the safety and efficacy of a four-fold increase or more in ICS dose in children; and

- additional studies on a four-fold or greater increase in ICS dose in adults with specific focus on the determinants of effectiveness and maximum dose.

\section{REFERENCES}

1. Fitzgerald JM, Becker A, Sears MR, et al. Doubling the dose of budesonide versus maintenance treatment in asthma exacerbations. Thorax 2004;59:550-6. 
2. Harrison TW, Oborne J, Newton S, Tattersfield AE. Doubling the dose of inhaled corticosteroid to prevent asthma exacerbations: Randomised controlled trial. Lancet 2004:363:271-5.

3. Rice-McDonald G, Bowler S, Staines G, Mitchell C. Doubling daily inhaled corticosteroid dose is ineffective in mild to moderately severe attacks of asthma in adults. Intern Med J 2005;35:693-8.

4. Global Strategy for Asthma Management and Prevention. Global Initiative for Asthma (GINA), 2010. <www.ginasthma.org>

5. British Guideline on the Management of Asthma - a national clinical guideline. Scottish Intercollegiate Guidelines Network (SIGN); British Thoracic Society, 2011.

6. National Asthma Education and Prevention Program (NAEPP). Expert Panel Report 3: Guidelines for the diagnosis and management of asthma. Bethesda: National Heart, Lung, and Blood Institute (NHLBI), 2007.

7. Foresi A, Morelli MC, Catena E. Low-dose budesonide with the addition of an increased dose during exacerbations is effective in long-term asthma control. On behalf of the Italian Study Group. Chest 2000;117:440-6.

8. Oborne J, Mortimer K, Hubbard RB, Tattersfield AE, Harrison TW. Quadrupling the dose of inhaled corticosteroid to prevent asthma exacerbations: A randomized, double-blind, placebo-controlled, parallel-group clinical trial. Am J Respir Crit Care Med 2009; 180:598-602.

9. Quon BS, FitzGerald JM, Lemiere C, Shahidi N, Ducharme FM. Increased versus stable doses of inhaled corticosteroids for exacerbations of chronic asthma in adults and children. Cochrane Database of Syst Rev 2010(10):CD007524.

10. Reddel HK, Barnes DJ. Pharmacological strategies for selfmanagement of asthma exacerbations. Eur Respir J 2006;28:182-99.

11. Levy ML, Stevenson C, Maslen T. Comparison of short courses of oral prednisolone and fluticasone propionate in the treatment of adults with acute exacerbations of asthma in primary care. Thorax 1996;51:1087-92.

12. Garrett J, Williams S, Wong C, Holdaway D. Treatment of acute asthmatic exacerbations with an increased dose of inhaled steroid. Arch Dis Child 1998;79:12-7.

13. Ducharme FM, Lemire C, Noya FJ, et al. Preemptive use of high-dose fluticasone for virus-induced wheezing in young children. N Engl J Med 2009;360:339-53.

\section{SECTION IV}

\section{CONTROLLER THERAPY FOR ACTION PLANS}

\section{Part 3 - Fixed-dose ICS/LABA Combination}

\section{Question}

8. As part of a self-management plan in children (6 to 11 years of age) and adults (12 years of age and over) experiencing an acute loss of asthma control, what is the efficacy of using a FABA reliever and:

a. starting a fixed-dose ICS/LABA combination in individuals on who are on no maintenance therapy or ICS monotherapy?

b. escalating to a higher predetermined fixed dose of an ICS/LABA combination* compared with usual ICS/LABA dose in individuals on an ICS/LABA combination as controller therapy?

c. escalating to a higher predetermined fixed dose of ICS/LABA combination* compared with escalating only the ICS dose (either by addition of supplemental ICS to a fixed-dose ICS/ LABA or escalating to a higher ICS dose of a fixed-dose ICS/ LABA) in individuals on ICS/LABA combination as controller therapy?

*NOTE: for BUD/FORM this has been referred to as an adjustable maintenance dose strategy (BUD/FORM-AMD) (See Table 5).

\section{Introduction}

Currently in Canada, there are three combinations of ICS and LABA available for use as regular maintenance controller therapy in asthma: fluticasone plus salmeterol, BUD plus formoterol (BUD/FORM and mometasone plus FORM). The role of ICS/LABA combination products for adjunct therapy of chronic asthma is well established, but their role as part of action plans for acute loss of asthma control has not been addressed in previous guidelines.

To escalate controller therapy as part of self-management action plans in individuals on fixed-dose ICS/LABA combinations, it has become common practice to switch from a single inhaler of a lowdose ICS/LABA to a higher ICS strength single inhaler, or to add in supplemental ICS in a separate inhaler. In individuals who are on fixed-dose BUD/FORM, another option is to switch to BUD/FORM adjustable maintenance dose (BUD/FORM-AMD) strategy (thereby increasing both the ICS and LABA dose [Table 5]). The efficacy of these approaches (which typically at least double the ICS dose plus or minus increase the LABA dose) as part of a written self-management action plan is uncertain. Furthermore, the efficacy introducing an ICS/LABA combination in the yellow zone of an action plan should be clarified.

We reviewed the evidence examining the efficacy of: i) starting an ICS/LABA in individuals who are on no maintenance controller or ICS monotherapy compared with the usual maintenance dose of controller (if any); and ii) escalating to a higher fixed-dose of ICS/LABA (including BUD/FORM-AMD), with FABA as reliever, compared with the usual maintenance dose of ICS/LABA or higher ICS dose of an ICS/LABA combination with FABA as reliever.

\section{Methods}

Practice guidelines, systematic reviews of RCTs and RCTs addressing one or more of the clinical questions as part of a self-management strategy in children and adults with acute loss of asthma control were included. Outcomes of interest were use of systemic steroids, ED visits, hospitalization, duration of symptoms, quality of life and adverse effects.

Asthma search terms were combined with the following $\mathrm{MeSH}$ and text words in OVID MEDLINE and EMBASE to identify systematic reviews: exacerbat: or acut: or status: or sever: or emergenc: or crisis: or worsen: or attack: and terms for ICS and LABA. Systematic reviews were included if they were published in 2005 or later.

The Cochrane Airways Group "asthma and wheez*" database was searched from September 2008 to September 2011 using the search strategy of the most recent systematic review to identify any new RCTs. The following search terms were used: "single inhaler therapy" or SiT or SMART or relie: or "as need:" or as-need: or prn or flexible or titrat: AND combin: or symbicort or viani or steroid: or corticosteroid: or ICS or budesonide or BUD or Pulmicort or beclomethasone or BDP or becotide AND "beta agonist:" or "adrenergic beta-agonist:" or formoterol or eformoterol or oxis or foradil.

\section{Key evidence}

No guidelines addressed this question. One systematic review of 11 trials, and three publications from two primary trials informed the recommendations (Tables 11 and 12).

\section{Systematic reviews and RCTs}

After identification of relevant systematic reviews of RCTs published by April 2009, we used the same search strategy as used in the systematic reviews to update the literature search for additional trials until September 2011 using the CAGR "asthma and wheez*" database (Table 12). No new systematic reviews were identified. Three new publications pertaining to two trials which addressed this topic were identified (1-3). Post hoc subgroup or pooled analyses of previously published trials (4) were excluded due to risk of bias and overrepresentation.

The results of the literature search regarding the initiation or dose escalation of ICS/LABA combinations as controller therapy within self-management plans were examined according to the maintenance controller therapy. 
TABLE 11

Evidence/trials evaluating the efficacy of an ICS/LABA combination as a controller within self-management plans

\begin{tabular}{|c|c|}
\hline \multirow[b]{2}{*}{$\begin{array}{l}\text { Maintenance } \\
\text { treatment }\end{array}$} & Intervention \\
\hline & $\begin{array}{l}\text { Initiation or escalation of ICS/LABA controller } \\
\text { versus usual controller with FABA as reliever }\end{array}$ \\
\hline No ICS & No trials \\
\hline ICS monotherapy & No trials \\
\hline \multirow{9}{*}{ Fixed-dose ICS/LABA } & Compared with usual ICS/LABA dose \\
\hline & Edwards et al. (5), 2007 \\
\hline & - 11 trials of BUD/FORM-AMD \\
\hline & Busse et al. (1), 2008 \\
\hline & Ige et al. (3), 2010 \\
\hline & O'Connor et al. (2), 2010 \\
\hline & Compared with escalating ICS dose in the \\
\hline & fixed-dose ICS/LABA \\
\hline & - No trials \\
\hline
\end{tabular}

FABA Fast-acting beta $_{2}$-agonist; ICS Inhaled corticosteroids; LABA Longacting beta ${ }_{2}$-agonist

a) No maintenance therapy or ICS monotherapy: initiation of ICS/LABA controller

No systematic reviews or trials were identified evaluating the efficacy of initiation of a combination of ICS/LABA as part of self-management plans for acute loss of asthma control in individuals on no maintenance therapy or on ICS monotherapy.

b) Maintenance fixed-dose ICS/LABA: Escalation of ICS/LABA controller compared with usual ICS/LABA dose, with FABA as reliever One systematic review and meta-analysis by Edwards et al. (5) identified 11 open label trials (including two unpublished trials) of patients 16 years of age and over $(n=11,932)$ with moderate to severe asthma comparing BUD/FORM-AMD (ranging from two to eight inhalations per day) to the usual fixed-dose BUD/FORM maintenance therapy using the same inhaler strength (either $100 \mathrm{mcg} / 6 \mathrm{mcg}$ or $200 \mathrm{mcg} / 6 \mathrm{mcg}$ in both treatment arms).

There was no significant difference comparing AMD to fixed maintenance dosing of BUD/FORM (with a SABA reliever in both groups) in the composite outcome of treatment failure, defined as one or more of: hospitalizations; ED visits requiring nebulized beta-agonist or systemic corticosteroids; serious exacerbations needing treatment other than an oral steroid; and lack of efficacy of trial medication requiring change in asthma medication or withdrawal from the trial (RR 0.88 [95\% CI 0.77 to 1.02]) (5). There was a reduced risk of hospitalizations/ED visits (RR 0.72 [95\% CI 0.52 to 0.99]) and reduced use of oral steroids (RR 0.81 [95\% CI 0.70 to 0.95]) favouring AMD. There were no significant differences in all-cause withdrawals (RR 1.01 [95\% CI0.91 to 1.12]) or withdrawals due to SAEs (RR 0.85 [95\% CI 0.68 to 1.07$]$ ). This meta-analysis was sponsored by a pharmaceutical company and authored by its employees. The authors acknowledge a number of limitations, particularly the use of a surrogate measure of serious exacerbations in several trials that did not report the primary outcome of treatment failure and lack of blinding due to the nature of the intervention. The authors of the systematic review concluded that BUD/FORM-AMD demonstrates “....important advantages over fixed dosing in relation to exacerbation prevention and reduced treatment load" (5).

Three publications of two randomized, open-label trials were identified comparing BUD/FORM-AMD to fixed doses of BUD/ FORM (3) or fixed doses of fluticasone propionate/salmeterol (FP/ SM) $(1,2)$. Busse et al. (1) found that BUD/FORM-AMD was comparable with fixed-doses of FP/SM in all efficacy outcomes including exacerbations, ED visits, urgent office visits, spirometry, symptom- free days, awakening-free nights, rescue medication-free days, asthma control, quality of life, satisfaction. The subgroup analysis of the adults ( $\geq 18$ years of age) from this trial found no significant differences in any efficacy outcome. The only identified differences were in some pairwise comparisons (such as quality of life and satisfaction) but the changes in quality of life were not clinically relevant in magnitude and there was no correction for multiple testing (2). The second trial by Ige et al. (3) did not report on systemic steroids, ED visits or hospitalizations, and found no significant group difference in night-time awakenings per week in both groups. In both trials, significantly less ICS (approximately three fewer inhalations/day, equating to approximately $480 \mathrm{mcg}$ BUD) was used in the BUD/ FORM-AMD compared with usual maintenance BUD/FORM dose groups. There was no significant group difference in adverse health events effects in either trial.

c) Maintenance fixed-dose ICS/LABA: Escalation of ICS/LABA compared with escalation of ICS dose only (either by addition of supplemental ICS to the fixed-dose ICS/LABA or change to higher ICS dose of fixed-dose ICS/LABA), with FABA as reliever

No systematic reviews or trials were identified comparing escalating ICS/LABA (eg, BUD/FORM-AMD) to the common non-evidencebased practice of either adding supplemental ICS to a fixed-dose ICS/ LABA or switching to a higher ICS dose of fixed-dose ICS/LABA as part of self-management plans for acute loss of control.

\section{Conclusions}

The Panel examined the evidence for starting or escalating an ICS/ LABA combination for acute loss of asthma control within selfmanagement plans. No trials were identified that evaluated the efficacy of starting an ICS/LABA as a self-management strategy for acute loss of asthma control in patients who are not on maintenance therapy or who are on ICS monotherapy, and guidelines do not address this question. Most of the available evidence compared the use of a combination product of BUD/FORM in an AMD strategy with fixed doses of ICS/LABA in the same or separate inhalers, with FABA as a reliever in both groups.

No guidelines addressed BUD/FORM-AMD or escalating to higher fixed doses of other ICS/LABA combination products within selfmanagement action plans. Our recommendations are based on one published systematic review of 11 clinical trials (5). There is evidence that $\mathrm{AMD}$ reduces the risk of exacerbations requiring oral corticosteroids or ED visits, compared with fixed maintenance doses of BUD/FORM in individuals 16 years of age and over. However, the quality of this evidence is limited due to varying definitions of exacerbations, inconsistent reporting of outcomes (and, therefore, use of surrogate outcomes in the meta-analysis), and open-label (ie, unblinded) study designs. We did not identify any systematic reviews of AMD in individuals less than 15 years of age, precluding a formal recommendation for individuals 12 to 15 years of age in Canada. We also noted that none of the trials in the systematic review compared AMD with current standard of care (ie, escalation of ICS dose in the control arm), which may be the more relevant comparator and is an area for future research.

In summary, there is no evidence to support initiation of ICS/ LABA for acute loss of asthma control in individuals 12 years of age and over who are on no maintenance therapy or ICS monotherapy. In patients on maintenance ICS/LABA, evidence at risk for bias supports the efficacy of BUD/FORM-AMD compared with the usual fixed maintenance doses of ICS/LABA to reduce rescue oral corticosteroids use, hospitalization and average daily dose of ICS. There is no evidence to support the addition of another ICS inhaler or switching to a higher ICS-containing strength of an ICS/LABA inhaler during acute loss of asthma control. This is an important area for future research. Until additional evidence is available, consideration could be given to fourfold or greater increase in ICS dose or a short course of systemic steroid. 
TABLE 12

Characteristics of controlled trials of adjustable BUD/FORM compared with fixed doses of ICS/LABA

\begin{tabular}{|c|c|c|c|c|c|c|c|}
\hline $\begin{array}{l}\text { Author (ref), } \\
\text { year }\end{array}$ & $\mathbf{n}$ & Design & Population & Intervention & Control & Duration & Outcomes \\
\hline $\begin{array}{l}\text { Busse et al. (1), } \\
2008\end{array}$ & 1225 & $\begin{array}{l}\text { Randomized } \\
\text { open-label } \\
\text { multicentre } \\
\text { trial }\end{array}$ & $\begin{array}{l}\text { Age } \geq 12, \text { asthma for } \\
\geq 6 \text { months, pre- } \\
\text { bronchodilator } \\
\mathrm{FEV}_{1} \geq 50 \% \\
\text { predicted. On } \\
\text { medium-dose ICS } \\
\text { or ICS/LABA } \\
\text { combination for } \\
12 \text { weeks or more } \\
\text { before screening, } \\
\text { from } 145 \text { centres in } \\
\text { the United States }\end{array}$ & $\begin{array}{l}\text { BUD/FORM-AMD } \\
\text { (adjustable from } 320 \mathrm{mcg} \\
/ 9 \mathrm{mcg} \text { twice daily to } \\
320 \mathrm{mcg} / 9 \mathrm{mcg} \text { once } \\
\text { daily to } 640 \mathrm{mcg} / 18 \mathrm{mcg} \\
\text { twice daily }\end{array}$ & $\begin{array}{l}2 \text { comparators: } \\
\text { 1) FD FP/SM } 250 \\
\text { mcg/50 mcg twice } \\
\text { daily; } \\
\text { 2) FD BUD/FORM } \\
160 \text { mcg/4.5 mcg, } \\
2 \text { inh twice daily + } \\
\text { as needed SABA } \\
\text { in both groups }\end{array}$ & 6 months & $\begin{array}{l}\text { No significant differences between } \\
\text { groups in use of systemic steroids, } \\
\text { ED visits or hospitalizations. } \\
\text { Patients in BUD/FORM-AMD used, } \\
\text { on average, } 3.0 \text { fewer inhalations } \\
\text { of study medication per day than } \\
\text { patients in the FD BUD/FORM } \\
\text { (P<0.001). No SAEs. No signifiant } \\
\text { difference in AEs. }\end{array}$ \\
\hline $\begin{array}{l}\text { O'Connor et al. } \\
\text { (2), } 2010 \\
\text { Note: } \\
\text { Secondary } \\
\text { publication of } \\
\text { Busse et al } \\
\text { (1), 2008, } \\
\text { reporting on } \\
\text { "patient out- } \\
\text { comes" }\end{array}$ & 1048 & As above & $\begin{array}{l}\text { Age } \geq 18 \text { years, } \\
\text { moderate to severe } \\
\text { asthma. (Note: } \\
\text { Busse et al. [1]) } \\
\text { 2008) publication } \\
\text { were of results of } \\
\text { individuals } \\
12 \text { years of age } \\
\text { and over, this is a } \\
\text { subgroup analysis } \\
\text { of individuals } \\
18 \text { years of age } \\
\text { and over) }\end{array}$ & As above & As above & As above & $\begin{array}{l}\text { Use of systemic steroids, ED visits } \\
\text { and hospitalizations not reported. } \\
\text { No clinically important difference in } \\
\text { AQLQ scores. NS difference in } \\
\text { ACQ. AMD vs. FD FP/SALM: } \\
\text { Greater satisfaction overall } \\
\text { (P=0.020) and for dosing manage- } \\
\text { ment (P<0.001). AMD vs FD BUD/ } \\
\text { FORM: Greater satisfaction for } \\
\text { daily activity, leisure activity and } \\
\text { dosing management (P<0.048). } \\
\text { Higher proportion in both BUD/ } \\
\text { FORM groups reported “..feel your } \\
\text { study medication begin to work } \\
\text { right away.” (71\% and } 71 \% \text { vs } \\
59 \% ; P<0.002) \text {. AEs not reported. }\end{array}$ \\
\hline $\begin{array}{l}\text { Ige et al. (3), } \\
2010\end{array}$ & 54 & $\begin{array}{l}\text { Randomized } \\
\text { open-label } \\
\text { parallel } \\
\text { group }\end{array}$ & $\begin{array}{l}\text { Age } \geq 18 \text {, asthma, on } \\
>400 \text { mcg/day ICS } \\
\times 4 \text { weeks, plus } \\
\text { need for combina- } \\
\text { tion therapy due to } \\
\text { either prior good } \\
\text { response OR sub- } \\
\text { optimal control by } \\
\text { GINA criteria } \\
\text { despite ICS + } \\
\text { LABA; FEV } 1 \text { or } \\
\text { PEF < } 80 \% \text { pre- } \\
\text { dicted, from } \\
\text { Nigeria. }\end{array}$ & $\begin{array}{l}\text { BUD/FORM-AMD + prn } \\
\text { SABA. Increase to } 4 \text { inh } \\
\text { twice daily } \times 14 \text { days if } \\
\text { patients needed SABA } \\
3 \times \text { /day for } 2 \text { consecutive } \\
\text { days OR had night-time } \\
\text { awakenings; step down } \\
\text { from } 4 \text { inh twice daily to } \\
2 \text { inhalations twice daily, } \\
\text { then to } 1 \text { inh twice daily if } \\
\text { unaware of symptoms } \\
\text { and SABA need } \leq 2 \text { days } \\
\text { in previous week and no } \\
\text { night-time awakenings }\end{array}$ & $\begin{array}{l}2 \text { comparators: } \\
\text { 1) FD BUD/FORM } \\
80 \mathrm{mcg} / \\
4.5 \mathrm{mcg} \\
2 \text { inh twice daily } \\
\text { 2) BUD/FORM } \\
160 \mathrm{mcg} / 4.5 \mathrm{mcg} \text {, } \\
2 \text { inh twice daily + } \\
\text { as needed SABA }\end{array}$ & 12 weeks & $\begin{array}{l}\text { Use of systemic steroids, ED visits } \\
\text { and hospitalizations not reported. } \\
\text { Nighttime awakenings per week } \\
\text { decreased in both arms: } 2.5 / \text { week } \\
\text { to } 2 / \text { week in FD, 3/week to } \\
\text { 1.5/week in AMD (NS). } \\
\text { Frequency of BUD/FORM use was } \\
\text { less in AMD than FD ( } 2.5 \text { inh/day } \\
\text { versus } 4 \text { inh/day, P=0.0001). NS } \\
\text { difference in change in asthma } \\
\text { severity (both groups shifted } \\
\text { towards more patients having inter- } \\
\text { mittent asthma/fewer having mod- } \\
\text { erate and severe persistent). NS } \\
\text { difference in AEs. }\end{array}$ \\
\hline
\end{tabular}

AEs Adverse events; AMD Adjustable maintenenance dose; BUD Budesonide; ED Emergency department; FD Fixed-dose; FEV 1 Forced expiratory volume in 1 s; FP/SM Fluticasone propionate/salmeterol; ICS Inhaled corticosteroids; inh Inhalation(s); LABA Long-acting beta ${ }_{2}$-agonists; NS No significant; PEF Peak expiratory flow; prn As needed; ref Reference; SAEs Serious adverse events

\section{Question 8}

As part of a self-management plan in children (6 to 11 years of age) and adults (12 years of age and over) experiencing an acute loss of asthma control, what is the efficacy of using a FABA as a reliever and: a) starting a fixed-dose ICS/LABA combination in individuals who are on no maintenance therapy or on ICS monotherapy?

b) escalating to a higher predetermined fixed dose of ICS/LABA combination* compared with the usual ICS/LABA dose in individuals on ICS/LABA combination as controller therapy?

c) escalating to a higher predetermined fixed dose of ICS/LABA combination* compared with escalating only the ICS dose (either by addition of supplemental ICS to a fixed-dose ICS/LABA or escalating to a higher ICS dose of a fixed-dose ICS/LABA) in individuals on ICS/LABA combination as controller therapy?
*Note: for BUD/FORM, this has been referred to as an 'adjustable maintenance dose' strategy (BUD/FORM-AMD).

The following recommendations are based on review of evidence from one systematic review, three RCTs and the consensus of the CTS Asthma Clinical Assembly Expert Panel.

Recommendation 8A

There is insufficient evidence regarding the efficacy of starting a fixed dose of ICS/LABA combination with a SABA as a reliever as part of a self-management plan for children and adults on no controller therapy or on ICS monotherapy experiencing an acute loss of asthma control. Currently, we do not recommend this approach. (Consensus) 


\section{Recommendation $8 \mathrm{~B}$}

We suggest increasing budesonide/formoterol to a maximum of four inhalations twice daily (i.e. budesonide/formoterol-AMD) for 7 to 14 days in individuals 16 years of age and over on maintenance fixed-dose budesonide/formoterol as part of a self-management plan for acute loss of asthma control. (GRADE 2B)

There is insufficient evidence to make a recommendation regarding the efficacy of budesonide/formoterol-AMD self-management strategy in individuals 12 to 15 years of age and budesonide/ formoterol-AMD is not approved in Canada for use in individuals under 12 years of age.

In individuals on budesonide/formoterol, there is insufficient evidence to make a recommendation regarding budesonide/formoterolAMD as part of a self-management plan compared with escalation of ICS dose in any age group.

There is insufficient evidence to make a recommendation regarding the efficacy of escalating ICS strengths of ICS/LABA combinations in individuals on fixed-dose fluticasone/salmeterol or mometasone/ formoterol maintenance therapy, as part of a self-management plan for acute loss of control.

\section{Recommendation $8 \mathrm{C}$}

In adults who are exacerbation-prone despite maintenance fixeddose fluticasone/salmeterol or mometasone/formoterol, we suggest either a four-fold or greater increase in ICS dose for 7 to 14 days, or a course of systemic steroids be considered as part of a self-management plan for acute loss of asthma control. (Consensus)

\section{Future research needs}

Based on the evidence reviewed, the Clinical Assembly identifies the following research needs:

- to determine the efficacy of starting ICS/LABA combination therapy as part of self-management plans for acute loss of asthma control in children and adults on no maintenance therapy;

- to determine the efficacy of escalating ICS dose either by adding an extra ICS inhaler or switching to a higher ICS-containing strength of an ICS/LABA combination inhaler in selfmanagement plans for acute loss of asthma control in children and adults on ICS/LABA combination therapy; and

- to determine the relative efficacy of escalating both ICS and LABA compared with only escalating ICS dose for acute loss of asthma control.

\section{REFERENCES}

1. Busse WW, Shah SR, Somerville L, Parasuraman B, Martin P, Goldman M. Comparison of adjustable- and fixed-dose budesonide/formoterol pressurized metered-dose inhaler and fixed-dose fluticasone propionate/salmeterol dry powder inhaler in asthma patients. J Allergy Clin Immunol 2008;121:1407-14, 14 e1-6.

2. O'Connor RD, Patrick DL, Parasuraman B, Martin P, Goldman M. Comparison of patient-reported outcomes during treatment with adjustable- and fixed-dose budesonide/formoterol pressurized metered-dose inhaler versus fixed-dose fluticasone propionate/ salmeterol dry powder inhaler in patients with asthma. J Asthma 2010;47:217-23

3. Ige OM, Ohaju-Obodo JO, Chukwu C, Peters EJ, Okpapi J, Chukwuka C. Effectiveness and safety of adjustable maintenance dosing with budesonide/formoterol turbuhaler compared with traditional fixed doses in bronchial asthma: a multi-centre Nigerian study. Afr J Med Med Sci 2010;39:165-72.

4. Aalbers R. Fixed or adjustable maintenance-dose budesonide/ formoterol compared with fixed maintenance-dose salmeterol/ fluticasone propionate in asthma patients aged >or $=16$ years: Post hoc analysis of a randomized, double-blind/open-label extension, parallel-group study. Clin Drug Investig 2010;30:439-51.

5. Edwards SJ, Gruffydd-Jones K, Ryan DP. Systematic review and meta-analysis of budesonide/formoterol in a single inhaler. Curr Med Res Opin 2007;23:1809-20.

\section{SECTION IV CONTROLLER THERAPY FOR ACTION PLANS}

\section{Part 4 - Oral Corticosteroids}

\section{Question}

9. In individuals with asthma, what is the efficacy of adding oral corticosteroids as part of a written action plan for preschoolers (under 6 years of age), children (6 to 11 years of age) and adults (12 years of age and over) with acute loss of asthma control?

\section{Introduction}

Systemic corticosteroids are a long-accepted treatment for the management of asthma, acting as broad anti-inflammatory agents. With the introduction of ICS there is rarely a need now for the use of oral corticosteroids (OCS) in the chronic management of asthma. Systemic corticosteroids have been shown to be an effective treatment for acute asthma exacerbations. When added early in the management of acute asthma in ED, systemic corticosteroids have been shown to reduce the risk of hospitalizations by $25 \%$ (1). In addition, they reduce relapses and need for rescue SABAs when added to the management after discharge from the acute setting (2). The effectiveness of systemic corticosteroids is similar in children and adults. A variety of agents are used, including oral (eg. dexamethasone and prednisone) and parenteral (eg. triamcinolone, methyl-prednisolone and dexamethasone) agents; the dose and route of delivery has not been shown to influence effectiveness.

Because anti-inflammatory agents are effective in acute asthma, the concept of patient- or parent-initiated systemic corticosteroids at the first sign of loss of asthma control is appealing. In fact, several guideline groups have endorsed this strategy (3). Given that systemic corticosteroids have important short-term (eg. insomnia, gastrointestinal complaints, fluid retention, etc.) and long-term (eg. reduction of growth in children, adrenal suppression, osteoporosis, osteonecrosis, hypertension, diabetes mellitus) side effects, there is a need to consider the balance of evidence for effectiveness and safety. Thus, we examined the effectiveness and safety of patient-or parent-initiated systemic corticosteroids compared with placebo/no treatment at early signs of loss of asthma control and/or upper respiratory tract infections on the severity and duration of the exacerbation.

\section{Methods}

Practice guidelines, systematic reviews of RCTs and RCTs comparing systemic corticosteroids with other strategies as part of a written action plan for children and adults with acute loss of asthma control were included. Outcomes of interest were use of systemic steroids, ED visits, hospitalization, duration of symptoms, quality of life and adverse effects.

Asthma search terms were combined with the following $\mathrm{MeSH}$ and text words in OVID MEDLINE and EMBASE to identify systematic reviews: exacerbat: or acut: or status: or sever: or emergenc: or crisis: or worsen: or attack: and prednis: or medrone or methylprednis: or "precortisyl forte" or decadron or medrol tablets or hydrocortisone or hydrocortone. Systematic reviews were included if they were published in 2005 or later.

The CAGR "asthma and wheez*" database was searched in May 2011 using the search strategy of the most recent systematic review to identify any new pediatric trials from 2008 onward. In addition, the same search strategy was used without pediatric terms to identify any RCTs of systemic corticosteroids in adults up to May 2011. The following systemic corticosteroid search terms were used: prednisolone or prednisone or methyl-prednisolone or methylprednisolone or corticosteroid: or glucocorticoid: or *steroid: AND oral: or systemic: or solucortef or solu-cortef or solumedrol or dexamethasone. These were combined with the following terms for initiation of therapy: initiat: or start: or begin: OR commenc: or introduce: $O R$ instigate. 
TABLE 13

Randomized controlled trials of parent-initiated SCS at the earliest signs of loss of asthma control

\begin{tabular}{|c|c|c|c|c|c|c|c|c|c|}
\hline $\begin{array}{l}\text { Author } \\
\text { (ref), year }\end{array}$ & $\mathbf{n}$ & Design & Population & SCS & Control & Duration & Triggerloutcomes & S/Es & Effectiveness results \\
\hline $\begin{array}{c}\text { Grant et } \\
\text { al. (8), } \\
1995\end{array}$ & 86 & $\begin{array}{l}\text { Cross-over } \\
\text { RCT }\end{array}$ & $\begin{array}{l}\text { Children } 2-14 \\
\text { years of age } \\
\text { identified as } \\
\text { having asthma } \\
\text { from clinic } \\
\text { records }\end{array}$ & $\begin{array}{l}\text { A single oral } \\
\text { dose of } \\
\text { prednisolone } \\
(2 \mathrm{mg} / \mathrm{kg})\end{array}$ & Placebo & $\begin{array}{l}\text { Two con- } \\
\text { secutive } \\
6 \text {-month } \\
\text { periods }\end{array}$ & $\begin{array}{l}\text { Trigger: onset of } \\
\text { wheezing; } \\
\text { Outcome: } \\
\text { unscheduled } \\
\text { medical review }\end{array}$ & $\begin{array}{l}\text { No differnce } \\
\text { between } \\
\text { treatment } \\
\text { groups }\end{array}$ & $\begin{array}{l}\text { The likelihood of health resource use } \\
\text { was greater during the six months in } \\
\text { which the study medication was } \\
\text { prednisolone. There was no } \\
\text { difference between treatment } \\
\text { periods in the other measured } \\
\text { outcomes }\end{array}$ \\
\hline $\begin{array}{l}\text { Oommen, } \\
\text { et al. } \\
(9) \\
2003\end{array}$ & 217 & $\begin{array}{l}\text { Parallel } \\
\text { group RCT }\end{array}$ & $\begin{array}{l}\text { Children 1-5 } \\
\text { years of age } \\
\text { who had } \\
\text { previously } \\
\text { been admitted } \\
\text { to hospital with } \\
\text { an episode of } \\
\text { viral wheeze }\end{array}$ & $\begin{array}{l}\text { Oral } \\
\text { prednisolone } \\
\text { ( } 20 \mathrm{mg} \text { ) once } \\
\text { daily for } \\
5 \text { days }\end{array}$ & Placebo & $\begin{array}{l}\text { Variable } \\
\text { (7 months } \\
\text { to } 3 \text { years) }\end{array}$ & $\begin{array}{l}\text { Trigger: onset of an } \\
\text { episode of wheeze; } \\
\text { Outcome: 7-day } \\
\text { mean daytime and } \\
\text { night-time } \\
\text { respiratory symptom } \\
\text { scores }\end{array}$ & Not reported & $\begin{array}{l}\text { No difference between treatment } \\
\text { groups in symptom scores, health } \\
\text { resource use, substitution of the } \\
\text { study medication or other outcome } \\
\text { measures }\end{array}$ \\
\hline $\begin{array}{l}\text { Vuillermin, } \\
\text { et al. } \\
(10) \text {, } \\
2010\end{array}$ & 230 & $\begin{array}{l}\text { Double- } \\
\text { blind, } \\
\text { cross- } \\
\text { over RCT }\end{array}$ & $\begin{array}{l}\text { Children 5-12 } \\
\text { years of age } \\
\text { with a history } \\
\text { of recurrent } \\
\text { episodes of } \\
\text { acute asthma }\end{array}$ & $\begin{array}{l}\text { Oral } \\
\text { prednisolone } \\
\text { (1 mg/kg/ } \\
\text { day); parent } \\
\text { initiated }\end{array}$ & Placebo & $\begin{array}{l}\text { Variable } \\
\text { (up to } \\
3 \text { years) }\end{array}$ & $\begin{array}{l}\text { Trigger: parent } \\
\text { suspected this acute } \\
\text { asthma episode } \\
\text { was more severe, or } \\
\text { if symptoms did not } \\
\text { improve within } 6 \mathrm{~h} \\
\text { to } 8 \text { h of SABA; } \\
\text { Outcome: Mean } \\
\text { daytime symptom } \\
\text { score over } 7 \text { days }\end{array}$ & $\begin{array}{l}\text { No difference } \\
\text { in the rate of } \\
\text { behavioural } \\
\text { adverse } \\
\text { effects } \\
\text { between } \\
\text { treatment } \\
\text { groups }\end{array}$ & $\begin{array}{l}\text { Fewer substitutions with an oral } \\
\text { corticosteroid in children receiving } \\
\text { SCS (OR } 0.44 \text { [ } 95 \% \mathrm{Cl} 0.26 \text { to } \\
\text { 0.73]); health resource use was } \\
\text { reduced in children receiving SCS } \\
\text { (OR } 0.54 \text { [95\% } \mathrm{Cl} 0.34 \text { to } 0.86] \text { ); no } \\
\text { difference in hospitalizations (OR } \\
0.41 \text { [95\% } \mathrm{Cl} 0.16 \text { to } 1.05] \text { ); less } \\
\text { school absenteeism in children } \\
\text { receiving SCS (MD }-0.4 \text { days } \\
\text { [95\% } \mathrm{Cl}-0.8 \text { to } 0.0 \text { days]) }\end{array}$ \\
\hline
\end{tabular}

MD Mean difference; RCT Randomized controlled trial; ref Reference; SCS Systemic corticosteroids

Key evidence

Three practice guidelines, two systematic reviews and one additional RCT informed the recommendations.

\section{Guidelines}

Three guidelines have addressed the use of OCS as part of a written action plan for acute loss of asthma control. The 2011 BTS/SIGN guideline does not make any specific statement regarding the addition of corticosteroids at the early onset of loss of control; however, it suggests individualized treatment instructions using OCS are beneficial as part of a written action plan (4). Based on three citations, the 2007 NHLBI guideline adjudicated a grade A evidence assessment to short bursts of OCS: "Initiate oral glucocorticoids under certain circumstances (Evidence A)"(3). The guideline further stated that mild exacerbations could be treated at home and "possible short course of oral systemic corticosteroids" may be required. The GINA guideline did not provide a clear comment on the addition of OCS in adults and stated there was "weak" evidence (no references provided) for adding prednisone at the onset of loss of control (5).

\section{Systematic reviews}

Two systematic reviews that addressed systemic corticosteroids in children were identified $(6,7)$; none that specifically involved adults were identified. Both were by Vuillermin et al. $(6,7)$ and included RCTs of parent-initiated systemic corticosteroid therapy for intermittent wheezing illnesses in children. The most recent Cochrane review identified two RCTs $(8,9)$ involving 303 children one to 18 years of age (Table 13) (6). The trigger for initiating corticosteroids in both trials was the onset of wheezing (Table 13). While no meta-analyses could be performed, the evidence provided from the two trials failed to identify a benefit of the corticosteroid strategy on hospitalizations, intensity of symptoms and the use of rescue therapy. Only one included trial collected data on a range of side effects associated with the administration of prednisolone (eg. nausea, vomiting, headache, bad behaviour, laughing or crying and skin rash) and found no differences between prednisolone- and placebo-treated groups. The authors of the Cochrane review (6) concluded:

Limited current evidence is available and it is inconclusive regarding the benefit from parent-initiated OCS in the treatment of intermittent wheezing illnesses in children. Widespread use of this strategy cannot be recommended until the benefits and harms can be clarified further.

RCTs

The updated search of the Cochrane Airways Group database identified one additional pediatric trial. No adult trials were identified. This new pediatric RCT had not been included in previous systematic reviews or guidelines (10). This Australian cross-over trial of parentinitiated oral prednisolone $(1 \mathrm{mg} / \mathrm{kg}$ in dosing intervals of $10 \mathrm{mg}$; maximum dose $50 \mathrm{mg}$ ) for three to five days depending on the persistence or resolution of the child's asthma symptoms after starting OCS was compared with placebo in children five to 12 years of age. The trigger for initiating corticosteroids was parent suspicion that the acute asthma episode was more severe, or if symptoms did not improve within $6 \mathrm{~h}$ to $8 \mathrm{~h}$ of SABA administration. In total, 230 children who had experienced four or more episodes of acute asthma requiring at least $24 \mathrm{~h}$ of bronchodilator therapy in the previous 12 months, regardless of the presence or absence of asthma interval symptoms were enrolled.

Overall, episodes treated with parent-initiated prednisolone were less likely than those treated with placebo to result in substitution of the study medication with an OCS following a medical review (OR 0.44 [95\% CI 0.26 to 0.73]). Health resource use, defined by the occurrence of a medical visit for acute asthma during the seven days after initiation of OCS, was reduced (OR 0.54 [95\% CI 0.34 to 0.86$]$ ). Hospitalization was also reduced in children receiving OCS (OR 0.41 [95\% CI 0.16 to 1.05$]$ ). 
Of note, there was no measurement of episode severity or the appropriateness of the parents' decision to initiate OCS. Moreover, the training of parents was poorly described. While the authors reported no differences between the groups for side effects, most of the side effects were short-term, limited in scope and poorly reported. The long-term risks associated with frequent, repeated dosing of OCS were not measured and only briefly discussed.

\section{Conclusions}

In summary, there is evidence supporting the benefit from OCS in an established asthma exacerbation. There is uncertainty regarding the benefit of the very early introduction of OCS at the earliest sign of loss of asthma control. In adults, there were no identified published trials or systematic reviews examining the safety and efficacy of the early addition of OCS as part of an asthma action plan. The guideline recommendations fail to provide clear evidence for their variable recommendations, and the beneficial effect of oral prednisone at the onset of an exacerbation is not supported with valid and reliable evidence. An action plan is designed to prevent exacerbations or unscheduled physician encounters or to reduce the severity of the subsequent attack. The majority of evidence favouring OCS arises from the treatment of acute exacerbations in the ED setting and it may not be valid to extrapolate this as a justification for its inclusion in asthma action plans. There is no evidence available from any of the reports we reviewed regarding the effectiveness of adding OCS as step-up therapy (eg. from increased SABA and ICS use).

In children, there appears to be at least some support from a highquality RCT reporting a beneficial effect of oral prednisone at the onset of an exacerbation not relieved by 12 puffs of salbutamol $100 \mathrm{mcg}$ (1200 mcg) every $3 \mathrm{~h}$ (Table 13) (6,10). The short-term side effects associated with systemic corticosteroids and the possible long-term consequences of repeated and frequent doses of systemic corticosteroids result in caution with respect to this intervention. There are no comparative effectiveness trials or reviews of ICS versus systemic corticosteroids at the onset of loss of asthma control. Once again, there is no evidence available from any of the reports we reviewed regarding the effectiveness of adding OCS as step-up therapy (eg, from increased SABA and ICS use). Moreover, some guidelines recommend restricting short courses of systemic corticosteroids to viral respiratory infections that provoke moderate-to-severe exacerbations, and at the first sign of infection in children (five to 17 years of age) who have a history of severe exacerbations with viral respiratory infections (3). Further research in this area is required before widespread implementation.

Finally, there is concern regarding the use of systemic corticosteroids in children who have not experienced varicella infections or been immunized against varicella. In the event that a child without immunity needs a short course of corticosteroids, it is recommended that they receive varicella vaccine and, if they develop acute infection, antiviral agents should be initiated (3).

\section{Question 9}

In individuals with asthma, what is the efficacy of adding oral corticosteroids as part of a written action plan for preschoolers (under 6 years of age), children (6 to 11 years of age) and adults (12 years of age and over) with acute loss of asthma control?

The following recommendations are based on evidence from three guidelines, two systematic reviews, one RCT and the consensus of the Asthma Clinical Assembly Expert Panel.

\section{Recommendation 9A}

We do not recommend routinely adding oral corticosteroids in adults as part of a written action plan at the onset of an episode of acute loss of control. (GRADE 2C)

\section{Recommendation 9B}

We suggest that health care practitioners add oral corticosteroids in adults with recent severe exacerbations who fail to respond to inhaled SABA therapy as part of a written action plan at the onset of an episode of acute loss of control. (GRADE 2C)

\section{Recommendation 9C}

Prednisone dose and duration in adults should be individualized based on previous or current response. We suggest a dose of 30 to $50 \mathrm{mg} /$ day for at least 5 days. (Consensus)

\section{Recommendation 9D}

We do not recommend routinely adding oral corticosteroids in preschoolers or children as part of a written action plan at the onset of an episode of acute loss of control. (GRADE 2B)

\section{Recommendation 9E}

We suggest health care practitioners add oral corticosteroids in children with recent severe exacerbations who fail to respond to inhaled SABA as part of a written action plan at the onset of an episode of acute loss of control. (GRADE 2B) Practitioners are advised to ensure that the child is adequately immunized in general, and in particular immune to, or vaccinated for, chickenpox or advise parents to seek prompt medical attention if exposed to chickenpox while taking oral steroids. (Consensus)

\section{Recommendation 9F}

Prednisone/prednisolone dose and duration in children should be individualized based on previous or current response. We suggest a dose of $1 \mathrm{mg} / \mathrm{kg} / \mathrm{day}$ (maximum $50 \mathrm{mg}$ ) for at least 3 days. (GRADE 2C)

\section{Recommendation 9G}

In all age groups, the use of oral corticosteroids for an episode of acute loss of asthma control requires prompt practitioner reassessment of the current episode and review of the daily controller therapy. Frequent courses of oral corticosteroids should prompt referral to a specialist. (Consensus)

\section{Future research needs}

Based on the evidence reviewed, the Clinical Assembly identifies the following research needs:

- to evaluate the efficacy of systemic corticosteroid use, dose and duration of therapy, as part of self-management plans for acute loss of asthma control.

\section{REFERENCES}

1. Rowe BH, Spooner C, Ducharme FM, Bretzlaff JA, Bota GW. Early emergency department treatment of acute asthma with systemic corticosteroids. Cochrane Database Syst Rev 2001(1);CD002178.

2. Rowe BH, Spooner CH, Ducharme FM, Bretzlaff JA, Bota GW. Corticosteroids for preventing relapses following acute exacerbations of asthma. Cochrane Database Syst Rev 2001(1);CD000195.

3. National Asthma Education Prevention Program (NAEPP). Expert Panel Report 3: Guidelines for the diagnosis and management of asthma. Bethesda, MD: National Heart, Lung, and Blood Institute (NHLBI), 2007.

4. British Guideline on the Management of Asthma: A national clinical guideline. Scottish Intercollegiate Guidelines Network (SIGN); British Thoracic Society, 2011.

5. Global Strategy for Asthma Management and Prevention. Global Initiative for Asthma (GINA), 2010. <www.ginasthma.org> (Accessed October 11, 2011).

6. Vuillermin P, South M, Robertson C. Parent-initiated oral corticosteroid therapy for intermittent wheezing illnesses in children. Cochrane Database Syst Rev 2006(3):CD005311.

7. Vuillermin PJ, Robertson CF, South M. Parent-initiated oral corticosteroid therapy for intermittent wheezing illnesses in children: Systematic review. Paediatr Child Health 2007;43:438-42.

8. Grant CC, Duggan AK, DeAngelis C. Independent parental administration of prednisone in acute asthma: A double-blind, placebo controlled, crossover study. Pediatrics 1995;96:224-9.

9. Oommen A, Lambert PC, Grigg J. Efficacy of a short course of parent initiated oral prednisolone for viral wheeze in children aged 1-5 years: Randomised controlled trial. Lancet 2003;362:1433-8.

10. Vuillermin PJ, Robertson CF, Carlin JB, Brennan SL, Biscan MI, Soyuth M. Parent initiated prednisolone for acute asthma in children of school age: Randomised controlled crossover trial. BMJ 2010;340:c843. 


\section{SECTION V}

\section{EXECUTIVE SUMMARY}

The present clinical practice guideline (CPG) is the first formal update of the most recent Canadian Asthma Consensus Guidelines (1-3), the Canadian Thoracic Society (CTS) Asthma Management Continuum - 2010 Consensus Summary (4) and CTS Commentary on long-acting beta ${ }_{2}$-agonists (LABAs) in asthma (5), and was completed according to the Canadian Respiratory Guidelines Committee's (CRGC's) new guideline development process. The purpose is to provide evidence-based recommendations to physicians and other health care professionals for the diagnosis and management of asthma in preschoolers (under 6 years of age), children (6 to 11 years of age) and adults (12 years of age and over). We combined adults and adolescents under the heading 'adults' in the present guideline because in most instances, this grouping was a reflection of the literature that was reviewed. Where appropriate, we have separated these two groups according to age. The CTS Asthma Clinical Assembly Expert Panel will continue to identify new topics and update sections of the previous guidelines on an ongoing basis.

\section{Asthma definition}

The definition of asthma remains unchanged. Asthma is an inflammatory disorder of the airways characterized by paroxysmal or persistent symptoms such as dyspnea, chest tightness, wheezing, sputum production and cough, associated with variable airflow limitation and airway hyper-responsiveness to endogenous or exogenous stimuli (1). Inflammation and its resultant effects on airway structure and function are considered to be the main mechanisms leading to the development and maintenance of asthma.

\section{Asthma diagnosis}

Recommendations for the assessment and management of asthma addressed in the present CPG pertain to individuals with a confirmed asthma diagnosis. Asthma is diagnosed by the combination of a compatible clinical history (see asthma definition) and objective measures of lung function in individuals 6 years of age and over. Pulmonary function criteria supportive of an asthma diagnosis include: spirometry showing reversible airway obstruction, peak expiratory flow (PEF) variability, and a positive challenge test such as methacholine or exercise challenge (Table 14) $(1,4)$. In preschoolers, for whom it is not possible to routinely assess lung function, the combination of a careful clinical history (including family history and risk factors for asthma development) and physical examination are used to differentiate asthma from other causes of episodic respiratory symptoms (6).

\section{Topics in the 2012 update:}

The literature was reviewed and four main topics were critically appraised:

1. Asthma control: the role of noninvasive measures of airway inflammation (induced sputum cell counts and fraction of exhaled nitric oxide [FeNO]) to guide adjustments to therapy;

2. Adjunct controller therapy: which medication to add and, at what inhaled corticosteroid (ICS) dose;

3. ICS/LABA combination therapy used as a reliever, or as both a reliever and a controller in a single inhaler;

4. Asthma action plans: how to adjust controller therapy in the 'yellow zone'.

The panel of experts made 34 recommendations (Table 15) based on adaptation of other national and international guidelines, appraisal of the evidence from systematic reviews and published randomized controlled trials (RCTs), and input from external reviewers. Asthma control criteria (Table 16) and the Asthma Management Continuum for individuals 6 years of age and over, and adults (Figure 3) have been updated accordingly. New recommendations regarding adjustment of controller therapy for acute loss of asthma control as part of self-management plans are presented in Table 17.

\section{Asthma control}

The primary goal of asthma management is to control the disease and, by doing so, to prevent or minimize future risk of short- and long-term complications, morbidity and mortality (4). Asthma control should be assessed regularly to guide adjustments to therapy. While airway inflammation is a fundamental feature of asthma, its assessment had not been included as a measure of asthma control until now. The CTS Asthma Assembly appraised the literature comparing the use of FeNO or sputum eosinophil count to measure airway inflammation, in addition to or instead of standard measures of asthma control to guide adjustment of controller therapy.

We conclude that there is still insufficient evidence to recommend the use of $\mathrm{FeNO}$ in addition to or in lieu of standard measures of asthma control. However, treating asthma according to the results of sputum cell counts is an effective strategy to reduce severe eosinophilic asthma exacerbations in adults 18 years of age and over with moderate to severe asthma. Accordingly, we recommend sputum eosinophils be considered as an additional measure of asthma control in individuals with moderate to severe asthma who are assessed in specialized centres (Table 16).

\section{Adjunct controller therapy}

ICS remain the foundation of chronic maintenance pharmacotherapy for patients with asthma in all age groups. Leukotriene receptor antagonists (LTRAs) are acceptable, second-line, daily monotherapy for children 6 years of age and over and adults. Failure to achieve acceptable asthma control on low doses of ICS should prompt reevaluation to identify the reason. This is often due to one or more of many factors, such as erroneous diagnosis of asthma, poor inhaler device technique, poor adherence to maintenance ICS, ongoing exposure to environmental triggers and comorbidities. Controller therapy should only be escalated after reviewing and addressing these factors. The literature was reviewed to determine at what maintenance ICS dose adjunct therapy should be considered (see Section II Table 3 for ICS dosing categories). The three options reviewed were: increasing to medium or high doses of ICS; adding a LABA; or adding an LTRA.

We conclude that no changes are necessary to the guidance provided on this topic in the most recent CTS Asthma Management Continuum - 2010 Consensus Summary for children 6 years of age and over, and adults (4), and CTS commentary on the role of LABAs (5). We reiterate the following key messages:

- LABAs should never be used alone (as monotherapy) for asthma in any age group;

- LABAs should only be used as add-on therapy to an ICS (ideally in the same inhaler device) in any age group;

- If low-dose ICS is not adequate to maintain control:

- in children 6 to 11 years of age: increase ICS to a medium dose;

- in individuals 12 years of age and over: add a LABA to the low-dose ICS, ideally in the form of a combination inhaler.

- If asthma remains uncontrolled on medium-dose ICS in children 6 to 11 years of age:

- the addition of either a LABA or LTRA are both therapeutic options, and treatment decisions should be individualized.

- If asthma remains uncontrolled on the combination of an ICS and LABA in individuals 12 years of age and over:

- consider the addition of an LTRA;

- consider referral to a specialist for assessment.

- High doses of ICS may be associated with significant side effects in children and adults, and should only be used by asthma specialists. 
TABLE 14

Diagnosis of asthma: Pulmonary function criteria

\begin{tabular}{|c|c|c|}
\hline Pulmonary function measurement & Children ( 6 years of age and over) & Adults \\
\hline \multicolumn{3}{|l|}{ Preferred: Spirometry showing reversible airway obstruction } \\
\hline $\begin{array}{l}\text { Increase in } \mathrm{FEV}_{1} \text { after a bronchodilator or after course of } \\
\text { controller therapy }\end{array}$ & $\geq 12 \%$ & $\geq 12 \%$ (and a minimum $\geq 200 \mathrm{~mL}$ ) \\
\hline \multicolumn{3}{|l|}{ Alternative: Peak expiratory flow variability } \\
\hline Diurnal variation ${ }^{\dagger}$ & Not recommended & $\begin{array}{l}>8 \% \text { based on twice daily readings; } \\
>20 \% \text { based on multiple daily readings }\end{array}$ \\
\hline \multicolumn{3}{|l|}{ Alternative: Positive challenge test } \\
\hline a) Methacholine challenge & \multicolumn{2}{|c|}{$\begin{array}{c}\mathrm{PC}_{20}<4 \mathrm{mg} / \mathrm{mL} \\
(4-16 \mathrm{mg} / \mathrm{mL} \text { is borderline; }>16 \mathrm{mg} / \mathrm{mL} \text { is negative) }\end{array}$} \\
\hline
\end{tabular}

${ }^{*}$ Approximate lower limits of normal ratios for children and adults. ${ }^{\dagger}$ Difference between minimum am pre-bronchodilator value in 1 week and maximum pm value as $\%$ of recent maximum. FEV ${ }_{1}$ Forced expiratory volume in $1 \mathrm{~s}$; FVC Forced vital capacity; $P C_{20}$ Provocative concentration of methacholine producing a $20 \%$ fall in FEV $V_{1}$. Reproduced from reference 4 , with permission

TABLE 15

Summary of evidence-based recommendations and grading

Recommendation Description Grade

SECTION I: Noninvasive measurements of airway inflammation

1A We recommend the monitoring of sputum eosinophil counts, in addition to standard measures of asthma control, to adjust

1B

anti-inflammatory therapy of individuals 18 years of age and over with moderate to severe asthma in tertiary care or specialized centres.

$1 B$

We do not suggest the routine use of FeNO, either in addition to or instead of standard measures of asthma control, to adjust

2B anti-inflammatory therapy in children or adults with asthma.

There is insufficient evidence to recommend for or against the monitoring of sputum eosinophil counts to adjust the antiinflammatory treatment of children and adolescents (12 to 17 years of age) with asthma.

There is insufficient evidence to make a recommendation regarding the use of FeNO either in addition to or instead of standard measures of asthma control to adjust anti-inflammatory therapy in preschoolers.

SECTION II: Adjunct therapy

General Regular need for a reliever (of any kind) merits re-evaluation to identify the reason(s) for poor asthma control. For SABA, regular Consensus use is defined as more than three doses per week.

General All treatment decisions should be based on individual characteristics which, depending on resources, could include clinical

Consensus characteristics, objective measures of pulmonary function, and inflammatory markers.

General The effectiveness of each treatment decision should be carefully evaluated for its impact on current control, future risk (in particular) asthma exacerbations, and side effects.

$2 \mathrm{~A} \quad$ We recommend initiation of adjunct therapy in adults with asthma uncontrolled despite adherence to a low dose of ICS.

$2 B \quad$ We recommend initiation of adjunct therapy in children with asthma uncontrolled despite adherence to a medium dose of ICS

$3 \mathrm{~A} \quad$ In adults with asthma not achieving control despite adherence to a low dose of ICS, we recommend the addition of a LABA.

Alternative third-line options include adding an LTRA or increasing to a medium dose of ICS.

$1 \mathrm{~A}$

$1 \mathrm{~A}$

$1 \mathrm{~A}$

Consensus

3B In children with asthma not achieving control despite adherence to a low dose of ICS, we recommend increasing to a medium

$1 \mathrm{~A}$

dose of ICS.

3C In children not achieving asthma control on a medium dose of ICS, we suggest the addition of a LABA or LTRA.

2B

3D Children who fail to achieve control on a medium dose of ICS should be referred to a specialist.

Consensus

SECTION III: ICS/LABA Combination as a reliever and ICS/LABA combination as a reliever and a controller

4A We do not recommend the use of an ICS/LABA combination as a reliever in lieu of a FABA as a reliever in individuals 16 years of $1 B$

age and over with mild intermittent asthma on no maintenance controller therapy.

There is insufficient evidence to make a recommendation regarding the efficacy of an ICS/LABA combination as a reliever in

individuals under 16 years of age on no maintenance controller therapy.

There is insufficient evidence to make a recommendation regarding the efficacy of an ICS/LABA combination as a reliever in children and adults on ICS monotherapy.

$4 \mathrm{~B}$

$4 \mathrm{C}$

4D

We recommend the use of a SABA instead of either a LABA (GRADE 1A) or an ICS/LABA combination inhaler (GRADE 1B),

as a reliever in individuals with mild intermittent asthma on no maintenance controller therapy.

We suggest the use of a SABA instead of an ICS/LABA combination inhaler as a reliever in individuals with mild asthma on ICS monotherapy.

In exacerbation-prone individuals 12 years of age and over with moderate asthma and poor control on a fixed-dose maintenance ICS/ $2 \mathrm{~B}$ LABA combination, we suggest the use of budesonide/formoterol as a reliever be considered at the same maintenance ICS dose. 
TABLE 15 - CONTINUED

\section{Recommendation Description}

$5 \mathrm{~A} \quad$ We do not suggest use of a single inhaler of budesonide/formoterol as a reliever and a controller as a self-management strategy $2 \mathrm{~B}$

in lieu of ensuring adherence to low-dose ICS (400 mcg/day CFC-BDP equivalent) and a FABA as a reliever in individuals

12 years of age and over.

There is insufficient evidence to make a recommendation regarding the use of a single inhaler of budesonide/formoterol as a reliever and a controller as a self-management strategy compared with fixed-dose ICS/LABA in individuals who are exacerbation prone despite adherence to low-dose ICS.

$5 B$

We do not currently suggest the use of a single inhaler of budesonide/formoterol as a reliever and a controller as a selfmanagement strategy in children 4 to 11 years of age, and this approach is not approved in Canada in this age group.

5C We suggest the use of a single inhaler of budesonide/formoterol as a reliever and a controller at the same ICS dose be

considered in individuals 12 years of age and over with asthma uncontrolled on fixed-dose ICS/LABA combination therapy in lieu of increasing the ICS dose of the combination therapy.

$5 \mathrm{D}$

Use of a single inhaler of budesonide/formoterol as a reliever and a controller and 'guideline best practice' of a practitioner titrating controller medication according to current control are both effective therapeutic options in individuals 12 years of age and over. We suggest that the choice between these therapeutic strategies be individualized based upon patient preferences and steroid load.

SECTION IV: Controller therapy for action plans

Part 1: Intermittent ICS

$6 \mathrm{~A} \quad$ We recommend daily ICS in lieu of starting intermittent ICS at the onset of an episode of acute loss of asthma control in patients $1 \mathrm{~B}$ with mild persistent asthma.

$6 \mathrm{~B}$

We recommend that the safest and minimal effective ICS dose be prescribed to minimize side effects in all age groups, particularly in children to address the concern regarding growth velocity.

Part 2: Escalating ICS

$7 \mathrm{~A} \quad$ We suggest that children and adults already on maintenance ICS monotherapy do not routinely double the dose of their ICS as $2 \mathrm{~B}$ part of a written action plan (or self-management plan) at the onset of an episode of acute loss of asthma control.

$7 \mathrm{~B}$

We suggest a trial of increasing the ICS maintenance dose by four- or five-fold for 7 to 14 days as part of an action plan (or self- $2 \mathrm{C}$ management plan) for acute loss of asthma control in adults with a history of severe exacerbations in the past year requiring systemic steroids.

$7 \mathrm{C}$

We recommend that children on maintenance ICS monotherapy do not routinely increase by a four-fold or more the dose of their ICS as part of a self-management plan for acute loss of asthma control. There is no evidence of efficacy and there is evidence of potential harm.

Part 3: Fixed-dose ICS/LABA combination

8A There is insufficient evidence regarding the efficacy of starting a fixed dose of ICS/LABA combination with a SABA as a reliever as part of a self-management plan for children and adults on no controller therapy or on ICS monotherapy experiencing an acute loss of asthma control. Currently, we do not recommend this approach.

$8 B$

We suggest increasing budesonide/formoterol to a maximum of four inhalations twice daily (i.e. budesonide/formoterol-AMD) for 7 to14 days in individuals 16 years of age and over on maintenance fixed-dose budesonide/formoterol as part of a selfmanagement plan for acute loss of asthma control.

There is insufficient evidence to make a recommendation regarding the efficacy of budesonide/formoterol-AMD self-management strategy in individuals 12 to 15 years of age and budesonide/formoterol-AMD is not approved in Canada for use in individuals under 12 years of age.

In individuals on budesonide/formoterol, there is insufficient evidence to make a recommendation regarding budesonide/ formoterol-AMD as part of a self-management plan compared with escalation of ICS dose in any age group.

There is insufficient evidence to make a recommendation regarding the efficacy of escalating ICS strengths of ICS/LABA combinations in individuals on fixed-dose fluticasone/salmeterol or mometasone/formoterol maintenance therapy, as part of a self-management plan for acute loss of control.

8C In adults who are exacerbation-prone despite maintenance fixed-dose fluticasone/salmeterol or mometasone/formoterol, we suggest either a four-fold or greater increase in ICS dose for 7 to 14 days or a course of systemic steroids be considered as part of a self-management plan for acute loss of asthma control.

Part 4: Systemic corticosteroids 9A $\quad$ We do not recommend routinely adding oral corticosteroids in adults as part of a written action plan at the onset of an episode of $2 \mathrm{C}$
acute loss of control.

$9 B$

We suggest that health care practitioners add oral corticosteroids in adults with recent severe exacerbations who fail to respond to inhaled SABA therapy as part of a written action plan at the onset of an episode of acute loss of control.

$9 \mathrm{C}$

Prednisone dose and duration in adults should be individualized based on previous or current response. We suggest a dose of 30 to $50 \mathrm{mg} /$ day for at least 5 days.

9D

We do not recommend routinely adding oral corticosteroids in preschoolers and children as part of a written action plan at the onset of an episode of acute loss of control.

$9 \mathrm{E}$

We suggest health care practitioners add oral corticosteroids in children with recent severe exacerbations who fail to respond to inhaled SABA as part of a written action plan at the onset of an episode of acute loss of control (GRADE 2B). Practitioners are advised to ensure that the child is adequately immunized in general, and in particular immune to, or vaccinated for, chickenpox or advise parents to seek prompt medical attention if exposed to chickenpox while taking oral steroids (Consensus).

$9 \mathrm{~F}$

Prednisone/prednisolone dose and duration in children should be individualized based on previous or current response.

We suggest a dose of $1 \mathrm{mg} / \mathrm{kg} /$ day (maximum $50 \mathrm{mg}$ ) for at least 3 days.

$9 G$ 
ICS/LABA as a reliever and budesonide/formoterol as a reliever and a controller

The 2003 Canadian Asthma Consensus Guidelines broadened the recommended class of reliever medication from short- to fast-acting bronchodilator (1). One LABA (formoterol [FORM]) is also a fast-acting beta $_{2}$-agonist (FABA). However, use of formoterol alone (without an ICS) as a reliever in asthma is not recommended and it is not approved for this indication in Canada because of concerns that LABAs increase the risk of asthma-related deaths. Whether concomitant use of an ICS mitigates this risk is the subject of ongoing research. Combination inhalers of controller and reliever medication offer theoretical advantages both for chronic management to maintain asthma control and as part of guided asthma self-management strategies and action plans that prompt patient-initiated adjustments of both reliever and controller therapy to treat acute loss of asthma control.

FORM in combination with budesonide (BUD) (but not in combination with mometasone) is approved in Canada for use as a reliever in individuals 12 years of age and over. Until now, the CTS had not formally reviewed the efficacy of an ICS/LABA combination agent as a reliever or the efficacy of a single inhaler of BUD/ FORM as a reliever and a controller. The literature was reviewed to examine the efficacy of: i)a single inhaler of BUD/FORM as a reliever compared with a FABA (either short-acting beta agonist [SABA] or fast-acting LABA); and ii) a single inhaler of BUD/ FORM as a reliever and a controller compared with the usual maintenance dose of controller (ICS, lower fixed-dose ICS/LABA) or 'best practice' of a practitioner adjusting maintenance therapy at office visits.

We conclude that:

- SABAs are appropriate relievers for asthma in all age groups and severity, and are the preferred class of reliever for use on demand in all patients with mild asthma (including individuals not on controller therapy and individuals on ICS monotherapy);

- BUD/FORM as a reliever may be considered in exacerbationprone individuals 12 years of age and over with moderate asthma and poor control despite fixed-dose maintenance ICS/LABA combination;

- Use of a single inhaler of BUD/FORM as a reliever and a controller may be of value in select subgroups of individuals 12 years of age and over, particularly exacerbation-prone individuals with uncontrolled asthma despite high maintenance doses of ICS or ICS/LABA combination therapy;

- Additional data are needed to clarify the risk/benefit of the use of a single inhaler of BUD/FORM as a reliever and a controller compared with conventional best practice of a practitioner adjusting maintenance therapy.

Action plans: What to do in the 'yellow zone'

Written action plans are the foundation of guided-self management. Although all major guidelines recommend the use of written action plans, specific evidence-based recommendations regarding adjustment to controller therapy in the 'yellow zone' are either absent or unclear. The Asthma Assembly, therefore, undertook to review the literature and provide guidance regarding how to escalate controller therapy for loss of control (in the 'yellow zone'), based on the baseline maintenance ('green zone') medication. Specifically, we reviewed the evidence examining the efficacy of escalation of controller medication as part of a written action plan for preschoolers, children and adults with acute loss of asthma control in patients not on regular controller therapy, ICS monotherapy, LTRA monotherapy, or ICS and LABA combination therapy.

Recommended step-up ('yellow zone') therapy, based on maintenance ('green zone') therapy, is summarized according to age group in Table 17 and Figure 2. The following key messages warrant special emphasis:
TABLE 16

Asthma control criteria

\begin{tabular}{ll}
\hline Characteristic & Frequency or value \\
\hline Daytime symptoms & $<4$ days/week \\
Night-time symptoms & $<1$ night/week \\
Physical activity & Normal \\
Exacerbations & Mild, infrequent \\
Absence from work or school due to asthma & None \\
Need for a fast-acting beta & -agonist \\
FEV ${ }_{1}$ or PEF & $<4$ doses/week \\
PEF diurnal variation* & $\geq 90 \%$ personal best \\
Sputum eosinophils &
\end{tabular}

*Diurnal variation is calculated as the highest peak expiratory flow (PEF) minus the lowest divided by the highest peak flow multiplied by 100 for morning and night (determined over a two-week period). ${ }^{\dagger}$ Consider in adults with uncontrolled moderate to severe asthma who are assessed in specialist centres. FEV 1 Forced expiratory volume in 1s. Adapted from reference 4

- Adherence to maintenance ('green zone') therapy is a fundamental component of written action plans;

- Evidence does not support the use of intermittent ICS started only at the onset of an episode of loss of asthma control in children or adults, which underlines the importance of prescribing and ensuring adherence to daily controller therapy;

- The common practice of doubling the dose of ICS has not been shown to be efficacious in RCTs and, therefore, is not routinely recommended;

- A trial of four-fold or greater increase in ICS dose for 7 to 14 days is suggested in adults with a history of severe exacerbations in the past year. This is not recommended in preschoolers, children or adolescents;

- The most appropriate 'yellow-zone' therapy for individuals on fixed-dose ICS/LABA therapy is not yet known. There is insufficient evidence to make a recommendation for or against escalating ICS strengths of fluticasone propionate/salmeterol or mometasone/FORM as part of self-management action plans. Older adolescents (16 years of age and over) and adults on BUD/ FORM may benefit from adjustable maintenance dose (increasing to a maximum of four inhalations twice daily);

- Oral corticosteroids (OCS) are beneficial in the management of established asthma exacerbations. In adults, most of the evidence of the efficacy of OCS arises from trials of treatment of asthma in the emergency department setting and it may not be valid to extrapolate that as justification for its inclusion in action plans. There is at least some direct evidence from RCTs of the efficacy of OCS in pediatric action plans. As part of a written action plan, in children and adults, we suggest OCS be reserved for individuals with recent severe exacerbations who fail to respond to inhaled SABAs within 6 to 8 hours.

Guideline dissemination, implementation and knowledge translation tools

The present CPG will be available for viewing and download from the CRGC website (www.respiratoryguidelines.ca) and the Canadian Respiratory Journal website (www.pulsus.com). The trifold pocket Asthma Management brochure ('Slim Jim') will be updated to reflect these new recommendations. It will also be available via the CRGC website and will be mailed along with the CPG to Provincial Lung Associations for distribution to local target users, such as family physicians, allied health professionals working in respiratory care and certified respiratory educators (CREs). A slide kit for teaching and self-directed learning will be posted for viewing and download on the CRGC website. The CPG and derivative resources and tools will be disseminated across Canada via CTS 


\section{Asthma Management Continuum Children (6 years and over) and Adults}

\begin{tabular}{|l|}
\hline Regularly Reassess \\
- Control \\
- Spirometry or PEF \\
- Inhaler technique \\
- Adherence \\
- Triggers \\
- Comorbidities \\
- Sputum eosinophils \\
\hline
\end{tabular}

\section{Inhaled Cortic osteroid (ICS)*}

\section{*Second-Line: Leukotriene Receptor Antagonist (LTRA)}

\begin{abstract}
Low Dose
$\geq 12$ yrs: $\leq 250 \mathrm{mcg} / \mathrm{day}^{\dagger}$

6-11 yrs: $\leq 200 \mathrm{mcg} \mathrm{day}^{\dagger}$
\end{abstract}

\author{
Medium Dose \\ $251-500 \mathrm{mcg} /$ day $^{\dagger}$ \\ $201-400 \mathrm{mcg} / \mathrm{day}^{\dagger}$
}

High Dose

$>500 \mathrm{mcg} /$ day $^{\dagger}$

$>400 \mathrm{mcg} /$ day $^{\dagger}$

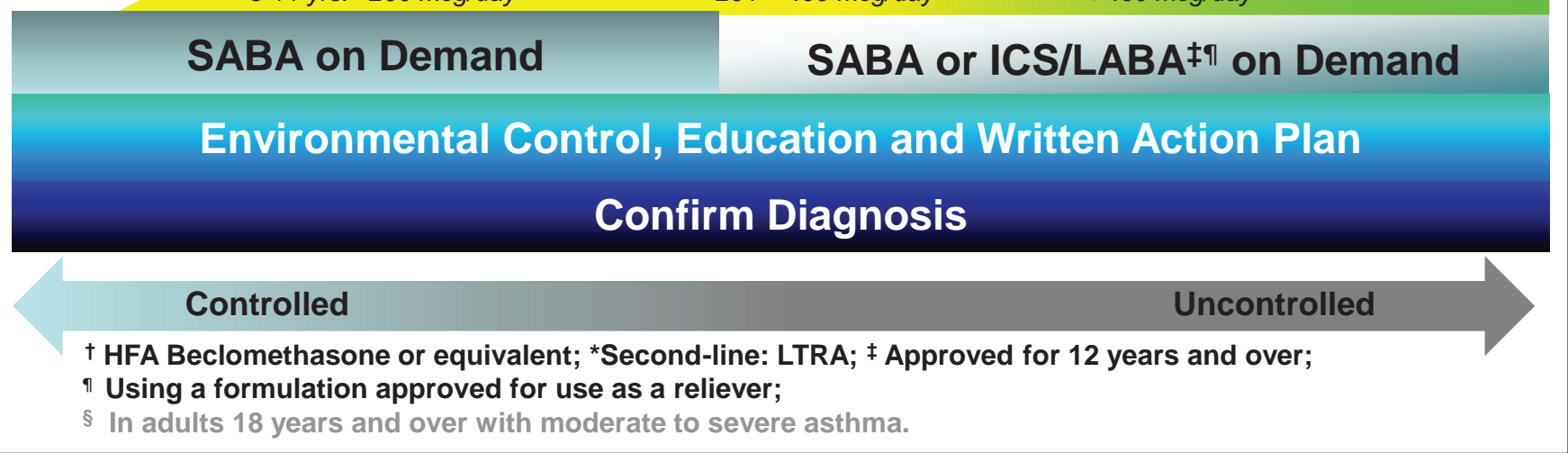

Figure 3) Management hinges on confirming the diagnosis. All individuals with confirmed asthma should receive self-management education, including a written action plan. Very mild intermittent asthma may be treated with a short-acting beta 2 -agonist (SABA) taken as needed. SABAs are recommended for relief of symptoms; individuals 12 years of age and over with moderate to severe asthma (particularly those who are exacerbation prone and have poor control) who are taking an ICS/LABA formulation approved also for use as a reliever may do so. Inhaled corticosteroids (ICS) should be introduced early as the initial maintenance treatment for asthma even in individuals who report asthma symptoms less than three times a week. LTRA are second-line monotherapy for mild asthma. If asthma is not adequately controlled by low doses of inhaled corticosteroids, additional therapy should be considered. In children 6 years of age and over, the ICS should be increased to a medium dose before adding an adjunct agent such as a long-acting beta 2 -agonist (LABA) or LTRA. In children 12 years of age and over and adults, a LABA should be considered first as adjunct therapy. A LABA should only be used in combination with an ICS. Increasing to a medium dose of ICS or the addition of an LTRA are third-line therapeutic options. Theophylline may be considered as a fourth-line agent in adults. Severely uncontrolled asthma may require additional treatment with prednisone. Omalizumab may be considered in individuals 12 years of age and over with atopic asthma poorly controlled despite high doses of ICS and appropriate add-on therapy, with or without prednisone. Asthma symptom control and lung function tests, inhaler technique, adherence to asthma treatment, exposure to asthma triggers in the environment, and the presence of co-mordibities should be reassessed at each visit and before altering the maintenance therapy. Consider also assessment of sputum eosinophils in adults with uncontrolled moderate to severe asthma managed in specialialized centres. After achieving acceptable asthma control for at least a few weeks to months, the medication should be reduced to the minimum necessary dose to achieve adequate asthma control and prevent future risk of exacerbations. HFA: Hydrofluoroalkane; IgE: Immunoglobulin E; mcg: Micrograms; PEF: Peak expiratory flow; yrs: Years

e-bulletins to individuals and organizations that have an interest in this topic area.

The CTS Asthma Clinical Assembly welcomes the opportunity to partner with other organizations and stakeholders in the development of educational resources and tools that support implementation and uptake of the guidelines with various target groups. The CTS Asthma Clinical Assembly will continue its collaboration with the Ontario Lung Association's Provider Education Program (www.olapep.ca) to update the asthma e-Learning modules and cases; an 'Action Plan' module is in development. The Assembly will continue to collaborate with the Lung Association's RESPTrec ${ }^{\circledR}$ Program to update the asthma curriculum for CREs (www.resptrec.org/). The CTS Asthma Clinical Assembly will also work with the Canadian Lung Association (CLA) on The Pan-Canadian REspiratory STandards INitiative for Electronic Health Records (PRESTINE) initiative (7), to recommend asthma elements that prompt and enable adherence with the CTS Asthma Guidelines.

The CTS Asthma Clinical Assembly Expert Panel recognizes and acknowledges that there may be resource implications related to implementing the present CPG. These were taken into consideration 
TABLE 17

Action plan recommendations based on age and maintenance controller therapy

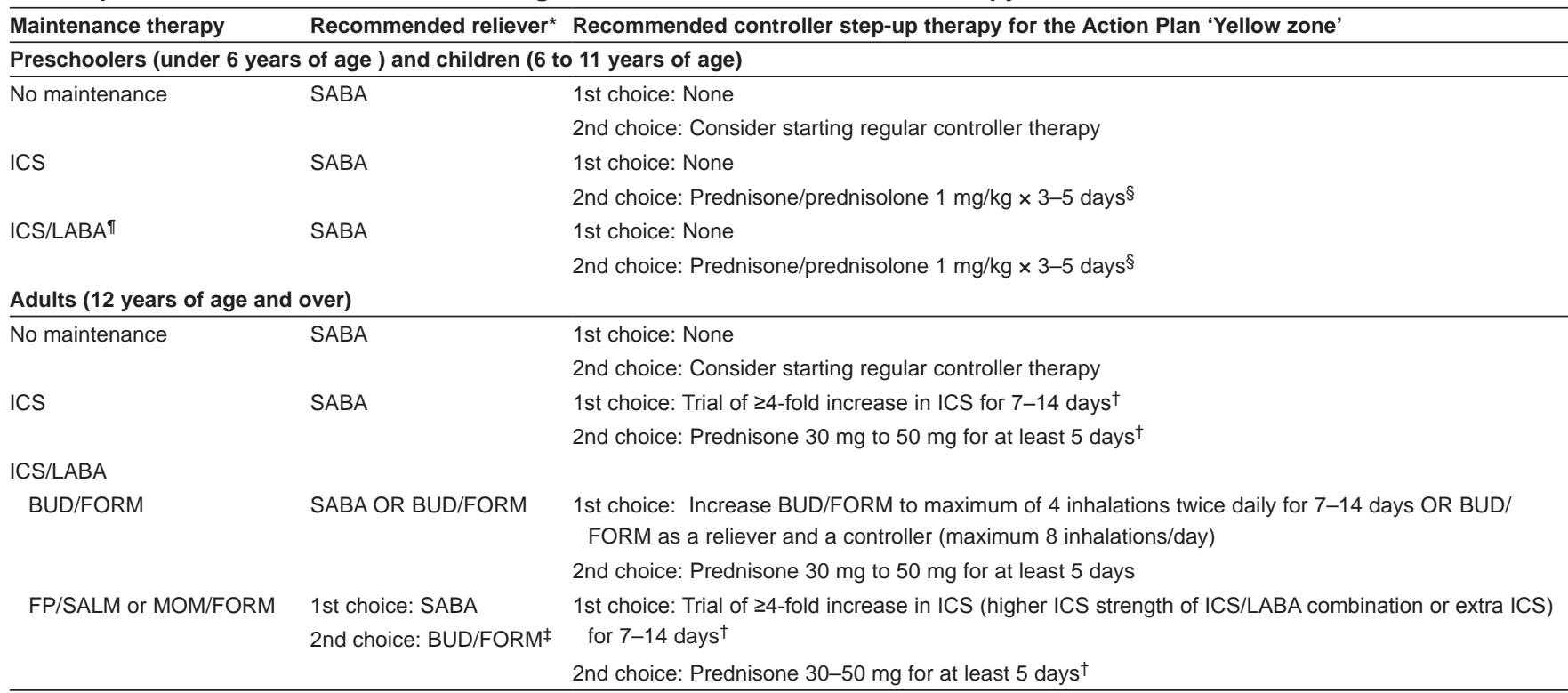

*If regular need for reliever or frequent step-up therapy, identify reason for poor control, adjust (start or increase) maintenance therapy; ${ }^{\dagger}$ In individuals $\geq 15$ years of age with a history of severe acute loss of asthma control in the preceding year; ${ }^{\ddagger}$ In exacerbation-prone individuals; ${ }^{\S}$ In children with a recent history of severe exacerbation and suboptimal response to SABA during index exacerbation; "Does not apply to preschoolers. BUD/FORM Budesonide/formoterol; FP/SALM Fluticasone propionate/salmeterol; ICS Inhaled corticosteroid; LABA Long-acting beta ${ }_{2}$-agonist; max Maximum; MOM/FORM Mometasone/formoterol; SABA Short-acting beta ${ }_{2}{ }^{-}$ agonist

in forming the recommendations (eg, limiting the recommendation that induced sputum be accessible in specialized centres). It is hoped that the implementation of these recommendations will be cost-neutral or cost-effective by promoting evidence-based diagnosis, assessment and use of medications.

Monitoring adherence with guideline recommendations

The following parameters may be used to monitor or audit adherence with some of the key recommendations contained in the present CPG:

- asthma diagnosis is confirmed by an objective measure of lung function in individuals 6 years of age and over;

- asthma control criteria are assessed at asthma follow-up visits (including sputum eosinophils in individuals 18 years of age and over with moderate asthma in tertiary care or specialized centres);

- patient has a reliever (SABA for any severity; or BUD/FORM for exacerbation-prone individuals 12 years of age and over with moderate asthma and poor control);

- patient is prescribed a controller (ICS or LTRA, or ICS/LABA, or prednisone);

- adjunct controller therapy (either a LABA or LTRA) is prescribed for children with asthma uncontrolled on a medium dose of ICS;

- adjunct controller therapy (LABA as an ICS/LABA combination) is prescribed for adults with asthma uncontrolled on a low dose of ICS;

- patient/parent/caregiver receives self-management education, including a written asthma action plan (with 'yellow zone' instructions based upon maintenance 'green zone' controller therapy); and

- children with asthma uncontrolled on a medium dose of ICS are referred to an asthma specialist.
EDITORIAL INDEPENDENCE: The CTS Asthma Clinical Assembly is accountable to the CTS Respiratory Guidelines Committee and the CTS Board of Directors. The CTS Asthma Clinical Assembly is functionally and editorially independent from any funding sources of the CTS and does not receive any direct funding from external sources. The CTS receives unrestricted grants, which are combined into a central operating account to facilitate the knowledge translation activities of CTS Clinical Assemblies. Sources include the Canadian Institutes of Health Research, AstraZeneca Canada, Boehringer Ingelheim Canada, GlaxoSmithKline Inc, Pfizer and Talecris. No funders played a role in the collection, review, analysis or interpretation of the scientific literature or in any decisions regarding the recommendations or key messages presented in this document.

DISCLOSURE OF COMPETING INTERESTS: Members of the Asthma Clinical Assembly declared potential conflicts of interest at the time of appointment and these were updated throughout the process in accordance with the CTS Conflict of Interest Disclosure Policy. Individual member conflict of interest statements are posted at http://www.respiratoryguidelines.ca/guideline/asthma.

ACKNOWLEDGEMENTS: The authors thank: Canadian Lung Association staff Janet Sutherland and Anne Van Dam for outstanding administrative support; Candice Brown, Stella Muthuri and Kristen Curren for dedicated project management; Karen Spithoff for methodological expertise; and the Canadian Respiratory Guidelines Committee for expert support and guidance. The authors also thank the expert peer reviewers: Dr. Alan Bell (Toronto, Ontario), Dr. Robert Cowie (Calgary, Alberta), Dr. Harold Kim (Kitchener, Ontario), for the Canadian Society of Allergy and Clinical Immunology), Jan Neumann, CRE (Saskatoon, Saskatchewan), Dr. Mary Noseworthy (Calgary, for the CTS Pediatric Clinical Assembly), Dr. Francisco Noya (Montreal, Quebec), for the Canadian Society of Allergy and Clinical Immunology. 


\section{Lougheed et al}

\section{REFERENCES}

1. Lemiere C, Bai T, Balter M, et al. Adult Asthma Consensus Guidelines Update 2003. Can Respir J 2004;11(Suppl A):9A-18A.

2. Becker A, Berube D, Chad Z, et al. Canadian Pediatric Asthma Consensus guidelines, 2003 (updated to December 2004): introduction. CMAJ 2005;173(6 Suppl):S12-S4.

3. Becker A, Lemiere C, Berube D, et al. Summary of recommendations from the Canadian asthma consensus guidelines, 2003. CMAJ 2005;173(6 Suppl):S3-11.

4. Lougheed MD, Lemiere C, Dell SD, et al. Canadian Thoracic Society Asthma Management Continuum - 2010 Consensus Summary for children six years of age and over, and adults. Can Respir J 2010;17:15-24.
5. Lougheed MD, Lemiere C, Dell S, et al. Canadian Thoracic Society Asthma Committee commentary on long-acting beta-2 agonist use for asthma in Canada. Can Respir J 2010;17:57-60.

6. Global Strategy for the Diagnosis and Management of Asthma in Children 5 Years and Younger. Global Initiative for Asthma (GINA), 2009. <www.ginasthma.org>

7. Lougheed MD, Minard JP, Dworkin S, et al.

The Pan-Canadain REspiratory STandards INiative for Electronic Health Records (PRESTINE) Initiative: Proceedings of the 2011 National Forum. Can Respir J 2012;19:117-126. 


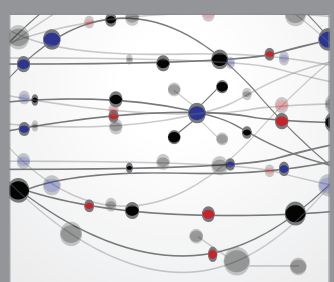

The Scientific World Journal
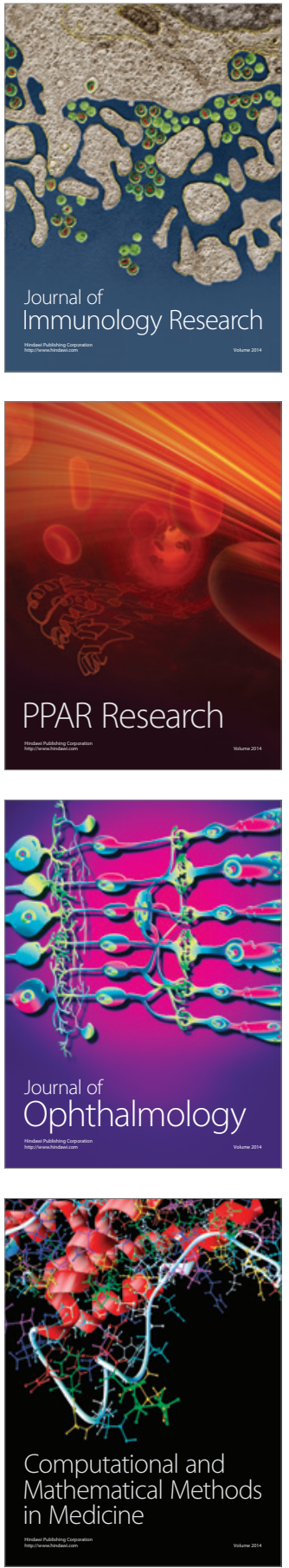

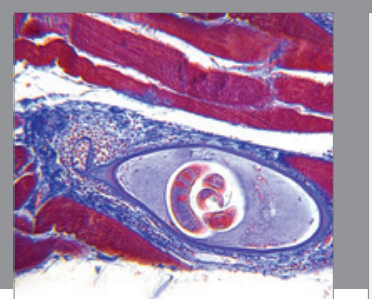

Gastroenterology Research and Practice

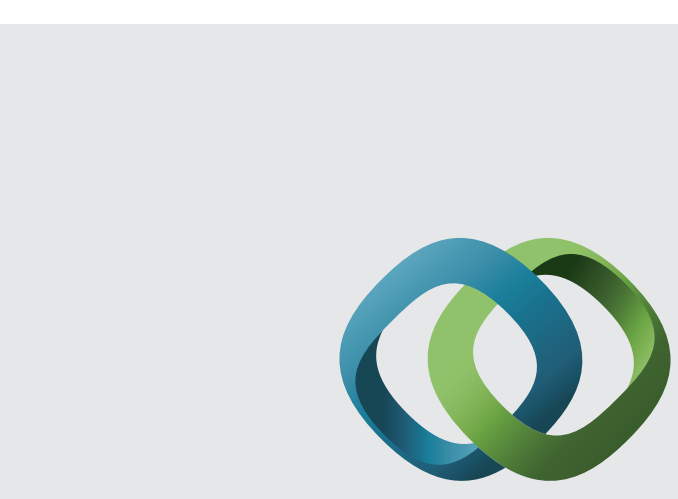

\section{Hindawi}

Submit your manuscripts at

http://www.hindawi.com
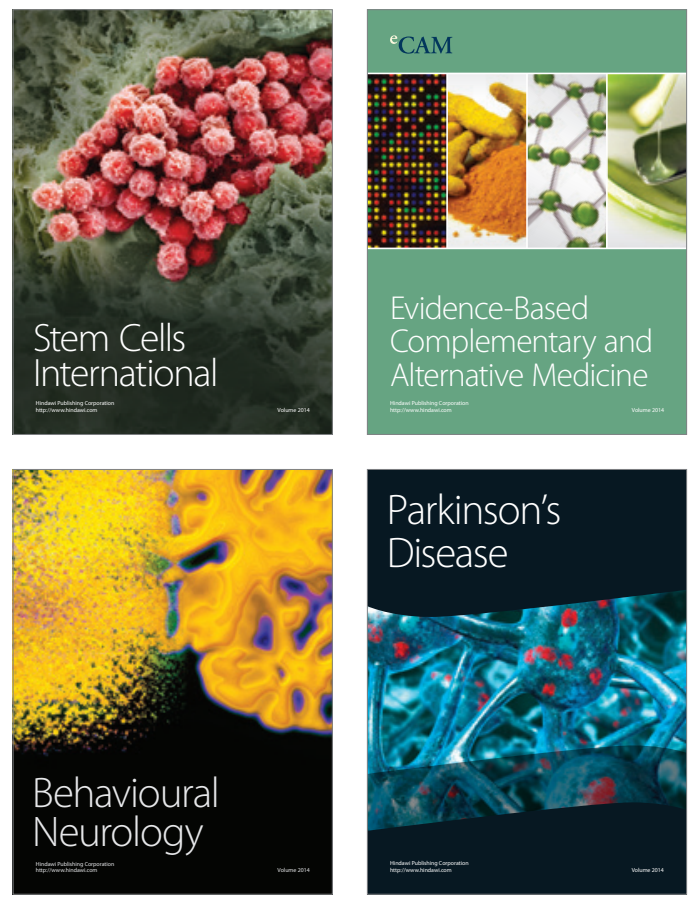
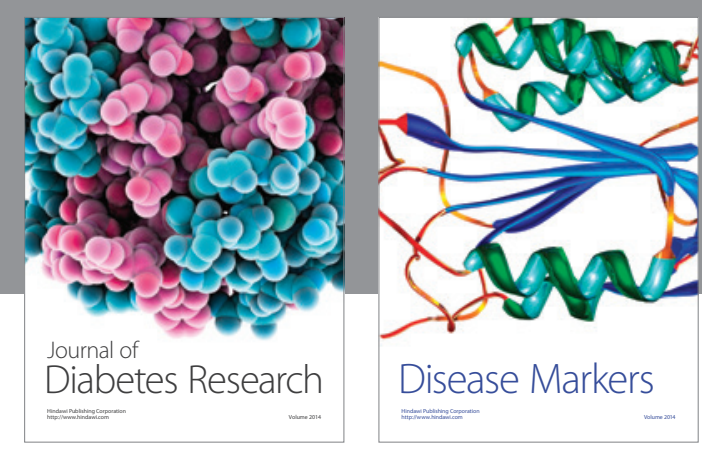

Disease Markers
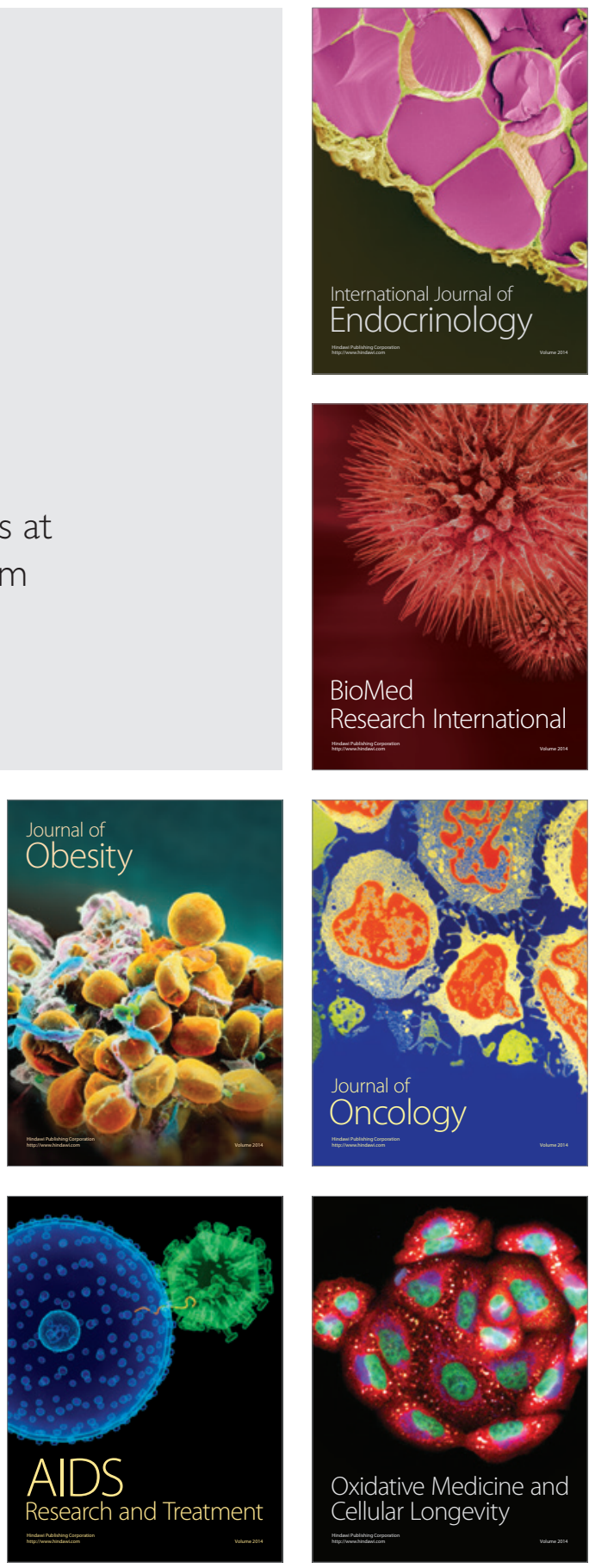